\author{
Universidade de São Paulo \\ Instituto de Física
}

\title{
Estudo do mecanismo de deposição de filmes finos de nitreto de boro assistida por feixe de íons
}

\author{
Mauro Pontes Langhi Junior
}

Banca Examinadora:

Prof. Dr. Masao Matsuoka - IFUSP

Prfa. Dra. Euzi Conceição Fernandes da Silva - IFUSP

Prof. Dr. Francisco Eduardo Gontijo Guimarães

Dissertação de mestrado apresentada ao Instituto de Física para a obtenção do título de Mestre em Ciências

São Paulo

2009 


\section{Agradecimentos:}

Ao professor Masao pelo apoio indispensável e dedicação sem precedentes.

À profa. Mazé, Celso Perego, Otávio, Serginho e todos os colegas do D.F.N., pela ajuda valiosa.

Aos colegas Karina e Wilmer, pelo companheirismo e convivência produtiva.

Aos colegas Pedro Carelli, João Basso, Ferenc, Ana Luisa, Rose, Bruno, Hellen, Giovani e Victor, pela amizade.

Aos amigos, Paulinho, Hoffman, Luana, James, Passetti, Yuri, Lucila e a todos aqueles cujos nomes não escrevi, pelo apoio moral tão importante.

Aos meus pais e irmãs pelo apoio e amor incondicionais.

Ao meu filho João pelo que eu nem sei.

Obrigado

Para Manuela 
os espaços abertos

onde a luz foi uma

segunda luz do mundo

são agora

noite vertical

as difíceis estrelas

Fabrício Corsaletti 


\section{Índice}

Resumo

Capítulo 1 - Introdução..................................................................... 8

1.1 Considerações gerais..................................................................... 8

1.2 Fases cristalinas do BN................................................................ 9

1.3 Propriedades do BN........................................................................... 11

1.4 Identificação das fases do BN...................................................... 12

1.5 Resumo de trabalhos anteriores........................................................ 14

1.5.1 Métodos de obtenção de BN.......................................................... 14

1.5.2 Descrição fenomenológica do processo de formação de filmes de c-BN por métodos assistidos por feixes de íons................. 19

1.6 Objetivos do presente trabalho........................................................ 22

Capítulo 2 - Método de deposição...................................................... 23

2.1 Sistema IBAD............................................................................................ 23

2.1.1 Fonte de íons................................................................................. 24

2.1.2 Evaporador............................................................................ 25

2.2 Preparação dos filmes de BN............................................................... 27

2.2.1 Procedimento de deposição....................................................... 27

2.2.2 Parâmetros de deposição............................................................. 27

Capítulo 3 - Técnicas de caracterização.............................................. 31

3.1 Espectroscopia do infravermelho......................................................... 31

3.1.1 Espectroscopia do infravermelho por transformada de Fourier (FTIR),.................................................................................. 40

3.1.2 Lei da absorção........................................................................ 41

3.2 Perfilometria......................................................................................... 42

3.3 Difração de raios-X (XRD)..................................................................... 43 
3.4 Microscopia óptica (MO)........................................................................ 44

Capítulo 4 - Resultados de medidas e discussões............................. 45

4.1 Espectros de FTIR................................................................45

4.1.1 Amostras depositadas em uma camada.................................. 46

4.1.2 Amostras depositadas em duas camada................................... 68

4.2 Difratogramas de raios-X....................................................................... 79

Capítulo 5 - Conclusões............................................................ 83

5.1 Dependência da TS............................................................. 83

5.2 Dependência da En.................................................................... 84

5.3 Dependência do MTA......................................................................... 85

5.4 Dependência do bombardeamento prévio do substrato com íons de argônio.............................................................................. 87

Apêndice A - Cálculo da razão $\operatorname{ARR(N/B)....................................~} 88$

A1 Cálculo do fluxo de átomos de boro........................................ 88

A.2 Cálculo do fluxo de átomos de nitrogênio..................................... 88

A.3 Cálculo da razão ARR(N/B)................................................. 92

Apêndice B - Momentum transferido por átomo de boro (MTA). 93

Referências bibliográficas............................................................. 95 


\section{Resumo}

Filmes finos de $\mathrm{BN}$ foram depositados em uma ou duas camadas, em temperaturas entre a temperatura ambiente e $400^{\circ} \mathrm{C}$, por deposição a vapor de átomos de boro sobre substratos de $\mathrm{Si}$ (111) ou Si (100), com irradiação simultânea de íons de argônio e/ou nitrogênio. A energia de íons variou de 400 a $1000 \mathrm{eV}$, e a razão de chegada ARR(N/A), definida pela razão do fluxo de partículas atômicas de nitrogênio relativa ao fluxo de átomos de boro transportados ao substrato, de 0,3 a 3,1. A pressão de gás na câmara de vácuo foi mantida a $1,6 \times 10^{-2} \mathrm{~Pa}$ durante o processo de deposição. As amostras assim depositadas foram analisadas através de absorção no infravermelho, difração de raios-X e microscopia óptica. Todas as amostras apresentaram dois picos de BN hexagonal (h-BN) em 780 e $1370 \mathrm{~cm}^{-1}$ nos espectros de absorção e algumas, um pico de BN cúbico (c-BN) em $1070 \mathrm{~cm}^{-1}$. Estes picos foram analisados com os parâmetros de deposição, tais como temperatura de substrato, espessura nominal (En), momentum transferido por íons aos átomos depositados (MTA) e bombardeamento prévio do substrato com íons de argônio (BP). Foi verificado que a formação de c-BN nos filmes depende fortemente dos parâmetros En, MTA e BP. Os limiares da formação de c-BN encontrados para estes parâmetros são explicados em termos de: tensão compressiva, mobilidade de átomos no filme e rendimento de sputtering. 


\begin{abstract}
Thin BN films were deposited in one or two layers at temperatures from room temperature to $400^{\circ} \mathrm{C}$, using boron vapor deposition on $\mathrm{Si}(111)$ or $\mathrm{Si}(100)$ substrates with simultaneous irradiation by nitrogen and/or argon ions (ion energy ranges from 400 to $1000 \mathrm{eV}$ ). The arrival rate ratio ARR(N/B), defined as the ratio of the flux of incident atomic nitrogen particles relative to the flux of evaporated boron atoms transported to the substrate, extends from 0.3 to 3.1. The gas pressure in the vacuum chamber was maintained at $1,6 \times 10^{-2} \mathrm{~Pa}$ during the deposition. The samples deposited in this manner were analyzed through different characterization techniques such as infrared absorption, X-ray diffraction, and optical microscopy. Several samples presented two peaks of hexagonal BN (h-BN) at 780 and $1370 \mathrm{~cm}^{-1}$ in their IR spectra and a few samples, a peak of cubic $\mathrm{BN}$ (c-BN) at $1070 \mathrm{~cm}^{-1}$. These peaks were analyzed in terms of: substrate temperature, nominal thickness (En), momentum transferred from the ions to the boron atoms (MTA), and previous bombardment of the substrate by argon ions (BP). The formation of c-BN in those films was verified and it shows a strong relation onto depend strongly on the parameters En, MTA, and BP. The thresholds of the c-BN formation found for those parameters are explained in terms of compressive stress, atom mobility and sputtering efficiency.
\end{abstract}




\section{Capítulo 1}

\section{Introdução}

\subsection{Considerações gerais}

Nitreto de boro cúbico (c-BN) e nitreto de carbono em forma de $\beta-\mathrm{C}_{3} \mathrm{~N}_{4}$ são conhecidos como os materiais superduros de próxima geração. Por exemplo, filmes finos de c-BN são materiais muito interessantes por causa de estrutura e propriedades semelhantes às do diamante. O c-BN apresenta alta dureza, condutividade térmica alta, inércia química a materiais ferrosos mesmo em altas temperaturas, band-gap largo e transmitância maior de luz ultravioleta a visível [1, 2, 3]. Em aplicações há revestimento protetor duro para ferramentas de corte, dispositivos eletrônicos em altas temperaturas, etc.

Porém, a sinterização de filmes finos de c-BN é muito difícil, pois os materiais de B-N são compostos metastáveis e, portanto, podem ser sintetizados, no processo de equilíbrio termoquímico, somente sob temperaturas e pressões altas. Para formar esses materiais como filmes sobre substratos em temperaturas próximas à temperatura ambiente, é indispensável a utilização de um campo ativo de não-equilíbrio, onde $\mathrm{B}, \mathrm{C}$ e $\mathrm{N}$ estão em estados altamente excitados. Por isso, o emprego de íons energéticos na preparação desses filmes é um aspecto comum em qualquer método.

O presente estudo trata de: deposição de filmes finos de $\mathrm{BN}$ usando o chamado método de deposição assistida por feixe de íons (ion beam assisted deposition: IBAD) e caracterização dos 
filmes sintetizados. No método IBAD, a deposição a vácuo de boro sobre um substrato é combinada com irradiação simultânea por íons energéticos; o fluxo e a energia de íons incidentes podem ser mudados independentemente do fluxo de átomos depositantes, assim controlando facilmente a composição química de filmes compostos $[4,5]$.

Na próxima seção, serão descritas as fases cristalinas de BN. Nas seções 1.3 e 1.4, serão apresentadas algumas propriedades de $\mathrm{BN}$ e a identificação das fases de $\mathrm{BN}$, respectivamente. $\mathrm{Na}$ seção 1.5, será apresentado um resumo dos trabalhos realizados por outros autores, em seguida as características do método IBAD. Na seção 1.7, serão mostrados os objetivos do trabalho e, enfim, o conteúdo da presente tese.

\subsection{Fases cristalinas do BN}

O diamante é conhecido como o material mais duro na natureza, possuindo a chamada estrutura de diamante pertencente ao sistema cristalino cúbico. O boro e o nitrogênio são os vizinhos mais próximos de carbono na tabela periódica e a soma do número atômico de boro e do de nitrogênio é igual ao dobro do número atômico de carbono. Portanto, dois átomos de carbono conjugados na estrutura de diamante podem ser substituídos por um átomo de boro e um de nitrogênio, obtendo-se assim a estrutura zinc-blende que pertence, também, ao sistema cristalino cúbico. A substância de BN assim formado (c-BN) pode ser encontrada com o nome comercial de Borazine desde 1969.

Os compostos de $\mathrm{BN}$ apresentam-se em pelo menos quatro fases cristalinas diferentes: hexagonal (h-BN), romboédrico (r-BN), cúbico (c-BN) e wurtzítico (w-BN) [6] (ver a figura 1.1). As primeiras duas fases são compostas por ligações hibridizadas $\mathrm{sp}^{2}$ e as outras, de ligações entre orbitais $\mathrm{sp}^{3}$. As propriedades físico-químicas de cada uma dessas fases são semelhantes às do 
composto de carbono correspondente. A fase hexagonal, com propriedades tribológicas semelhantes às do grafite, é aplicada com sucesso como lubrificante sólido. Já a fase cúbica, analogamente ao diamante, apresenta alta dureza e band-gap largo, estas propriedades serão apresentadas na seção 1.3 .

$\mathrm{O}$ h-BN é composto de uma estrutura em camadas semelhante à da grafite, com a diferença

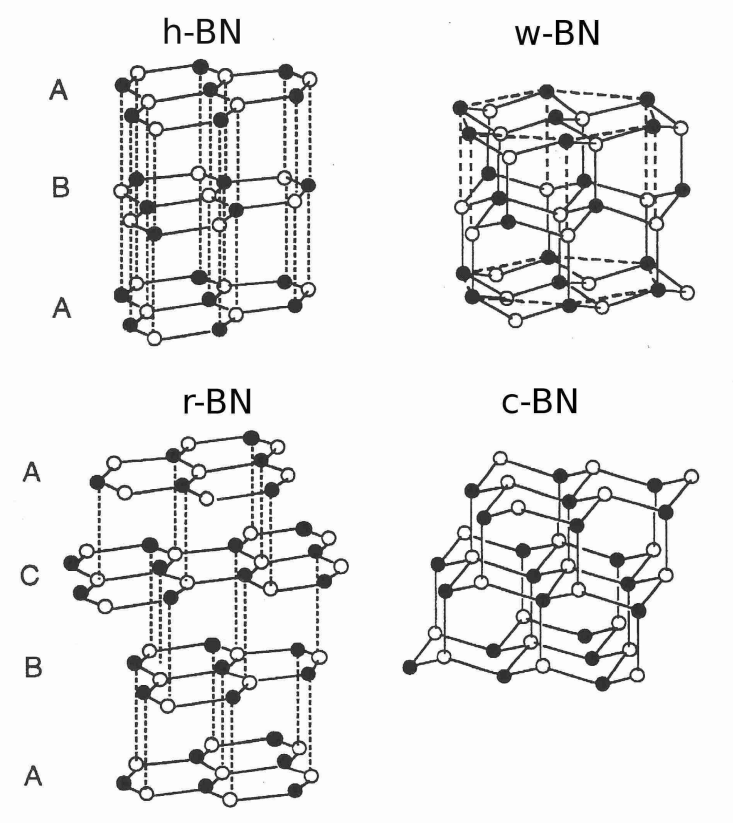
que os anéis hexagonais em um plano basal do h-BN se localizam diretamente uns sobre os outros nos planos basais adjacentes rodados de $180^{\circ}$, levando a uma alternância do tipo $\mathrm{ABAB}$ na direção do eixo c, com átomos de boro e nitrogênio se alternando nos vértices dos anéis. As ligações atômicas no plano basal são do tipo covalente $\mathrm{sp}^{2}$ e as ligações interplanares são fracas do tipo van de Waals. O r-BN é análogo à grafite romboédrica formando um padrão de

Figura 1.1. Estruturas cristalinas das fases h-BN, alternância do tipo ABCA ao longo do eixo c. $w-B N, r-B N$ e c-BN.

Além disso, existe outra fase cristalina, usualmente chamada t-BN, entre a fase $\mathrm{h}-\mathrm{BN}$ e um material amorfo composto de ligações $\mathrm{sp}^{2}$..

$\mathrm{O}$ w-BN é composto por planos empilhados com alternância do tipo $\mathrm{ABAB}$ ao longo do eixo c, sendo uma forma derivada do h-BN em que átomos de boro e nitrogênio formam ligações covalentes $\mathrm{sp}^{3}$ não só nos planos basais, mas entre eles. A conversão de h-BN em w-BN foi realizada com sucesso por Meng [7] e colaboradores através da compressão sem aquecimento de h-BN poli-cristalino de alta pureza. Analises do material durante a compressão demonstraram que: sob pressões entre 8 e $14 \mathrm{GPa}$ forma-se h-BN com o eixo c orientado na direção de aplicação da compressão; sob pressão superior a $14 \mathrm{GPa}$ surgem ligações $\mathrm{sp}^{3}$ entre os átomos de B e N e a fase w-BN começa a se formar. 
Por outro lado, o c-BN não pode ser obtido a partir do h-BN por simples compressão, uma vez que a conversão exige tanto mudança no tipo de ligação química quanto mudança no tipo de empilhamento interplanar.

As semelhanças entre os tipos de empilhamento de planos entre as fases h-BN e w-BN e entre r-BN e c-BN se mostram como um fator importante na transformação de uma fase em outra. A tabela 1.1 apresenta os valores das constantes da rede para as quatro fases cristalinas do BN.

Tabela 1.1: Parâmetros de rede das fases cristalinas do BN [3].

\begin{tabular}{|c|c|c|}
\hline Fase & $a(\AA)$ & $c(\AA)$ \\
\hline h-BN & 2,5043 & 6,6562 \\
\hline r-BN & 2,5042 & 9,99 \\
\hline c-BN & 3,6153 & \\
\hline w-BN & 2,5505 & 4,210 \\
\hline
\end{tabular}

\subsection{Propriedades do BN}

A dureza do c-BN cristalino é apenas superada pela do diamante (ver a tabela 1.2). Mas o cBN apresenta diferenças em relação ao diamante no que se refere ao band-gap $(6,5 \mathrm{eV}$ contra 5,5 eV do diamante), e estabilidade química (c-BN é inerte ao ferro e o diamante não) além da possibilidade de dopagem com silício ou berílio para obtenção de semicondutores tipo n, ou tipo $\mathrm{p}$ [6], enquanto o diamante, atualmente, só apresenta possibilidade de dopagem $p$.

Considerando tais propriedades singulares, a gama de possíveis aplicações técnicas e tecnológicas de filmes finos de BN é vasta. Combinando-se as fases cristalinas em diferentes proporções consegue-se propriedades também combinadas no filme. Por exemplo, com uma mistura de h-BN e c-BN pode-se conseguir um filme duro, resistente ao desgaste e liso.

A analogia entre os compostos de $\mathrm{BN}$ e os de carbono correspondentes falha quando se 
trata de algumas propriedades elétricas dos compostos. Por exemplo, o h-BN é isolante, enquanto que o composto de carbono correspondente, grafite, é bom condutor. Este fato é devido à não equivalência dos sítios entre os dois compostos, gerando uma quebra da simetria em relação ao grafite. Tal quebra de simetria faz com que os compostos de BN apresentem dipolo elétrico permanente, possibilitando a observação de modos vibracionais na faixa do infra-vermelho, o que não ocorre nos compostos de carbono.

Tabela 1.2:. Propriedades do diamante, $c$-BN e $h$-BN.

\begin{tabular}{|l|c|c|c|}
\hline & diamante & $c$-BN & $h$-BN \\
\hline Densidade $\left(\mathrm{g} / \mathrm{cm}^{3}\right)$ & 3,52 & 3,45 & 1,9 \\
\hline Dureza Vickers $\left(\mathrm{kg} / \mathrm{mm}^{2}\right)$ & 10.000 & $4.500 \sim 8.600$ & $200 \sim 400$ \\
\hline Condutividade térmica $\left[\mathrm{W} /\left(\mathrm{m}^{2} \mathrm{~K}\right)\right]$ & 20 & 13 & 0,18 \\
\hline
\end{tabular}

\subsection{Identificação das fases do BN}

O uso da espectroscopia de infravermelho por transformada de Fourier (FTIR) tem sido uma forma padrão não só para detectar as fases cristalinas de $\mathrm{BN}$, mas também para fornecer informações sobre tensão e orientação no filme.

Nos espectros de FTIR, tentamos procurar pelos picos característicos dos modos ópticos de bending da ligação $\mathrm{B}-\mathrm{N}-\mathrm{B}$ entre os planos basais adjacentes $\left(\sim 780 \mathrm{~cm}^{-1}\right)$ e de stretching da ligação B-N no plano basal $\left(\sim 1370 \mathrm{~cm}^{-1}\right)$ de h-BN, e de c-BN $\left(\sim 1070 \mathrm{~cm}^{-1}\right)$, pois a presença dos picos 780 e $1370 \mathrm{~cm}^{-1}$ é a "impressão digital" do h-BN e a do pico $1070 \mathrm{~cm}^{-1}$, a "impressão digital" do c-BN.

As propriedades vibracionais do c-BN e h-BN são bastante conhecidas, enquanto que aquelas de r-BN e w-BN não são muito investigadas. Como as freqüências vibracionais são sensíveis ao tipo de ligação, são esperadas similaridades nas posições dos picos entre h-BN e r-BN e entre cBN e w-BN. Por essa razão, é difícil distinguir as fases $\mathrm{sp}^{2}$ (h-BN e r-BN) ou fases $\mathrm{sp}^{3}$ (c-BN e w- 
$\mathrm{BN})$. Portanto, o termo "h-BN" usado neste trabalho se refere à fase composta de ligações $\mathrm{sp}^{2}$ e o termo "c-BN", à fase de ligações $\mathrm{sp}^{3}$.

O pico do óxido de silício $\left(\mathrm{SiO}_{\mathrm{n}}\right)$ em $\sim 1100 \mathrm{~cm}^{-1}$, que aparece em algumas amostras no presente trabalho, dificulta a análise dos picos de BN. O aumento do pico de c-BN com o aumento da espessura do filme pode servir para diferenciar o pico de $\mathrm{SiO}_{\mathrm{n}}$.

Por outro lado, a análise por difração de raios-X (XRD) é um método simples para identificar a formação de fases cristalinas e determinação de tamanho de cristalitos nos filmes de BN. Por isso, foi usada a técnica XRD neste trabalho (ver a seção 4.2 do capitulo 4). Entretanto, há alguns fatores que complicam a caracterização pela $\mathrm{XRD}$, tais como os baixos números atômicos de $\mathrm{B}$ e $\mathrm{N}$ que resultam em baixas intensidades de espalhamento, tamanho pequeno de cristalitos e desordem cristalográfica. 


\subsection{Resumo de trabalhos anteriores}

\subsubsection{Métodos de obtenção de $B N$}

\section{- Conversão direta}

Neste método, cristais de c-BN e w-BN são obtidos a partir de h-BN por compressão, com ou sem aquecimento. Sob pressão típica da ordem de $10 \mathrm{GPa}$ e temperaturas entre a ambiente e $\sim 10^{3}$ ${ }^{\circ} \mathrm{C}$, as variantes deste método levam a obtenção de c-BN policristalino com tamanho de grão da ordem de micrometros. A fase c-BN é mais facilmente obtida em altas temperaturas $\left(>1000^{\circ} \mathrm{C}\right)$ e a partir de h-BN com baixo grau de cristalinidade (a-BN), enquanto a fase w-BN é formada preferencialmente a baixas temperaturas (ambiente) e a partir de h-BN com alto grau de cristalinidade. [6-8]

Wentorf obteve, em 1957, cristais de c-BN a partir de h-BN utilizando uma cápsula de metal pressurizada, aquecida por resistência elétrica em temperaturas maiores que $1350^{\circ} \mathrm{C}$ e pressão superior a 62000 atm [9]. Os testes realizados pelo pesquisador demonstraram que o c-BN, chamado então de Borazon, apresentava baixa reatividade com gases atmosféricos e caráter isolante.

\section{- Deposição com laser pulsado assistida por feixe de íons (PLD)}

A síntese de filmes de c-BN policristalino a partir da técnica PLD é realizada combinando um fluxo de h-BN evaporado de um alvo, sob incidência de laser, e um fluxo de íons incidentes provenientes de uma fonte de íons [10]. Entre as vantagens do método PLD podemos citar o 
controle independente dos fluxos de íons e material evaporado, permitindo ajuste da ARR(N/B), a alta taxa de evaporação de material e a possibilidade de utilização de diferentes tipos de alvos.

Uma das desvantagens desta técnica é a incorporação de partículas indesejadas no filme. Tal desvantagem pode ser contornada através do uso de alvos de BN com alta densidade.

\section{- RF magnetron sputtering}

Este método é baseado na deposição de átomos removidos de um material sólido (h-BN) sobre um substrato. O h-BN é colocado em um catodo conectado a uma fonte de RF de 13,56 MHz [11], e o substrato está aterrado ou polarizado positiva ou negativamente.

Depois da evacuação da câmara de gás, o gás de nitrogênio, argônio ou uma mistura de nitrogênio e argônio é introduzido a uma pressão de aproximadamente 0,4 mTorr [11], como um meio no qual a descarga é iniciada e sustentada entre os eletrodos. Os íons de nitrogênio e/ou argônio criados são acelerados em direção ao catodo devido à polarização do mesmo [11-17]. A variação da tensão de polarização permite variar a energia de íons incidentes. O uso de um campo magnético para estender o plasma na direção do substrato pode ser usado para aumentar o fluxo de íons sobre o filme, levando a uma taxa de deposição mais alta [2].

Filmes ricos em c-BN foram obtidos a partir desta método e são reportados na literatura [11$14,16]$

\section{- IBAD}

$\mathrm{N}$ década de 80, um novo método de physical vapor deposition (PVD), conhecido como ion beam assisted deposition (IBAD), foi desenvolvido. Neste método, combina-se a deposição de material por evaporação (boro) e o bombardeamento simultâneo de íons energéticos (nitrogênio e/ou argônio). Filmes finos contendo h-BN e/ou c-BN foram obtidos através deste método e são 
reportados na literatura. [18-33]

\section{- Características do método IBAD}

Como dito anteriormente, uma das maiores dificuldades para formação de $\mathrm{BN}$ em temperaturas próximas à temperatura ambiente é a necessidade da criação de um campo de reação. Para superar tal obstáculo, o método IBAD se apresenta como vantajoso em alguns aspectos. Combinando evaporação de material com bombardeamento simultâneo de íons com energia entre dezenas de $\mathrm{eV}$ a keV, o método apresenta controle independente de parâmetros como energia dos íons, razão de chegada íon/metal, temperatura do substrato e velocidade de deposição.

O método consiste em bombardear um substrato com íons energéticos (energia entre 400 e $1000 \mathrm{eV}$, neste trabalho), provenientes da fonte de íons e simultaneamente depositar um material, previamente evaporado, sobre o mesmo substrato.

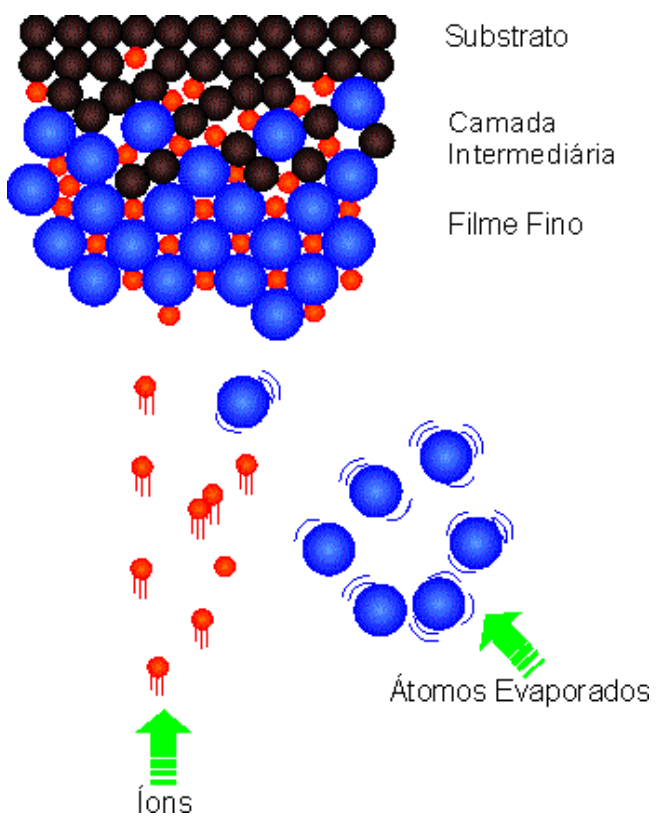

Figura 2.2. Formação de filme através do método IBAD

depositado ao substrato.
Os íons bombardeados penetram no substrato e chocam-se com átomos depositados sobre este, transferindo energia e momentum aos mesmos e impelindo-os da superfície para dentro; a seguir é formada entre o substrato e o filme uma nova fase intermediária mista de elementos do substrato, íons incidentes e átomos depositados. Sobre essa camada mista forma-se um filme fino livre de átomos do substrato. (figura 2.2).

A formação dessa nova fase intermediária aumenta, conseqüentemente, a aderência do filme 
As características do método IBAD são as seguintes:

1.inexistência de interface descontínua entre o substrato e o filme;

2.aplicabilidade a substratos em baixas temperaturas, devido ao princípio do processo de formação de filmes finos;

3.facilidade da modificação e controle das características físicas e químicas (dureza, densidade, tensão interna, morfologia, estequiometria), e propriedades cristalográficas (nucleação, densidade de nucleação, estrutura cristalina) de filmes finos com os controles independentes da energia cinética e da corrente de íons incidentes, e da velocidade de deposição.

Os filmes finos de BN discutidos neste trabalho foram depositados variando-se os seguintes parâmetros:

a) energia de íons incidentes (E), controlada pela tensão do feixe $\left(\mathrm{V}_{\mathrm{b}}\right)$ na fonte de íons;

b) proporção entre íons de $\mathrm{N}$ e Ar, controlada através dos MFC (mass flow controles).

c) arrival rate ratio $\mathrm{ARR}(\mathrm{N} / \mathrm{B})$ e $\mathrm{ARR}(\mathrm{Ar} / \mathrm{B})$, definida pela razão do fluxo de íons incidentes de $\mathrm{N}$ ou Ar relativa ao fluxo de átomos evaporados de $\mathrm{B}$ transportados ao substrato. Estes parâmetros são controlados através da variação da taxa de deposição aferida no monitor de deposição e do fluxo de íons incidentes calculado a partir da densidade de corrente no copo de Faraday, da pressão na câmara e da proporção nos fluxos de gases $\mathrm{N}_{2}$ e Ar. Os cálculos da ARR(N/B) e ARR(Ar/B) são explicitados com maiores detalhes no apêndice A;

d) momentum transferido por átomo de boro evaporado (MTA), calculado a partir da energia de íons e dos ARR(B/N) e ARR(B/Ar). Este cálculo é apresentado no apêndice B.

e) espessura nominal (En) do filme estimada a partir do tempo de deposição e da taxa de deposição de átomos de boro;

f) temperatura do substrato (TS) durante a deposição, controlada pelo módulo de aquecimento e monitorada pelo termopar presente no suporte de substrato. 


\section{- Interação entre íon e sólido}

O impacto de um íon energético com um sólido produz uma série de efeitos. O íon incidente pode transferir energia através de colisões elásticas com os átomos do sólido, o que leva ao deslocamento dos últimos, ou através de colisões inelásticas, que produzem excitações eletrônicas. O deslocamento de átomos resulta em novas colisões (cascata de colisões) entre átomos até que não haja energia suficiente para retirar um átomo de sua posição na rede. A energia restante é dissipada termicamente como vibrações da rede [33].

A cascata de colisões leva a formação de defeitos como lacunas na rede, defeitos intersistiais e à possibilidade de difusão e interação entre espécies e à formação de novas ligações interatômicas.

A profundidade de penetração do íon no sólido é chamada alcance. Cascatas de colisões que ocorrem perto da superfície do sólido expelem átomos da camada superficial, causando a dessorção de espécies na superfície (sputtering); o rendimento de sputtering depende da composição da camada superficial. Vacâncias produzidas nas cascatas de colisões aumentam a taxa de difusão e a interação entre vacâncias, intersticiais e átomos dissolvidos no sólido, conduzindo à redistribuição de átomos e à segregação. A composição da camada superficial, portanto, pode ser mudada por: sputtering, íons implantados, mistura de átomos por cascatas de colisões e segregação.

A temperatura de uma região localizada no sólido pode exceder o ponto de fusão do sólido em um período de $\sim 10$ ps, em conseqüência da dissipação, como fônons, da energia depositada nessa região na cascata de colisões (thermal spike). 


\subsubsection{Descrição fenomenológica do processo de formação de filmes de c-BN por métodos assistidos por feixes de íons}

O bombardeamento de íons se mostra essencial para a deposição de filmes contendo c-BN. A seguir apresentamos fundamentos básicos que pretendem explicar tal necessidade, além da descrição morfológica de filmes de BN.

\section{- Morfologia dos filmes de BN}

Filmes de BN são formados em camadas de fases compostas por ligações $\mathrm{sp}^{2} \mathrm{e} \mathrm{sp}^{3}$. Sendo que BN com ligação $\mathrm{sp}^{2}$ se forma antes da fase cúbica durante a deposição, aparecendo entre o substrato e a camada de c-BN [10-12,14,17,18,30,32]. Imagens de microscopia eletrônica de transmissão (HRTM) mostram uma camada de $~ 60 \AA \AA$ de BN com ligação sp ${ }^{2}$, sendo 20 Å de BN amorfo seguida por t-BN com eixo c perpendicular ao plano do substrato. Sobre esta camada forma-se c-BN policristalino [11].

Tanto a camada de t-BN como a de c-BN são inicialmente desorientadas e, conforme se tornam mais espessas se orientam em relação ao substrato. No caso do c-BN os planos (111) se tornam paralelos à superfície do substrato.

Sobre a camada de c-BN forma-se uma camada de $\mathrm{BN}$ com ligação $\mathrm{sp}^{2}$ com espessura de $\sim 10$ A.

\section{- Deposição versus sputtering}

Se a conversão do h-BN em c-BN ocorre devido à interação direta dos íons incidentes com o 
h-BN previamente formado, concluímos que a taxa de conversão num ponto será proporcional à densidade de corrente de íons. Entretanto, a profundidade de penetração no filme, calculada pelo modelo TRIM para íons de nitrogênio e argônio com energia inferior a $1 \mathrm{keV}$, é apenas da ordem de 2-4 nm [10]. Assim, a região irradiada do filme se desloca conforme o filme cresce e o tempo durante o qual um dado elemento de volume permanece sendo irradiado é igual à profundidade de penetração dos íons dividida pela velocidade de crescimento do filme (nm/s).

Uma vez que a velocidade de crescimento do filme é dada pela diferença entre a taxa de deposição e a taxa de sputtering gerado por íons incidentes, a concentração de c-BN no filme depende da razão entre os fluxos de íons incidentes e átomos de boro depositados. Se o fluxo de íons for baixo em relação à deposição de boro, a região irradiada não será totalmente convertida em c-BN. Conforme aumentarmos o fluxo de íons em relação à taxa deposição de átomos de boro, a taxa de sputtering aumentará até o limite em que não se formará filme algum. Desta forma, espera-se que para uma dada taxa de deposição de boro, haja um intervalo no valor do fluxo de íons para o qual o máximo na concentração de c-BN seja atingido.

Esta descrição do processo de formação de c-BN por IBAD não explica o mecanismo pelo qual este composto é formado, mas justifica a introdução da arrival rate ratio $\mathrm{ARR}(\mathrm{N} / \mathrm{B})$ na análise do processo de deposição.

\section{- Tensão compressiva}

Tensão compressiva ocorre em filmes finos depositados por IBAD devido a impactos entre íons e o material depositado [6] e se dá quando a energia dos íons incidentes é superior à energia necessária para impelir átomos evaporados para dentro do filme (subplantar).

Foi demonstrado que a tensão compressiva apresenta um valor máximo em função da energia dos íons incidentes $[13,34]$ o que pode ser compreendido como resultado de uma composição entre a tensão produzida pela formação de defeitos (choques elásticos) e a diminuição de tensão 
por reacomodação (anealing) de átomos devido à energia do impacto [31]. Foi observado também que a tensão é pequena para filmes muito finos e aumenta rapidamente com o aumento da espessura, atingindo um valor máximo e caindo para um patamar, o que pode ser compreendido como resultado do "fluxo plástico" do filme após atingido o valor máximo de tensão suportado pelo filme[19, 32].

Foi verificado, que a fase c-BN não aparece junto ao substrato, formando-se sempre sobre uma camada intermediária de $\mathrm{BN}$ amorfo seguida por uma de t-BN [10,12, 18, 25]. . McKenzie $[31,32,34]$ e colaboradores explicam essa morfologia em termos de um modelo de conversão do h-BN em c-BN baseado num aumento de tensão compressiva no filme devido ao bombardeamento de íons. Tal tensão aumenta de acordo com a espessura do filme, levando às condições termodinâmicas adequadas para formação da fase cúbica quando o filme atinge a espessura adequada.

Descrições alternativas em termos de parâmetros como momentum transferido por átomo de boro (apêndice A) depositado se mostram úteis porém não são capazes de explicar a necessidade de uma espessura mínima do filme para a formação do c-BN e devem ser considerados como complementares à interpretação em termos de tensão compressiva.

Visto que filmes finos ricos em c-BN costumam apresentar tensão intrínseca alta, levando a baixa aderência ao substrato e resultando em descascamento (pealing) [11], as possibilidades de aplicação dos mesmos depende da solução deste problema. Uma das maneiras de obter-se filmes, simultaneamente aderentes e ricos em c-BN, depositados por IBAD, é depositá-los em duas camadas, uma rica em h-BN junto ao substrato e outra rica em c-BN depositada sobre a primeira $[18,25]$.

Além da diminuição da tensão intrínseca e da melhor aderência dos filmes depositados em duas camadas, há evidências de que a deposição da primeira camada rica em h-BN junto ao substrato facilite, ou mesmo seja essencial, a formação da fase cúbica [18].

A fase h-BN é mais fácil de ser formada pelo método IBAD do que a fase c-BN [25],.que 
exige, além de uma quantidade mínima de momentum transferido por átomo de boro evaporado [29, 30], uma espessura mínima do filme responsável por aumento da tensão [31, 32].

\subsection{Objetivos do presente trabalho}

Os principais objetivos do presente trabalho são os seguintes:

(1) Produzir os filmes de nitreto de boro, utilizando o método IBAD;

(2) Caracterizar os filmes produzidos usando as técnicas de: espectroscopia do infravermelho por transformada de Fourier, difração de raios-X e microscopia óptica;

(3) Correlacionar as características dos filmes acima observadas com os parâmetros usados na produção dos filmes.

A presente tese consiste em cinco capítulos. No próximo, será descrito o método de deposição. No capitulo3, serão apresentadas as técnicas de caracterização dos filmes finos. O capitulo 4 descreverá os resultados experimentais obtidos com as técnicas acima mencionadas e a discussão dos resultados. No último capitulo serão mostradas as conclusões deste trabalho. 


\section{Capítulo 2}

\section{Método de deposição}

\subsection{Sistema IBAD}

O equipamento utilizado para preparação de amostras de filmes finos de BN está esquematizado na figura 2.1 e é composto basicamente dos seguintes itens:

1 - Uma fonte de íons tipo Kaufman (MPS 3000, Ion Tech) com três eletrodos feitos de molibdênio, diâmetro de feixe de $5 \mathrm{~cm}$ na saída, energia de íons de 50 a $1200 \mathrm{eV}$, corrente de feixe máxima de $200 \mathrm{~mA}$ (densidade máxima de corrente na saída da fonte de $10 \mathrm{~mA} / \mathrm{cm}^{2}$ ), sua unidade de potência e medidores de fluxo de gás independentes, para $\mathrm{N}_{2}$ e $\mathrm{Ar}$, compostos por dois controladores de fluxo de massa (Mass Flow Controler (MFC) 1179A, MKS);

2 - Um evaporador por feixe de elétrons (EB3, Edwards), com unidade de potência $(5 \mathrm{kV}$, $600 \mathrm{~mA}$ ), cadinhos de BN com volume de $4 \mathrm{~cm}^{3}$ cada e um suporte rotativo para alternância de cadinhos com capacidade para quatro cadinhos;

3 - Uma câmara de vácuo de aço inoxidável cilíndrica com $70 \mathrm{~cm}$ de altura e $60 \mathrm{~cm}$ de diâmetro, onde se encontram instalados, além da fonte de íons e do evaporador por feixe de elétrons já mencionados, dois sensores de pressão (um pirani e um catodo frio), módulo de aquecimento e suporte de substratos passível de aquecimento até $550{ }^{\circ} \mathrm{C}$, por resistência de platina com termopar tipo K e capacidade para substratos de até $2,5 \mathrm{~cm}$ x 2,5 cm, um copo de Faraday de aço inoxidável com diâmetro de 5,1 cm para aferição de densidade de corrente de íons na posição 
do substrato e um monitor de deposição por oscilador de quartzo (XTC/2, Leybold). O váuo na câmara foi mantido com uma bomba mecânica com velocidade de bombeamento de $40 \mathrm{~m}^{3} / \mathrm{h}$ durante uma hora $(2,7 \mathrm{~Pa})$ e depois por uma criogênica de $1500 \mathrm{l} / \mathrm{s}$ durante 24 horas. A pressão de fundo da câmara é de aproximadamente $7,0 \times 10^{-5} \mathrm{~Pa}$ e a pressão durante as deposições de filmes foi de aproximadamente $1,4 \times 10^{-2} \mathrm{~Pa}$. Os ângulos de incidência do fluxo de átomos evaporados e do feixe de íons sobre o substrato foram $45^{\circ}$ e $0^{\circ}$, respectivamente.
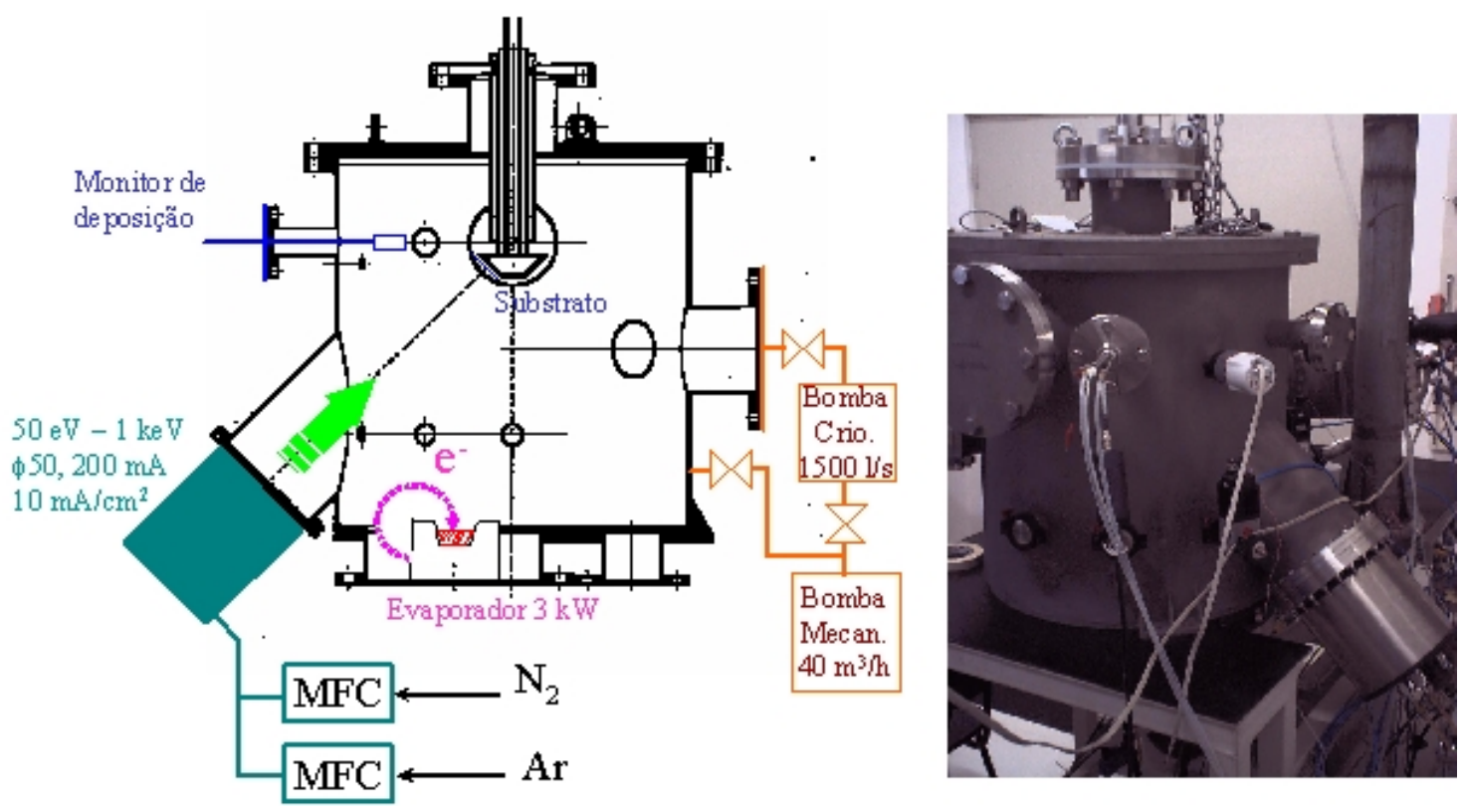

Figura 2.1: Diagrama esquemático e fotografia do equipamento de IBAD utilizado.

\subsubsection{Fonte de íons}

A fonte de íons é responsável pela produção de um feixe de íons que se movem em direção ao substrato. A fonte consiste de um compartimento de descarga com entrada de gases, cujas paredes funcionam como ânodo, um filamento de tungstênio que emite termo-elétrons (catodo), uma grade aceleradora e um filamento de tungstênio, para neutralizar íons na saída da fonte (ver figura 2.2). 
Os elétrons emitidos pelo catodo percorrem diferentes trajetórias em direção ao ânodo, que se encontra com tensão superior $\left(\mathrm{V}_{\mathrm{d}}\right)$. Tais trajetórias são ampliadas pela presença de um campo magnético de ímã que leva os elétrons a percorrer trajetórias helicoidais antes de atingir o ânodo. Durante o percurso atingem átomos e/ou moléculas de gases, ionizando-os. Como resultado dessas colisões, forma-se um plasma composto de elétrons, íons, átomos e moléculas. Elétrons liberados em colisões colidem com outros átomos e/ou moléculas aumentando a taxa de ionização.

Os íons positivos produzidos nesse processo são atraídos pela grade aceleradora, que se encontra com tensão negativa $\left(-\mathrm{V}_{\mathrm{a}}\right)$. atravessando-a em direção ao substrato. A energia dos íons (E) é dada por uma tensão aplicada entre o ânodo e a terra, chamada tensão do feixe $\left(\mathrm{V}_{\mathrm{b}}\right)$ [35].

O filamento de tungstênio na saída da fonte pode ser acionado gerando termo-elétrons e neutralizando os íons do feixe. Esse procedimento é usado para diminuir a dispersão do feixe por repulsão coulombiana.

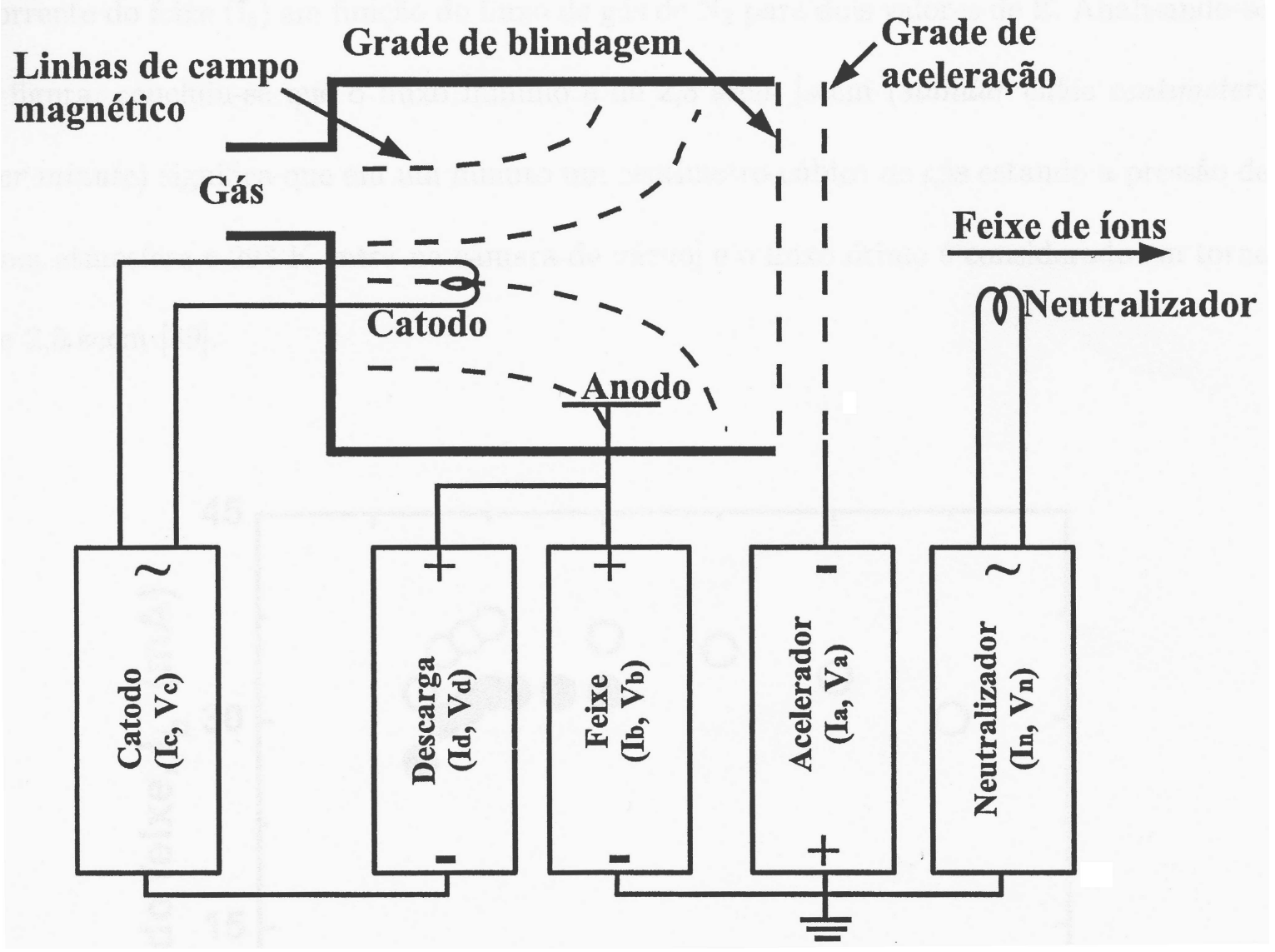

Figura 2.2: Diagrama da fonte de íons e esquema das conexões elétricas com as fontes de tensão. 


\subsubsection{Evaporador}

O evaporador por feixe de elétrons (ver figura 2.3) é formado por um suporte para cadinho resfriado através de circulação de água gelada, um filamento (catodo) e um magneto.

Os elétrons emitidos no filamento são acelerados por uma tensão de $5 \mathrm{kV}$ e, guiados pelo campo magnético do magneto, percorrendo uma trajetória circular com um ângulo de $270^{\circ}$ atingindo o material no cadinho. As colisões de elétrons resultam em transferência de momentum para o material, aumentando a temperatura e levando à evaporação do mesmo. Um outro campo magnético, gerado por bobinas, pode ser acrescentado remotamente mudando a região do material atingida pelo feixe e fazendo a varredura do feixe de elétrons.

Para controlar a taxa de deposição, medida através do monitor de deposição, varia-se a corrente do feixe de elétrons de zero a $600 \mathrm{~mA}$.

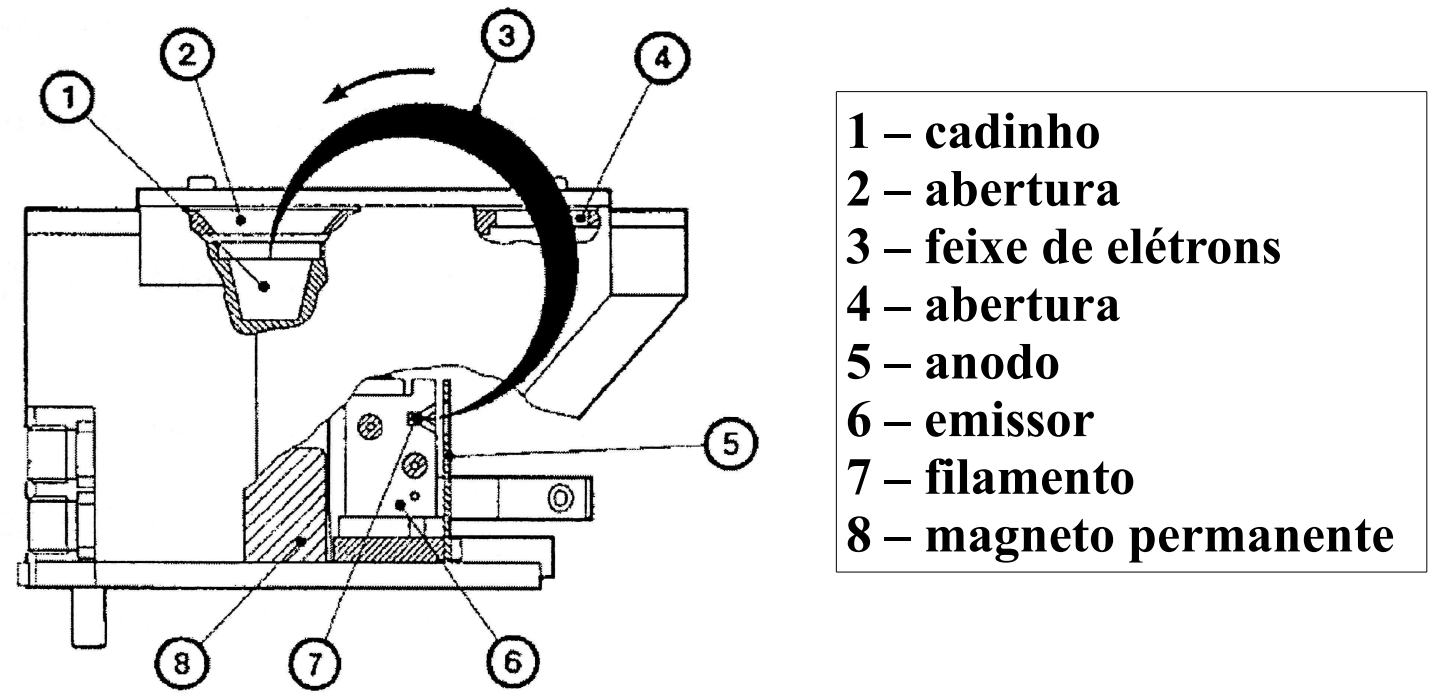

Figura 2.3: Esquema de funcionamento do evaporador por feixe de elétrons. 


\subsection{Preparação dos filmes de BN}

\subsubsection{Procedimento de deposição}

As amostras de BN foram depositadas da seguinte maneira:

Um substrato de $\mathrm{Si}(111)$ ou $\mathrm{Si}(100)$ com um lado polido, previamente lavado em $\mathrm{HF}$ (concentração de $2 \%$ em volume, 2 minutos) foi preso ao suporte de substrato. Uma vez comprovado o vácuo na câmara $\left(\sim 7,0 \times 10^{-5} \mathrm{~Pa}\right)$, o substrato foi aquecido à temperatura desejada, com o uso do módulo de aquecimento composto por uma resistência de platina, monitorada por um termopar tipo K fixado no suporte de substrato. Boro sólido, com pureza de 99,9\%, foi aquecido pelo feixe de elétrons do evaporador até que o monitor de deposição, ao lado do suporte de substrato, acusasse a taxa de deposição desejada. O fluxo de gás, nitrogênio puro ou misturado com argônio, foi devidamente regulado pelos respectivos controladores de fluxo de massa, e conduzido à fonte de íons. Finalmente, a fonte de íons foi acionada produzindo um feixe de íons incidente sobre o substrato, gerando uma densidade de corrente que havia sido previamente definida. Uma vez atingida a espessura pretendida do o filme (medida pelo monitor de deposição), o bombardeamento de íons e a evaporação de boro foram imediatamente interrompidos.

\subsubsection{Parâmetros de deposição}

Neste trabalho foram depositadas e analisadas 22 amostras de filmes finos de BN pelo método IBAD variando-se os parâmetros de deposição discriminados na sessão 2.1.

As amostras produzidas foram separadas em dois grupos: 
O primeiro grupo é composto por quinze amostras (1 a 15) depositadas com parâmetros fixos durante a deposição de cada amostra. Nos referimos às amostras deste grupo por amostras depositadas em uma camada;

Com o intuito de melhorar a aderência dos filmes ao substrato, as sete amostras do segundo grupo (amostras 16 a 22), foram depositadas em duas etapas [18]. Uma primeira camada, com espessura nominal de 250 a $1000 \AA \AA$, foi depositada somente com o uso de íons de nitrogênio variando-se a razão de chegada $\operatorname{ARR}(\mathrm{N} / \mathrm{B})$ de 0,3 a 1,2 . Sobre esta camada foi depositada a segunda camada, com o uso de íons de argônio e nitrogênio, variando-se a razão de chegada ARR(N/B) de 0,7 a 2,0. A energia de íons incidentes foi mantida constante e igual a $1000 \mathrm{eV}$ durante a deposição das duas camadas. Nos referimos às amostras desse grupo por amostras depositadas em duas camadas.

As tabelas 2.1 e 2.2 apresentam os seguintes parâmetros para as amostras:

-energia de íons incidentes (E);

-razão de chegada ARR(N/B);

-momentum transferido dos íons incidentes aos átomos de boro evaporados e depositados na superfície do substrato ou do filme (MTA);

-espessura nominal (En);

-espessura medida com perfilômetro (Em);

- temperatura do substrato (TS).

- fluxo de gás nitrogênio/ fluxo de gás argônio (k).

A razão $\operatorname{ARR}(N / B)$ é definida pelo fluxo de partículas atômicas de $\mathrm{N}$ do feixe de íons incidentes no substrato dividido pelo fluxo de átomos de B trasportados ao susbtrato. Os cálculos da ARR(N/B) e do MTA são apresentados com detalhes nos apêndices A e B, respectivamente.

A tabela 2.1 apresenta parâmetros para as amostras em uma camada e a tabela 2.2, para as 
amostras em duas camadas. As colunas $\mathrm{C} 1$ e $\mathrm{C} 2$ na tabela 2.2 referem-se à primeira e segunda camada de deposição, respectivamente

Tabela 2.1: Parâmetros das amostras depositadas em uma camada.

\begin{tabular}{|c|c|c|c|c|c|c|}
\hline Amostra & $E(e V)$ & $A R R(N / B)$ & $\begin{array}{c}M T A \\
(e V \times \text { u.m.a. })^{1 / 2}\end{array}$ & $\operatorname{En}(A)$ & $\operatorname{Em}(A)$ & $T S\left({ }^{\circ} \mathrm{C}\right)$ \\
\hline 1 & 1000 & 1,6 & 169 & 1500 & 3533 & 20 a 76 \\
\hline 2 & 800 & 1,6 & 152 & 1500 & 2241 & 19 a 85 \\
\hline 3 & 600 & 1,6 & 133 & 1500 & 81 & 19 a 74 \\
\hline 4 & 400 & 1,6 & 111 & 1500 & $\#$ & 20 a 63 \\
\hline 5 & 1000 & 1,6 & 169 & 1500 & 2118 & 350 \\
\hline 6 & 800 & 1,6 & 152 & 1500 & 5017 & 350 \\
\hline 7 & 600 & 1,6 & 133 & 1500 & 5943 & 350 \\
\hline 8 & 1000 & 0,3 & 34 & 2000 & 1896 & 200 \\
\hline $9 *$ & 500 & 3,1 & 392 & 400 & 1105 & 400 \\
\hline $10^{*}$ & 500 & 3,1 & 392 & 799 & 1915 & 400 \\
\hline $11^{*}$ & 500 & 3,1 & 392 & 1050 & 1762 & 400 \\
\hline $12^{*}$ & 500 & 3,1 & 392 & 603 & 668 & 400 \\
\hline $13^{*+}$ & 500 & 3,1 & 392 & 400 & -482 & 400 \\
\hline $14^{*}$ & 500 & 3,1 & 392 & 400 & 691 & 250 \\
\hline $15^{*}$ & 500 & 2,3 & 294 & 600 & 1460 & 400 \\
\hline
\end{tabular}

* : Amostras depositadas sobfluxo de gás nitrogênio/ fluxo de gás argônio $=\mathrm{k}=0,95$ (ver apêndice $\mathrm{A}$ ); \# : Não foi possível medir a espessura com perfilômetro devido ao alto grau de descascamento da amostra;

+: Substrato previamente bombardeado com íons de argônio. 
Tabela 2.2: Parâmetros das amostras depositadas em duas camadas.

\begin{tabular}{|c|c|c|c|c|c|c|c|c|c|c|c|}
\hline \multirow[t]{2}{*}{ Amostra } & \multirow[t]{2}{*}{$\begin{array}{c}E \\
(e V)\end{array}$} & \multirow{2}{*}{$\begin{array}{l}\boldsymbol{k} \\
\\
C 2\end{array}$} & \multicolumn{2}{|c|}{$A R R(N / B)$} & \multicolumn{2}{|c|}{$\begin{array}{c}M T A \\
(e V \times \text { u.m.a. })^{1 / 2}\end{array}$} & \multicolumn{2}{|c|}{$\operatorname{En}(\AA)$} & \multirow{2}{*}{$\begin{array}{l}\operatorname{Em}(\AA) \\
C 1+C 2\end{array}$} & \multicolumn{2}{|c|}{$\begin{array}{c}\text { Temperatura } \\
\text { do Substrato } \\
\left({ }^{\circ} \mathrm{C}\right)\end{array}$} \\
\hline & & & $\mathrm{C} 1$ & $\mathrm{C} 2$ & $\mathrm{C} 1$ & $\mathrm{C} 2$ & $\mathrm{C} 1$ & $\mathrm{C} 1+\mathrm{C} 2$ & & $C 1$ & $\mathrm{C} 2$ \\
\hline 16 & 1000 & 0,1 & 1,2 & 2,0 & 136 & 237 & 250 & 1200 & 3332 & 350 & 350 \\
\hline 17 & 1000 & 0,1 & 0,8 & 1,4 & 90 & 166 & 1000 & 3200 & 4278 & 200 & 200 \\
\hline 18 & 1000 & 0,2 & 0,5 & 1,3 & 50 & 165 & 250 & 880 & 2076 & 200 & 400 \\
\hline 19 & 1000 & 0,2 & 0,5 & 1,3 & 50 & 165 & 1000 & 2770 & 3962 & 200 & 400 \\
\hline 20 & 1000 & 0,5 & 0,5 & 1,2 & 50 & 166 & 1000 & 2500 & 3262 & 200 & 400 \\
\hline 21 & 1000 & 0,5 & 0,3 & 0,7 & 34 & 101 & 1000 & 2500 & 3819 & 200 & 400 \\
\hline 22 & 1000 & 0,5 & 0,3 & 1,2 & 34 & 166 & 500 & 2000 & -598 & 200 & 400 \\
\hline
\end{tabular}

$\mathrm{C} 1$ e $\mathrm{C} 2$ referem-se à $1^{\mathrm{a}}$ e $2^{\mathrm{a}}$ camadas respectivamente

A amostra 3 apresentou filme com alto grau de descascamento, prejudicando a medida de espessura. A amostra 4 apresentou alto grau de descascamento, impossibilitando a realização da medida de espessura. A amostra 13 apresentou espessura negativa devido ao bombardeamento prévio do substrato com íons de argônio, que gerou sputtering do substrato. A amostra 22 apresentou espessura negativa e não sabemos explicar tal resultado, uma vez que a a mostra apresentou filme. Discussões sobre estas amostras são apresentadas, juntamente com suas fotografias de microscopia óptica no capítulo 4. 


\section{Capítulo 3}

\section{Técnicas de caracterização}

Nas análises das amostras de $\mathrm{BN}$ depositadas durante a realização deste trabalho foram utilizadas as seguintes técnicas de caracterização: espectroscopia do infravermelho por transformada de Fourier, perfilometria, difração de raio-X e microscopia óptica. Descrições breves de cada técnica assim como fundamentos teóricos úteis para a interpretação dos resultados são apresentadas nas seções a 3.1 a 3.4, respectivamente.

\subsection{Espectroscopia do infravermelho}

Os espectros de absorção e de emissão devidas a rotações e vibrações de moléculas em seu estado eletrônico fundamental se encontram, na maior parte das vezes, na região do infravermelho (IR). Desta forma, a espectroscopia de IR se tornou uma técnica importante para a investigação das ligações químicas e da estrutura molecular de compostos. No presente trabalho, a análise dos espectros de absorção no infravermelho, devida a vibrações moleculares, foi essencial para a detecção das fases h-BN e c-BN nas amostras de BN.

Uma vez que as amostras a serem caracterizadas se encontram no estado sólido, foram analisados apenas o mecanismo de absorção de radiação infravermelha por vibrações moleculares, desprezando efeitos relativos a rotações. São apresentadas também considerações referentes ao equipamento de medidas e às análises dos espectros de absorção. 
Um modelo simples, que se pode utilizar para explicar os espectros vibracionais no infravermelho de moléculas reais, consiste em considerar os átomos, em um cristal ou em uma molécula, como partículas puntuais massivas, dotadas de propriedades elétricas como carga e momento de dipolo elétrico e representar as ligações covalentes entre os átomos por molas de Hooke.

Apesar de apresentar um número reduzido de parâmetros associados aos átomos e de utilizar uma simplificação na descrição das forças interatômicas, tal modelo se mostra útil para descrição dos fenômenos de absorção e emissão no infravermelho, apresentando soluções para freqüências e energias consistentes com as observações experimentais.

Para obter as equações de movimento relativas às vibrações de uma molécula serão descritas as expressões clássicas das energias potencial e cinética em termos das posições de seus átomos.

Sejam as três coordenadas cartesianas $(x, y, z)$ para cada átomo, uma para cada um dos graus de liberdade de movimento nas direções $x, y$ e $z$. Se considerarmos uma molécula com $\mathrm{N}$ átomos, teremos $3 \mathrm{~N}$ coordenadas para $3 \mathrm{~N}$ graus de liberdade de movimento.

Por motivos de simplicidade será representado o deslocamento de cada um dos $\mathrm{N}$ átomos em relação a suas posições de equilíbrio pelo conjunto de coordenadas generalizadas $\mathrm{q}_{1}, \mathrm{q}_{2}, \mathrm{q}_{3}, \mathrm{q}_{4} \ldots$, $\mathrm{q}_{3 \mathrm{~N}}$ ao invés da notação tradicional $x_{1}, y_{1}, z_{1}$ para o átomo $1 ; x_{2}, y_{2}, z_{2}$ para o átomo 2 e assim até $x_{\mathrm{N}}, y_{\mathrm{N}}, z_{\mathrm{N}}$ para o átomo $\mathrm{N}$.

As expressões clássicas das energias potencial e cinética em termos das coordenadas dos átomos se tornam:

$$
2 \mathrm{~V}=\sum_{i, j=1}^{3 \mathrm{~N}} f_{i j} q_{i} q_{j} \quad \mathrm{e} \quad 2 \mathrm{~T}=\sum_{i, j=1}^{3 \mathrm{~N}} m_{i j} \dot{q}_{i} \dot{q}_{j}
$$

onde V e T são as energias potencial e cinética do sistema, respectivamente, $f_{i j}$ são constantes de força (generalização das constantes de mola de Hooke) e $m_{i j}$ são funções das massas. Se forem 
utilizadas coordenadas cartesianas, os $\mathrm{m}_{\mathrm{ij}}$ representarão as massas e serão nulos para $q_{i} \neq q_{j}$.

Como T é função apenas de $\dot{q}_{i}$ e V é função apenas de $\mathrm{q}_{\mathrm{i}}$, a equação de Lagrange assume a seguinte forma:

$$
\frac{d}{d t}\left(\frac{\partial T}{\partial \dot{q}_{i}}\right)+\frac{\partial V}{\partial q_{i}}=0
$$

Das equações (3.1) e (3.2) obtemos:

$$
\sum_{j=1}^{3 \mathrm{~N}} m_{i j} \ddot{q}_{j}+\sum_{j=1}^{3 \mathrm{~N}} f_{i j} q_{j}=0
$$

Como tem-se $3 \mathrm{~N}$ valores para i, se tem $3 \mathrm{~N}$ equações referentes à equação (3.3) com solução geral dada por:

$$
q_{j}=A_{j} \operatorname{sen}(\sqrt{\lambda} t+\alpha), \quad \sqrt{\lambda}=2 \pi v
$$

Diferenciando (3.4) em relação ao tempo, obtêm-se:

$$
\dot{q}_{j}=\sqrt{\lambda} A_{j} \cos (\sqrt{\lambda} t+\alpha) \text { e } \ddot{q}_{j}=-\lambda A_{j} \operatorname{sen}(\sqrt{\lambda} t+\alpha)
$$

Combinando as equações (3.3), (3.4) e (3.5), terem-se, para cada um dos $3 \mathrm{~N}$ valor de $\mathrm{i}$,

$$
\sum_{j=1}^{3 N} f_{i j} A_{j} \operatorname{sen}(\sqrt{\lambda} t+\alpha)-\sum_{j=1}^{3 N} m_{i j} \lambda A_{j} \operatorname{sen}(\sqrt{\lambda} t+\alpha)=0
$$




$$
\sum_{j=1}^{3 \mathrm{~N}}\left(f_{i j}-m_{i j} \lambda\right) A_{j}=0
$$

Escrevendo os termos da soma, tem-se um sistema de $3 \mathrm{~N}$ equações lineares homogêneas, que somente terá soluções não triviais para os valores $\mathrm{A}_{\mathrm{j}}$ se a matriz dos coeficientes de $\mathrm{A}$ tiver determinante igual a zero. Expressando esta condição, teremos:

$$
\left|\begin{array}{cccc}
f_{11}-m_{11} \lambda & f_{12}-m_{12} \lambda & \cdots & f_{1,3 N}-m_{1,3 N} \lambda \\
f_{21}-m_{21} \lambda & f_{22}-m_{22} \lambda & \cdots & f_{2,3 N}-m_{2,3 N} \lambda \\
\vdots & \vdots & \ldots & \vdots \\
f_{3 \mathrm{~N}, 1}-m_{3 \mathrm{~N}, 1} \lambda & f_{3 \mathrm{~N}, 2}-m_{3 \mathrm{~N}, 2} \lambda & \cdots & f_{3 \mathrm{~N}, 3 N}-m_{3 \mathrm{~N}, 3 N} \lambda
\end{array}\right|=0
$$

A expressão acima é uma equação de ordem $3 \mathrm{~N}$ em $\lambda$. Apesar dos diferentes valores para as amplitudes $A_{j}$, o fato de cada valor de $\lambda$ corresponder a uma única freqüência de oscilação e uma fase $\alpha$ significa que cada valor de $\lambda$ corresponde a um estado de movimento em que todos os átomos oscilam com mesma freqüência e passam pelo ponto de equilíbrio simultaneamente. Tal estado de movimento é um modo normal de vibração do sistema e a freqüência associada a ele é uma freqüência natural de vibração.

Das 3N soluções possíveis para a equação 3.7, seis (para moléculas tridimensionais) ou cinco (para moléculas lineares) correspondem a translações do centro de massa e/ou rotações em torno do mesmo. Esses estados de movimento que não alteram as distâncias entre os átomos apresentam freqüência nula. Por esse motivo, diremos que uma molécula tridimensional de $\mathrm{N}$ átomos apresenta $3 \mathrm{~N}-6$ modos normais de vibração e uma molécula linear, $3 \mathrm{~N}-5$.

A molécula de $\mathrm{H}_{2} \mathrm{O}$, por exemplo, apresenta três modos normais de vibração. No chamado stretching simétrico os átomos de hidrogênio, em fase, se aproximam e se afastam do átomo de oxigênio na direção das ligações que os unem ao mesmo. O stretching assimétrico é o modo no qual os átomos executam esse mesmo movimento, porém alternadamente, e no modo bending, os átomos de hidrogênio se movem nas direções perpendiculares às suas ligações com o átomo de 
oxigênio e paralelos ao plano definido pelos três átomos (figura 3.1).
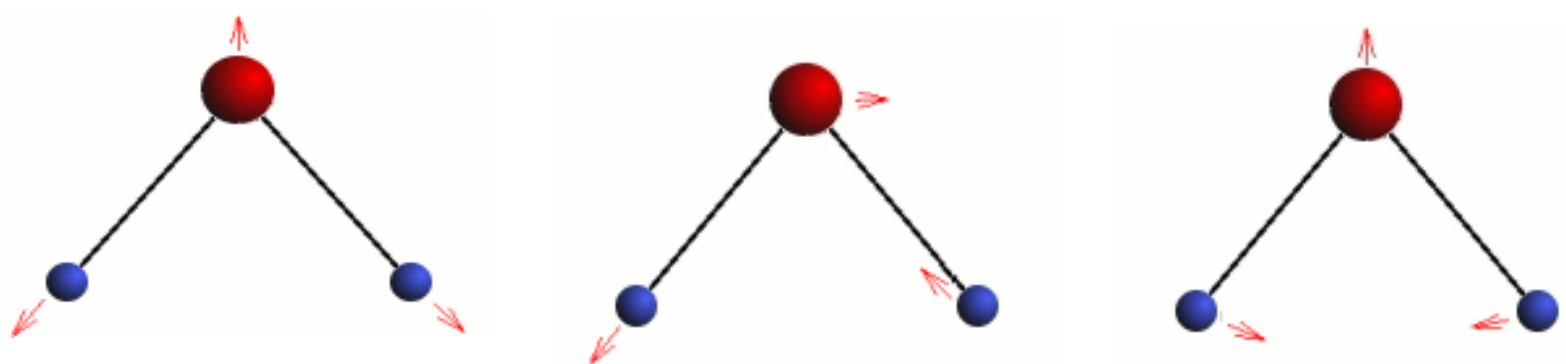

Figura 3.1: Representação dos modos normais de vibração da molécula de água. Da esquerda para a direita: modo stretching simétrico, stretching assimétrico e bending.

A notação apresentada acima também é usada para se referir aos modos de vibração dos compostos de BN.

A análise do modelo de massas e molas através da mecânica quântica leva a conclusões sobre o espectro vibracional no infravermelho que podem ser obtidas a partir de considerações clássicas Porém, apresenta uma descrição de caráter mais fundamental que é indispensável para a explicação de outros fenômenos relativos à interação da radiação com a matéria. Neste tópico conclusões serão obtidas através da mecânica quântica e em seguida comparadas e analisadas em termos do modelo clássico.

Usando coordenadas adequadas (coordenadas internas), é possível reduzir o sistema de 3N - 6 equações referentes à equação (3.6), simplificando consideravelmente o problema.

Definem-se as coordenadas internas $\mathrm{Q}_{\mathrm{k}}$ de tal modo que a equação (3.1) se torna:

$$
2 \mathrm{~V}=\sum_{k=1}^{3 \mathrm{~N}-6} \lambda_{k} Q^{2}{ }_{k} \quad \mathrm{e} \quad 2 \mathrm{~T}=\sum_{k=1}^{3 \mathrm{~N}} \dot{Q}^{2}{ }_{k}
$$

A equação de onda para os estados vibracionais da molécula assume a forma:

$$
\frac{-h}{8 \pi^{2}} \sum_{k=1}^{3 N-6} \frac{\partial^{2} \Psi_{v}}{\partial Q_{k}^{2}}+\frac{1}{2} \sum_{k=1}^{3 N-6} \lambda_{k} Q_{k}^{2} \Psi_{v}=W_{v} \Psi_{v}
$$


onde $\Psi_{k}$ é a função de onda vibracional da molécula, h é a constante de Planck, e $W_{V}$ é a energia vibracional.

Supondo que a função de onda possa ser escrita como um produto de funções, cada uma dependendo apenas de uma coordenada interna, teremos [36, 37]:

$$
\Psi_{V}=\Phi_{n_{1}}\left(Q_{1}\right) \Phi_{n_{2}}\left(Q_{2}\right) \ldots \Phi_{n_{3 \mathrm{~N}-6}}\left(Q_{3 \mathrm{~N}-6}\right)=\prod_{k}^{3 \mathrm{~N}-6} \Phi_{n_{k}}\left(Q_{k}\right)
$$

A equação (3.10) pode ser separada em $3 \mathrm{~N}-6$ equações de osciladores harmônicos independentes, uma para cada coordenada interna $\mathrm{Q}_{\mathrm{k}}$

Cada função $\Phi_{n_{k}}$ é solução para o oscilador harmônico de freqüência $v_{k}=\frac{\sqrt{\lambda_{k}}}{2 \pi}$ e a energia vibracional é dada pela soma das energias de cada modo normal,

$$
W_{v}=\sum_{k}^{3 \mathrm{~N}-6} W_{n_{k}}\left(v_{k}, n_{k}\right)=\left(n_{1}+\frac{1}{2}\right) h v_{1}+\left(n_{2}+\frac{1}{2}\right) h v_{2}+\ldots+\left(n_{3 \mathrm{~N}-6}+\frac{1}{2}\right) h v_{3 \mathrm{~N}-6}
$$

onde os $\mathrm{n}_{\mathrm{k}}$ assumem valores inteiros.

A probabilidade de transição de um estado vibracional $\Psi_{V}$, para um estado $\Psi_{V^{\prime \prime}}$ da molécula é dada pela integral $\int \Psi_{V^{\prime \prime}}^{*} u \Psi_{V^{\prime}} d \tau_{V}$, onde u é o momento de dipolo elétrico da molécula e $\quad d \tau_{V}=d Q_{1} d Q_{2} d Q_{3} \ldots d Q_{3 N-6}$ é o elemento de volume no espaço das coordenadas internas.

Expandindo o momento de dipolo u em função das coordenadas internas $Q_{k}$ em série de Taylor, teremos: 


$$
u=u_{0}+\sum_{k}^{3}\left(\frac{\partial u}{\partial Q_{k}}\right) Q_{0}+\frac{1}{2} \sum_{k}^{3} \sum_{l}^{\mathrm{N}-6}\left(\frac{\partial^{2} u}{\partial Q_{k} \partial Q_{l}}\right)_{0}+\ldots
$$

onde $\mathrm{u}_{0}$ é o momento de dipolo para a molécula em repouso. Supondo pequenas amplitudes de vibração, podemos ignorar termos de ordem superior e a probabilidade de transição pode ser escrita como se segue:

$$
\int \Psi_{V^{\prime \prime}}^{*} u \Psi_{V^{\prime}} d \tau_{V}=u_{0} \int \Psi_{V^{\prime \prime}}^{*} \Psi_{V^{\prime}} d \tau_{V}+\sum_{k}^{3}\left(\frac{\partial u}{\partial Q_{k}}\right) \int_{0} \Psi_{V^{\prime \prime}}^{*} Q_{k} \Psi_{V^{\prime}} d \tau_{V}
$$

Devido a ortogonalidade das funções $\Psi_{V}$, a primeira integral do lado direito será nula caso haja transição $\left(V^{\prime \prime} \neq V^{\prime}\right)$.

A segunda integral pode ser expandida como se segue:

$$
\begin{aligned}
& \int \Psi_{V^{\prime \prime}}^{*} Q_{k} \Psi_{V^{\prime}} d \tau_{V}=\int \Phi_{n_{1}{ }^{\prime}}^{*}\left(Q_{1}\right) \Phi_{n_{1}{ }^{\prime}}\left(Q_{1}\right) d Q_{1} \int \Phi_{n_{2}{ }^{\prime \prime}}^{*}\left(Q_{2}\right) \Phi_{n_{2}{ }^{\prime}}\left(Q_{2}\right) d Q_{2} \ldots \\
& \ldots \int \Phi_{n_{k}{ }^{\prime \prime}}^{*}\left(Q_{k}\right) Q_{k} \Phi_{n_{k}}, d Q_{k} \ldots
\end{aligned}
$$

Devido a ortogonalidade das funções $\Phi_{n_{k}}$, as integrais na forma $\int \Phi_{n_{k}{ }^{\prime \prime}}^{*}\left(Q_{k}\right) \Phi_{n_{k}{ }^{\prime}}\left(Q_{k}\right) d Q_{k}$ assumem valores não nulos somente se $n_{k}{ }^{\prime \prime}=n_{k}{ }^{\prime}$. O termo $\int \Phi_{n_{k}{ }^{\prime \prime}}^{*}\left(Q_{k}\right) Q_{k} \Phi_{n_{k}{ }^{\prime}} d Q_{k}$ é não nulo apenas quando $n_{k}{ }^{\prime}=n_{k}{ }^{\prime \prime} \pm 1$.

Assim, a integral (3.15) apresenta resultado não nulo apenas quando $n_{1}{ }^{\prime}=n_{1}{ }^{\prime}{ }^{\prime}, n_{2}{ }^{\prime}=n_{2}{ }^{\prime \prime}, \ldots, n_{k}{ }^{\prime}=n_{k}{ }^{\prime \prime} \pm 1, \ldots$ e a equação (3.14) se torna: 


$$
\int \Psi_{V^{\prime \prime}}^{*} u \quad \Psi_{V^{\prime}} d \tau_{V}=\sum_{k}^{3 \mathrm{~N}-6}\left(\frac{\partial u}{\partial Q_{k}}\right) \int_{0} \Phi_{n_{k}{ }^{\prime} \pm 1^{*}} Q_{k} \Phi_{n_{k}{ }^{\prime}} d Q_{k}
$$

onde consideramos as funções $\Phi_{n_{k}}$ normalizadas.

A equação (3.15) expressa duas condições necessárias para que ocorra transição de estado quântico e, isto é , absorção ou emissão de radiação. A primeira condição é que um ou mais osciladores associados aos modos normais de vibração sofra uma transição de um estado $\Phi_{n k}$ para $\Phi_{n \pm 1}$. Uma transição deste tipo corresponde a uma variação de energia vibracional dada por:

$$
\begin{gathered}
\Delta E_{k}=\left[\left(n_{k} \pm 1\right)+1 / 2\right] h v_{k}-\left(n_{k}+1 / 2\right) h v_{k} \\
= \pm h v_{k}
\end{gathered}
$$

onde o sinal + corresponde à absorção e o sinal -, à emissão de energia.

Se for considerado que a variação de energia é devida a absorção ou emissão de um fóton, a equação (3.16) exige que tal fóton tenha freqüência $v_{k}$ coincidente com uma freqüência natural do sistema. Essa imposição está de acordo com o modelo clássico. Se alguma força externa oscilante agir sobre um sistema de massas e molas com freqüência igual a uma das freqüências naturais do sistema, este absorverá energia da fonte responsável pela força aumentando sua amplitude de oscilação. Quando a freqüência da força não coincidir com uma das freqüências naturais, a absorção de energia será ineficiente.

Da mesma maneira, uma molécula absorve radiação eletromagnética apenas quando a freqüência da radiação coincide com uma freqüência natural de vibração da molécula. Portanto, todas as freqüências de radiação eletromagnética absorvida por uma molécula que não gira 
coincidem com as freqüências naturais de vibração da mesma [37].

Em muitos casos, nem todas as freqüências naturais de vibração correspondem a uma banda no espectro de absorção de radiação. Isso ocorre pois uma vibração molecular só absorve energia eletromagnética se houver uma variação no momento de dipolo da molécula. Moléculas de substâncias simples, por não apresentarem momento de dipolo ou vibrações de moléculas que não resultem na variação do momento de dipolo são inativas no infravermelho. Esta é a segunda

condição expressa pela equação (3.15) como a imposição de que o termo $\left(\frac{\partial u}{\partial Q_{k}}\right)_{0}$ seja não nulo para que ocorra transição de estado vibracional.

A visualização desta propriedade pode ser simples se for utilizada, como exemplo, a molécula

(a)

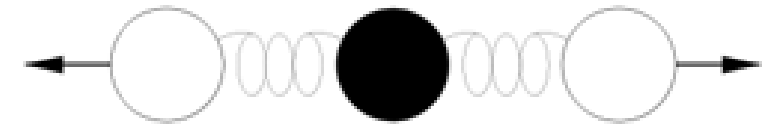

(b)

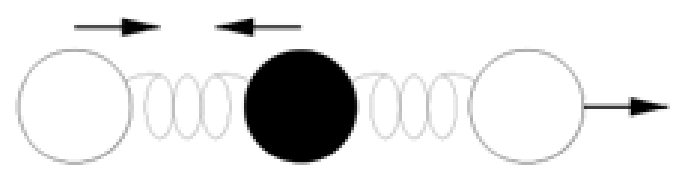

(c)

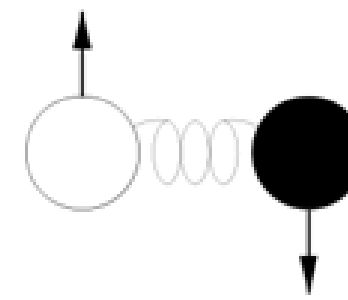

Figura 3.2: Modos normais de vibração do dióxido

de carbono: (a) stretching simétrico; (b) stretching assimétrico e ( c) bending. de $\mathrm{CO}_{2}$. Considerando que o centro de carga negativa está na metade da distância entre os átomos de oxigênio, da molécula em repouso e, que o centro de carga positiva se encontra sobre o átomo de carbono, verifica-se que o momento de dipolo permanente da molécula é nulo. O modo de stretching assimétrico faz com que a distância entre os centros de carga varie periodicamente, gerando um momento de dipolo variável na direção da linha que liga os átomos, apontando ora num sentido ora em outro (figura 3.2 (b)). Um modo bending gera um momento de dipolo variável nas duas direções perpendiculares à linha que liga os átomos na situação de repouso (figura 3.2 (c)). Estes modos são responsáveis pelas duas freqüências de vibração do $\mathrm{CO}_{2}$ ativas no infravermelho, já que o modo stretching simétrico não altera a distancia entre os centros de carga e por isso é inativo no infravermelho (figura 3.2(a)). 


\subsubsection{Espectroscopia de Infravermelho por Transformada de Fourier (FTIR)}

A técnica de espectroscopia do infravermelho por transformada de Fourier (FTIR) é resultado da combinação de um interferômetro de Michelson e um detector de radiação infravermelha sensível a variações de intensidade.

Um feixe de radiação infravermelha, contendo todas as freqüências a serem analisadas, incide sobre um espelho semi-transparente (figura 3.3). Metade do feixe, refletida no espelho semitransparente atravessa a amostra a ser investigada atingindo um espelho móvel. A outra metade é transmitida e atinge um espelho fixo. Após refletirem nos espelhos, os dois feixes se recombinam e atingem o detector, interferindo de forma construtiva ou destrutiva dependendo da posição do espelho móvel (figura 3.3).

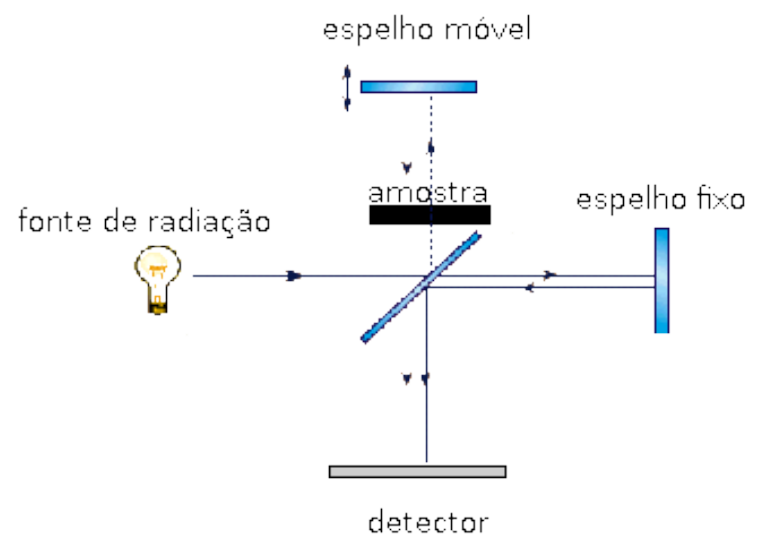

Figura 3.3: Desenho esquemático de um equipamento de FTIR.

O gráfico da intensidade da radiação $I$, que atinge o detector, versus a posição do espelho móvel $x$ é chamado de interferograma $(I(x))$. A intensidade em função da freqüência $v(I(v))$ é calculada a partir do interferograma pela transformada inversa de Fourier dada por:

$$
I(v)=\int_{-\infty}^{+\infty} I(x) \cos (2 \pi v x) d x
$$




\subsubsection{Lei da Absorção}

Considere um filme com contendo uma certa substância. Considere que sobre esse filme incida radiação infravermelha com freqüência igual a uma freqüência natural da dita substância.

Se $I_{0}$ é a intensidade da radiação incidente, $D$ é a espessura do filme e $I$ é a intensidade da radiação transmitida, podemos escrever:

$$
I=I_{0} e^{-A D}
$$

onde a constante $A$ é chamada coeficiente de absorção.

Extraindo o logaritmo de base dez, obtemos:

$$
\log _{10} \frac{I_{0}}{I}=a=A D \log _{10} e
$$

onde a é a absorbância do filme.

Neste trabalho, como na maior parte da literatura sobre filmes finos de $\mathrm{BN}$, a radiação infravermelha é expressada pelo número de onda, que é o inverso do comprimento de onda, em $\mathrm{cm}^{-1}$.

Para a realização das medidas apresentadas neste trabalho foi utilizado o aparelho de FTIR Spectrum GX (Parkin Elmer) que se encontra no Laboratório Cristais Iônicos, Filmes Finos e Datação (LACIFID). Este equipamento é baseado na técnica FTIR e apresenta resolução máxima de $0,5 \mathrm{~cm}^{-1}$ e região espectral entre FAR e NIR. Foram acumuladas 36 leituras para cada espectro 
com passo de $1 \mathrm{~cm}^{-1}$.

Foram obtidos os espectros de FTIR dos substratos utilizados e os mesmos foram subtraídos dos espectros das amostras para que fossem consideradas apenas as absorbância dos filmes.

\subsection{Perfilometria}

O perfilômetro é um aparelho para medição de planicidade de superfícies. É composto por um sensor constituído por uma agulha fina, com eixo acoplado ao núcleo magnético de um transformador diferencial variável linear (linear variable differential transformer: LVTD). Deslocamentos verticais da agulha levam a variações do fluxo magnético no interior da bobina do LVTD produzindo um sinal elétrico proporcional aos deslocamentos. Este sinal é amplificado, digitalizado, processado e visualizado em monitor de vídeo e armazenado digitalmente para análise posterior dos resultados.

As medidas de espessura das amostras depositadas neste trabalho foram realizadas com perfilômetro (3030, Dektak) com agulha de diamante de diâmetro igual a 12,5 $\mu$ m pertencente ao Laboratório de Sistemas Integrais (LSI) da Escola Politécnica da USP (EPUSP). A precisão das medidas é de + ou $-60 \AA$ (o equipamento encontra-se montado sobre uma mesa de isolamento vibracional numa área distante de fontes de vibração para evitar ruídos externos que possam afetar o resultado das medidas).

Como cada substrato das amostras foi fixado sobre o módulo de aquecimento com duas chapas metálicas final de aço inoxidável, durante a deposição a área do substrato sob as lâminas permaneceu isolada, levando à formação de dois degraus formados entre a superfície do filme e o substrato intacto. Assim, a espessura do filme pôde ser determinada através da medida da altura do degrau. Tal medida foi realizada em três posições diferentes do filme para obtenção de um valor médio 


\subsection{Difração de raios-X (XRD)}

O fenômeno de difração ocorre quando uma onda incide sobre centros espalhadores separados uns dos outros por distâncias com mesma ordem de grandeza do comprimento da onda incidente. Como o comprimento de onda de raios-X é da ordem de $10^{-10} \mathrm{~m}$, assim como para distâncias interatômicas em cristais, a radiação nesta faixa do espectro eletromagnético sofre difração ao incidir sobre cristais. Este fato faz com que a difração de raios-X (XRD - X-ray difraction) seja útil para o estudo das propriedades de cristais. Através desta técnica é possível detectar a presença de substâncias numa amostra e determinar os parâmetros da rede cristalina, orientação do plano e grau de cristalinidade da amostra.

Os átomos em um cristal se encontram dispostos de maneira ordenada fazendo que suas posições determinam planos virtuais, chamados de planos cristalográficos, distantes entre si por uma distância $d$ constante e indexados através dos índices de Miller (hkl) [38]. W.L. Bragg formulou uma equação, conhecida como Lei de Bragg [39] e exibida a seguir (equação 3.3.1), que permite determinar a distância interplanar de um cristal sobre o qual incide um feixe de raios-X, conhecendo-se o ângulo de incidência e o comprimento de onda do mesmo.

$$
2 d \operatorname{sen} \theta=n \lambda
$$

onde $\theta$ é o ângulo entre a direção do feixe incidente e o plana cristalográfico, $\lambda$ é o comprimento de onda da radiação e $n$ é um número inteiro referente à ordem de um máximo de difração. Fazendo incidir um feixe de raios-X sobre um cristal, seus átomos se comportarão como centros espalhadores gerando um padrão de difração.

Variando-se o ângulo de incidência de um feixe monocromático sobre o cristal e medindo a intensidade do feixe emergente obtém-se um gráfico da intensidade em função do ângulo de 
incidência do feixe, conhecido como difratograma. A presença de picos no difratograma permite identificar os ângulos relativos a máximos de difração, e a partir da lei de Bragg, sendo conhecido o comprimento de onda $\lambda$, pode-se obter as distâncias $d$ relativas a famílias de planos cristalográficos.

Os valores de $d$,juntamente com os índices de Miller e intensidades relativas para compostos padrões podem ser encontrados na forma de CD-ROM no sistema ICDD (JCPDS) da International Union of Crystalografy.

As medidas de XRD foram realizadas através do método utilizando uma varredura por passo de 0,05 eu tempo de contagem de $5 \mathrm{~s}$ em cada na região de $2 \theta=25^{\circ}$ a $70^{0}$.

Para realização das medidas foi utilizado um difratômetro (Rint 2100, Rigaku) com radiação CuK $(\lambda=1,5418)$ instalado no Laboratório de Cristalografia do Instituto de Física da USP IFUSP.

\subsection{Microscopia óptica (MO)}

No intuito de relacionar a morfologia com os parâmetros de deposição e entender melhor o processo de descascamento dos filmes, realizamos fotografias das superfícies das amostras com ampliação entre 50 e 1000x com microscópio equipado com módulo CCD na posição da ocular. 


\section{Capítulo 4}

\section{Resultados e Discussões}

Neste capítulo serão apresentados os resultados obtidos das medidas de: espectros de FTIR e difratogramas de raios-X, nas respectivas seções 4-1 e 4.2.

\subsection{Espectros de FTIR}

No arranjo experimental usado nas medidas de FTIR, a luz incide normalmente sobre a superfície da amostra. Quando os planos basais se tornam paralelos ao plano de substrato, o modo vibracional de $\mathrm{B}-\mathrm{N}$ no plano basal $\left(1370 \mathrm{~cm}^{-1}\right)$ será mais induzido do que o modo vibracional de B-N-B interplanar $\left(780 \mathrm{~cm}^{-1}\right)$, resultando na redução na razão da intensidade do pico $780 \mathrm{~cm}^{-1}$ relativa à do pico $1370 \mathrm{~cm}^{-1}$, I780/I1370. Analogamente, quando os planos basais tenderem orientar perpendicularmente ao plano de substrato, a I780/I1370 será aumentada. Por outro lado, a fração da fase c-BN pode ser avaliada aproximadamente usando-se a razão da intensidade do pico $1070 \mathrm{~cm}^{-1}$ relativa à soma das intensidades do pico $1070 \mathrm{~cm}^{-1} \mathrm{e}$ do pico $1370 \mathrm{~cm}^{-1}$.

Nos espectros de FTIR obtidos deu-se atenção especial aos dois picos 780 e $1370 \mathrm{~cm}^{-1}$ de h$\mathrm{BN}$ e ao pico $1070 \mathrm{~cm}^{-1}$ de c-BN. Estes picos observados foram analisados em termos da:

1. posição e largura cheia à meia altura de cada pico;

2. razão I780/I1370;

3. razão I1070/(I1070+I1370), caso o pico de c-BN fosse observado, em função dos seguintes parâmetros de deposição:

(a) temperatura do substrato, TS; 
(b) espessura nominal, En;

(c) momentum transferido dos íons incidentes aos átomos de boro evaporados e depositados na superfície do substrato ou do filme (MTA);

(d) bombardeamento prévio do substrato com íons de argônio.

As subseções 4.1.1 e 4.1.2 se referem aos resultados de análises obtidos, em relação a cada parâmetro de deposição previamente mencionado, para as amostras preparadas em uma ou em duas camadas de deposição, respectivamente.

\subsubsection{Amostras preparadas em uma camada}

As figuras 4.1 a 4.15 apresentam os espectros de FTIR para as amostras 1 a 15 . Como houve problemas nas medidas de espessura das amostras 3 e 13, os espectros para estas duas amostras (figuras 4.4 e 4.13) são apresentados em termos da absorbância e os demais como o coeficiente de absorção em função do número de onda, para efeito de comparação entre eles. 


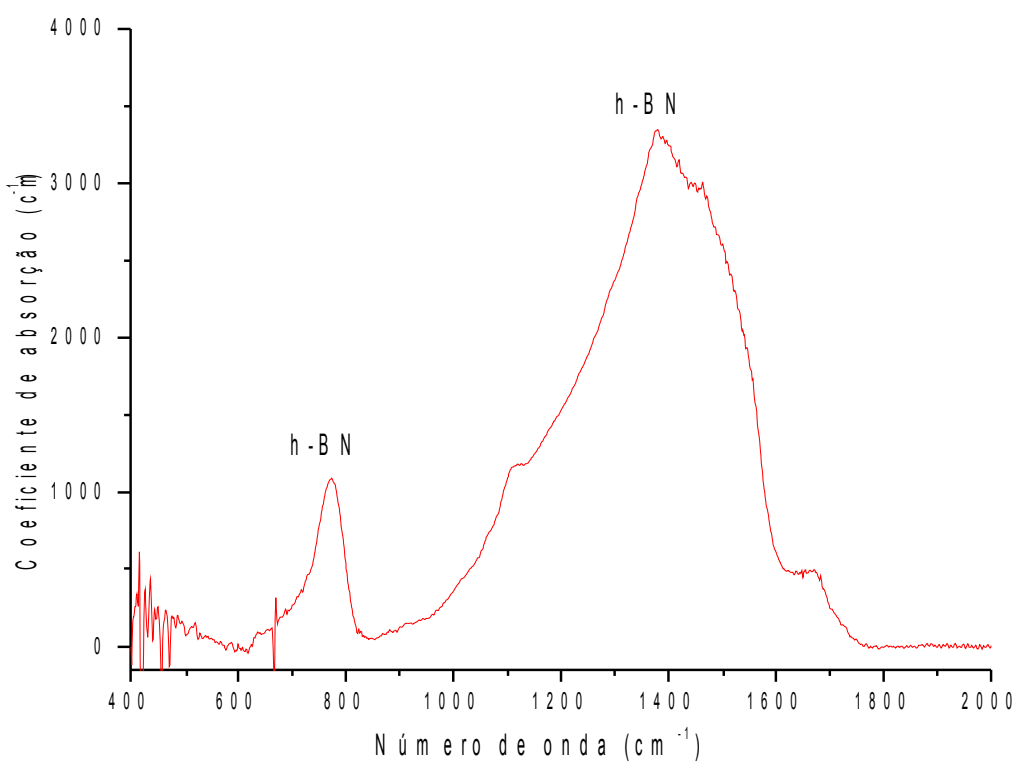

Figura 4.1: Espectro de FTIR da amostra 1.

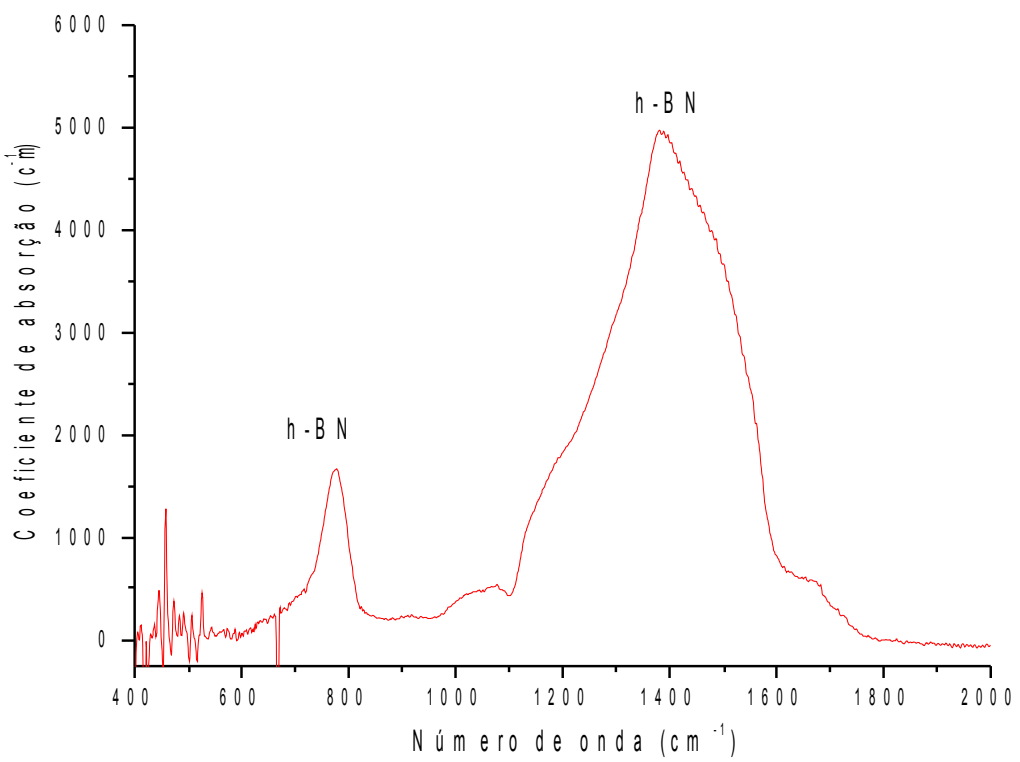

Figura 4.2: Espectro de FTIR da amostra 2 


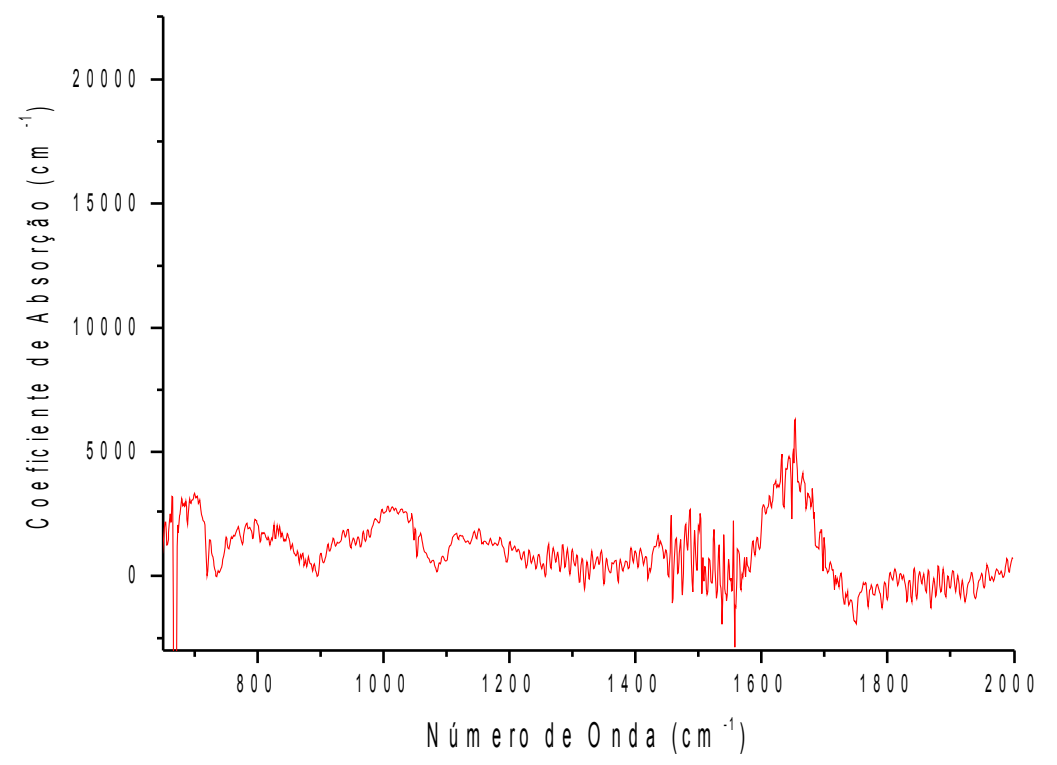

Figura 4.3: Espectro de FTIR da amostra 3

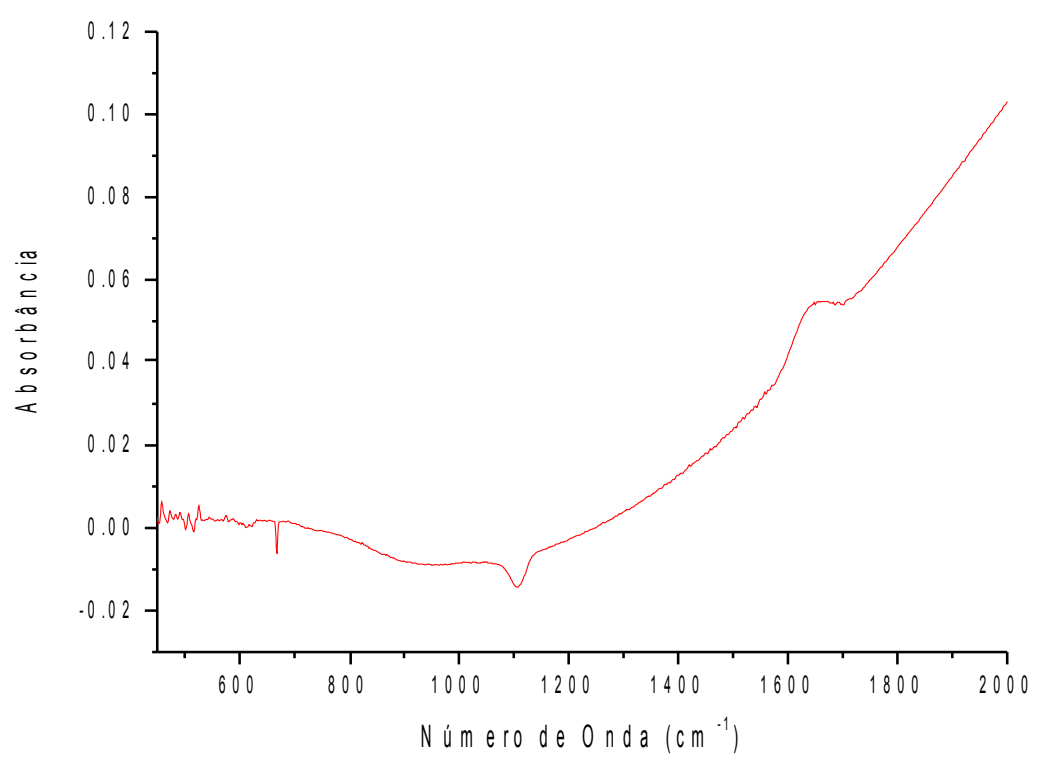

Figura 4.4: Espectro de FTIR da amostra 4 


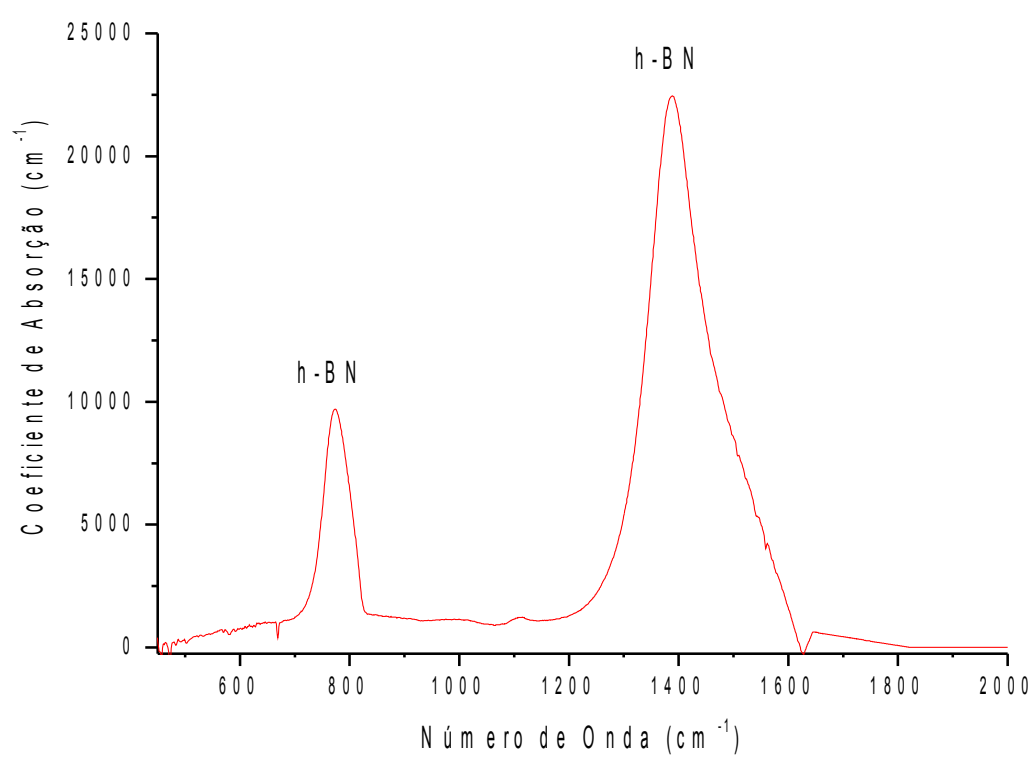

Figura 4.5: Espectro de FTIR da amostra 5

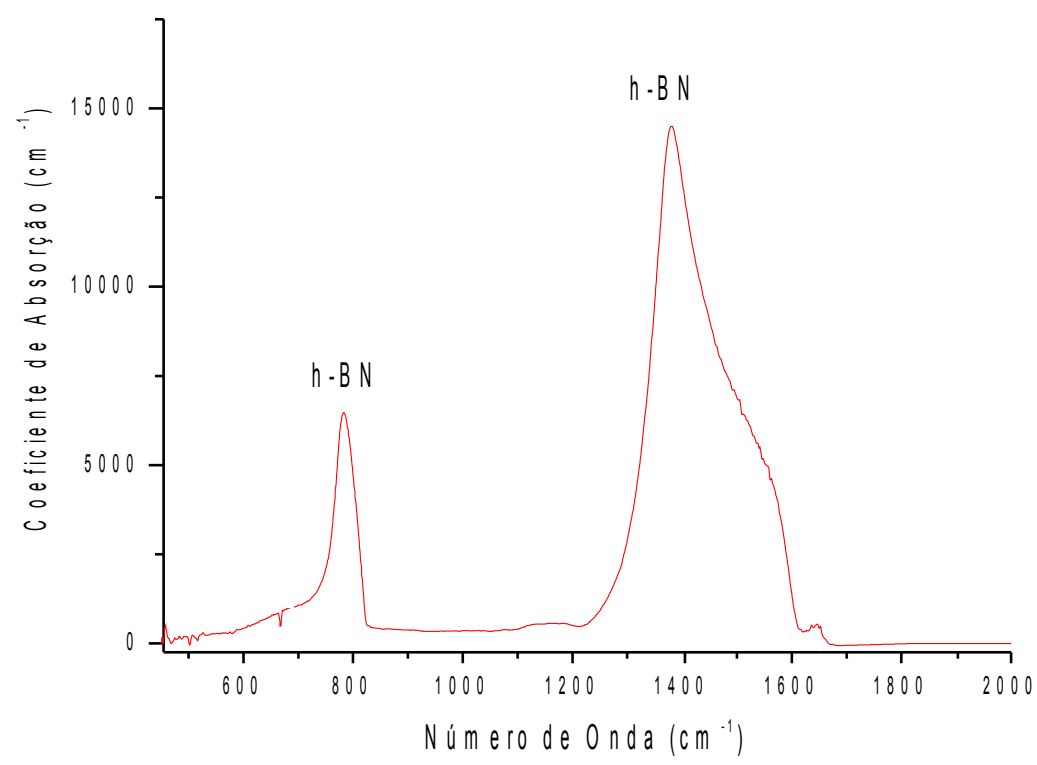

Figura 4.6: Espectro de FTIR da amostra 6 


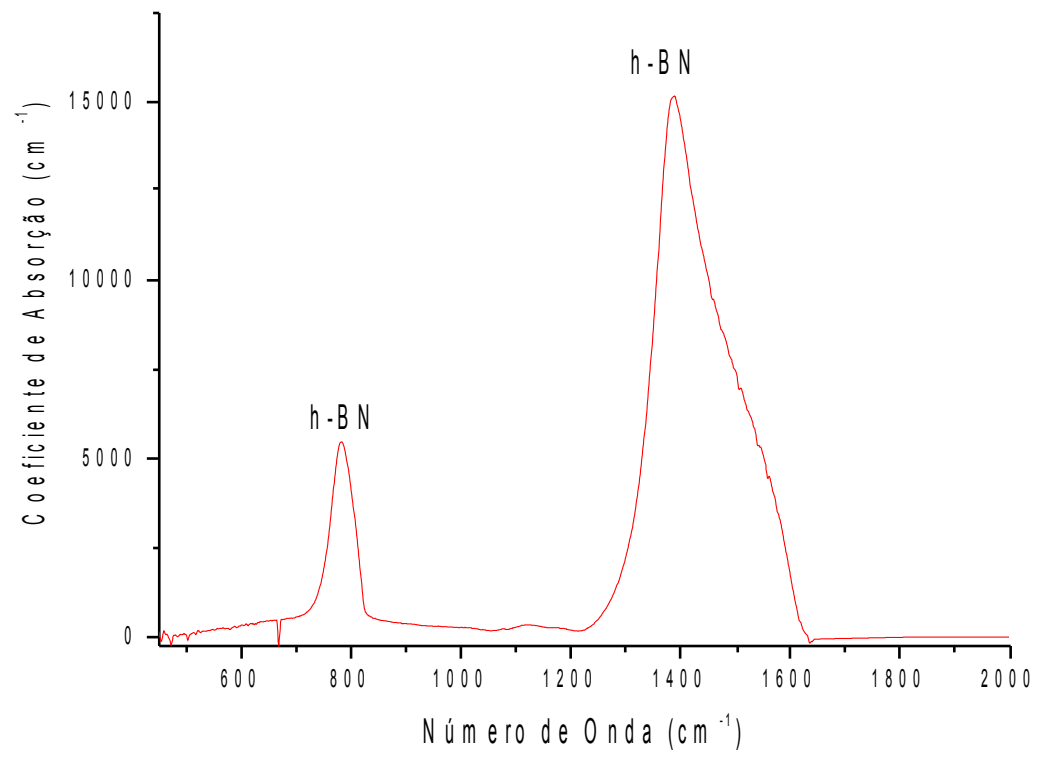

Figura 4.7: Espectro de FTIR da amostra 7

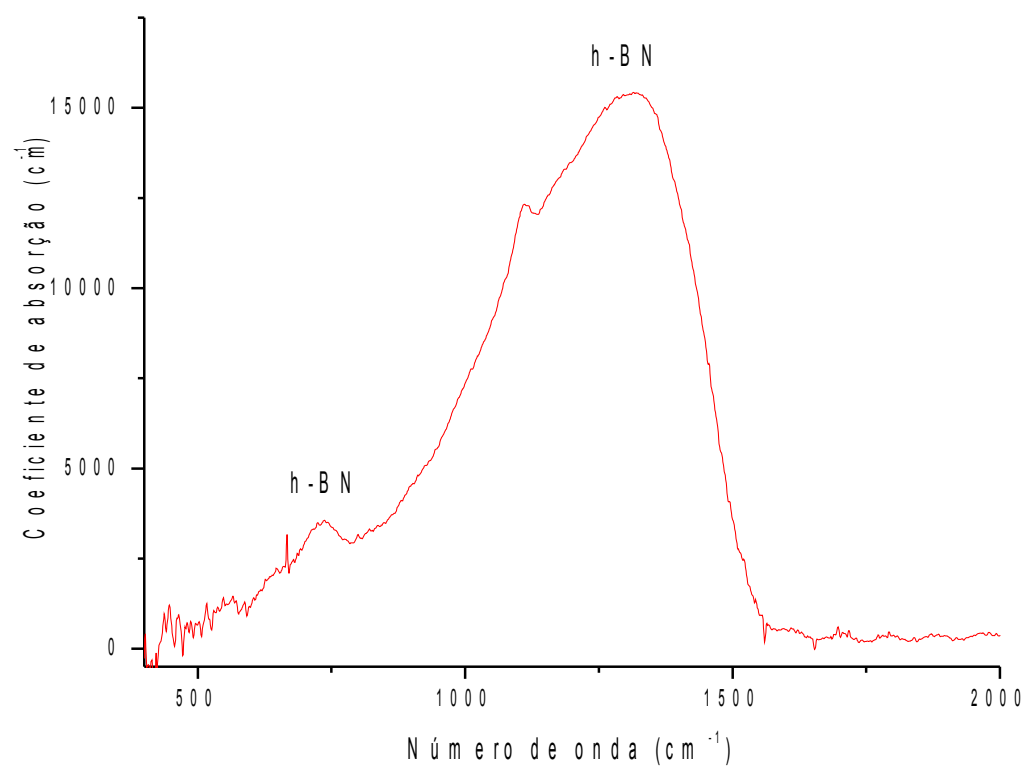

Figura 4.8: Espectro de FTIR da amostra 8 


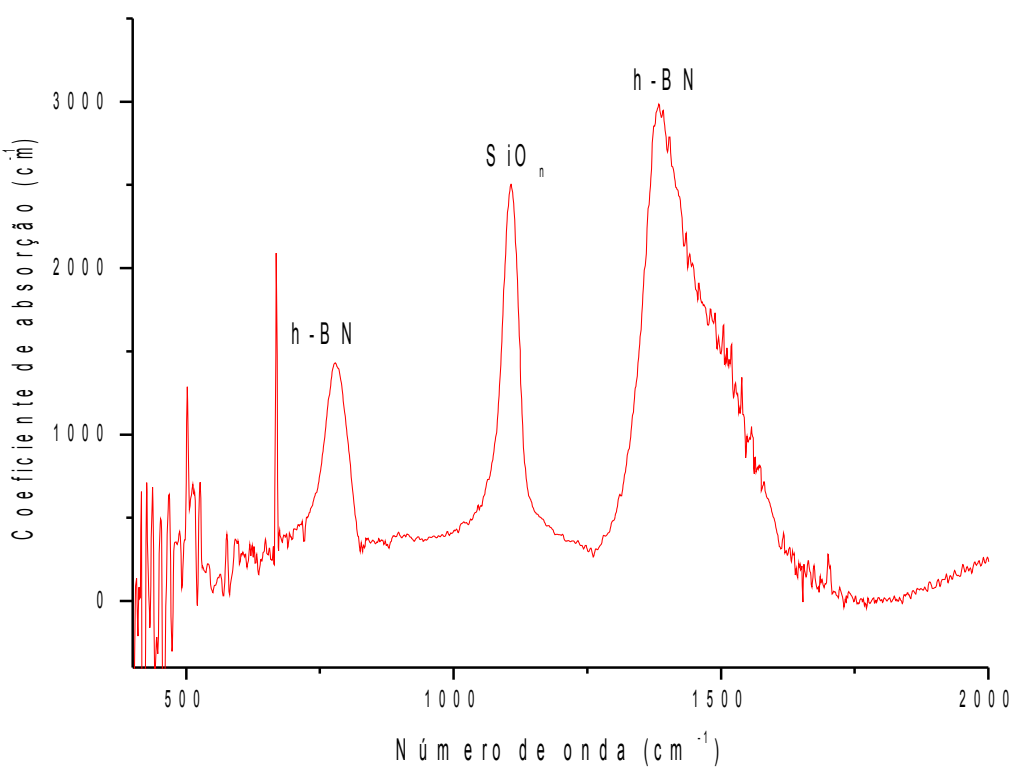

Figura 4.9: Espectro de FTIR da amostra 1

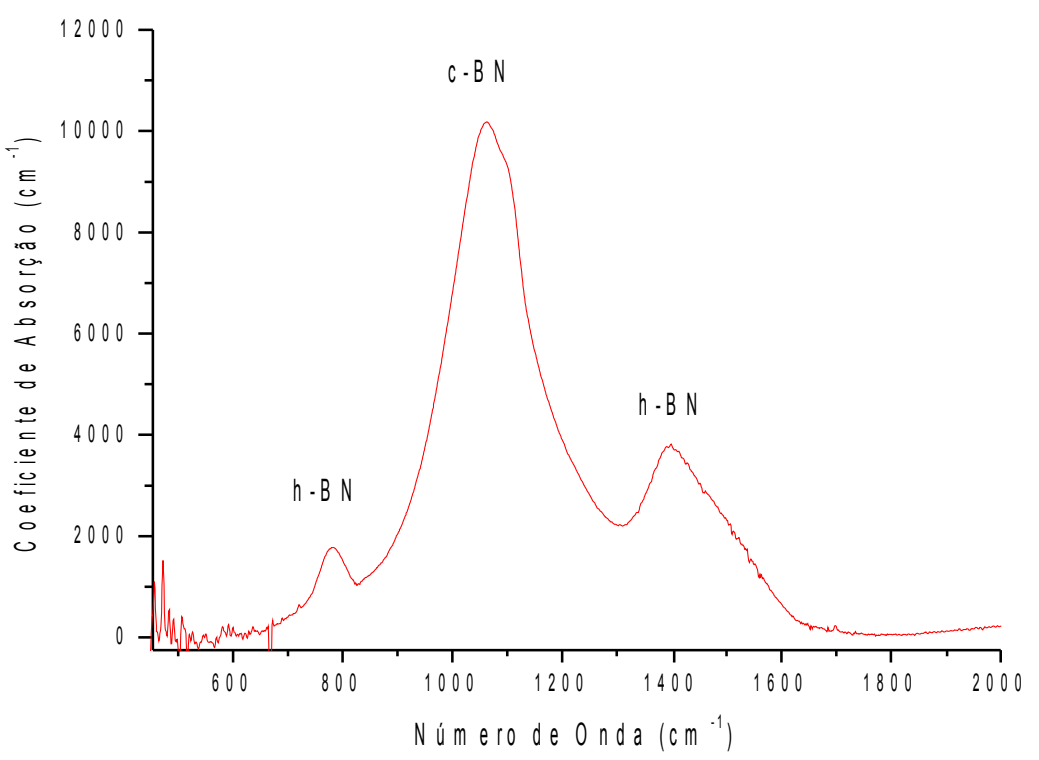

Figura 4.10: Espectro de FTIR da amostra 10 


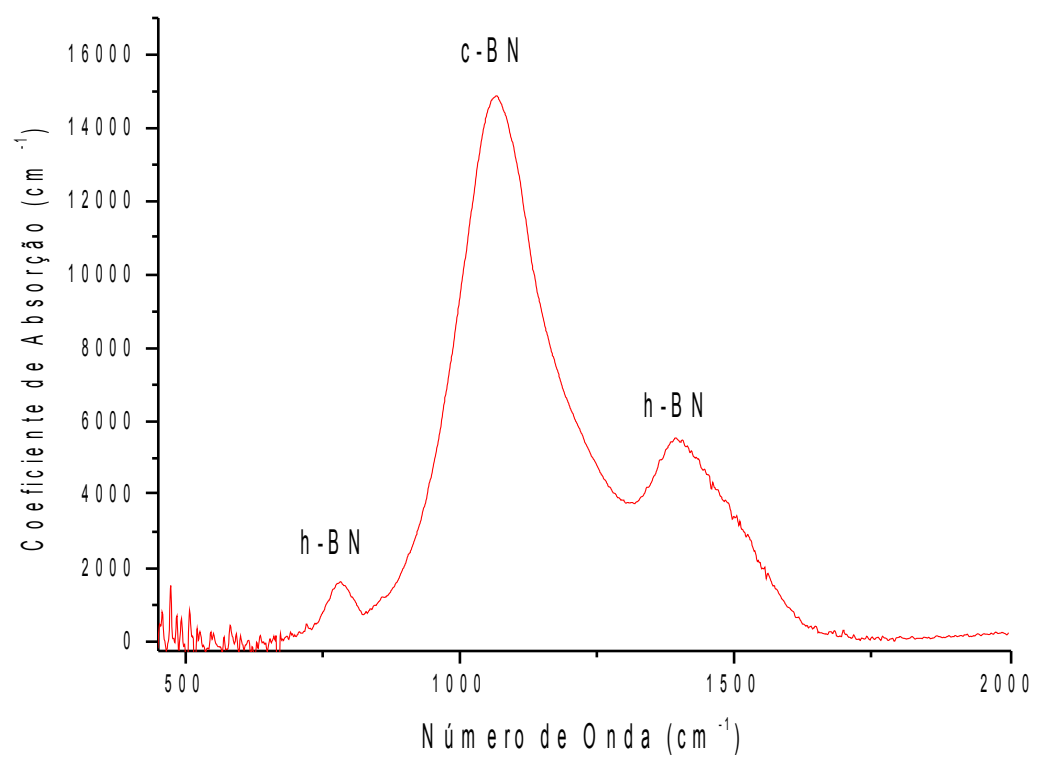

Figura 4.11: Espectro de FTIR da amostra 11

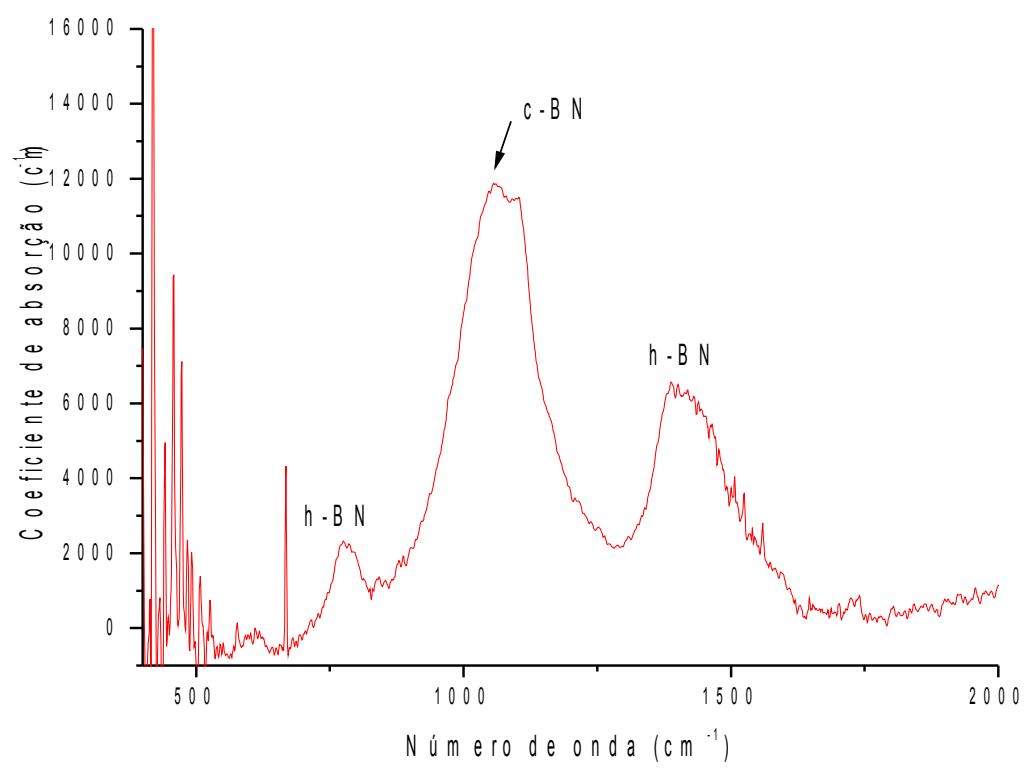

Figura 4.12: Espectro de FTIR da amostra 12 


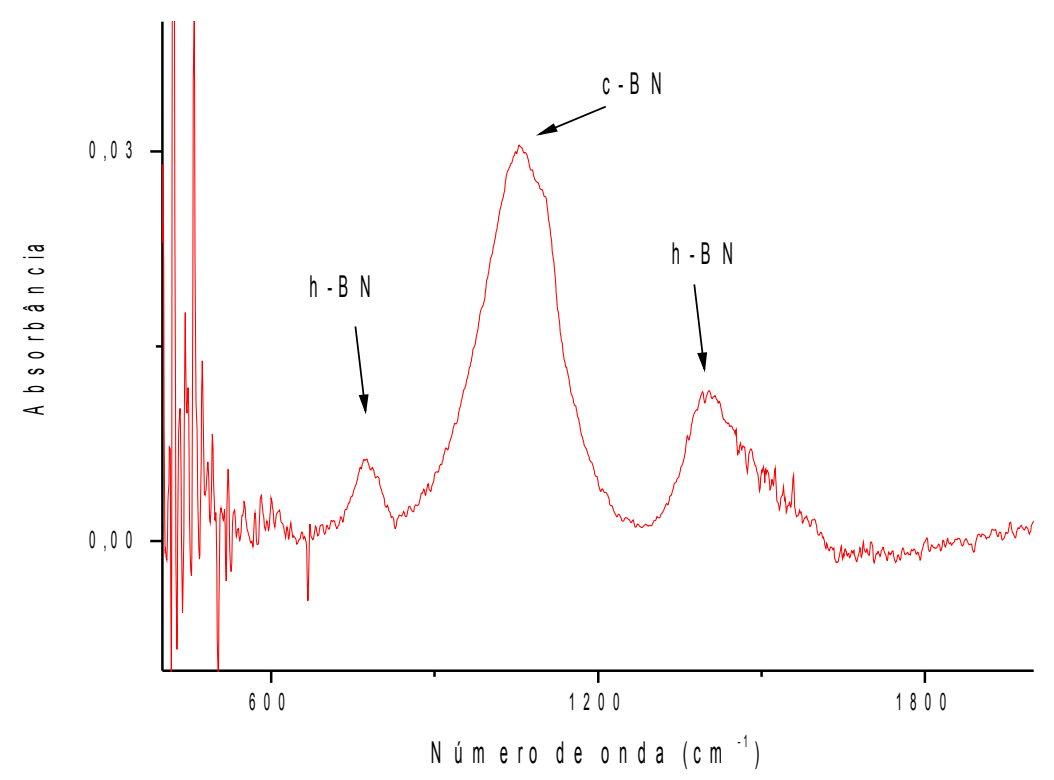

Figura 4.13: Espectro de FTIR da amostra 13

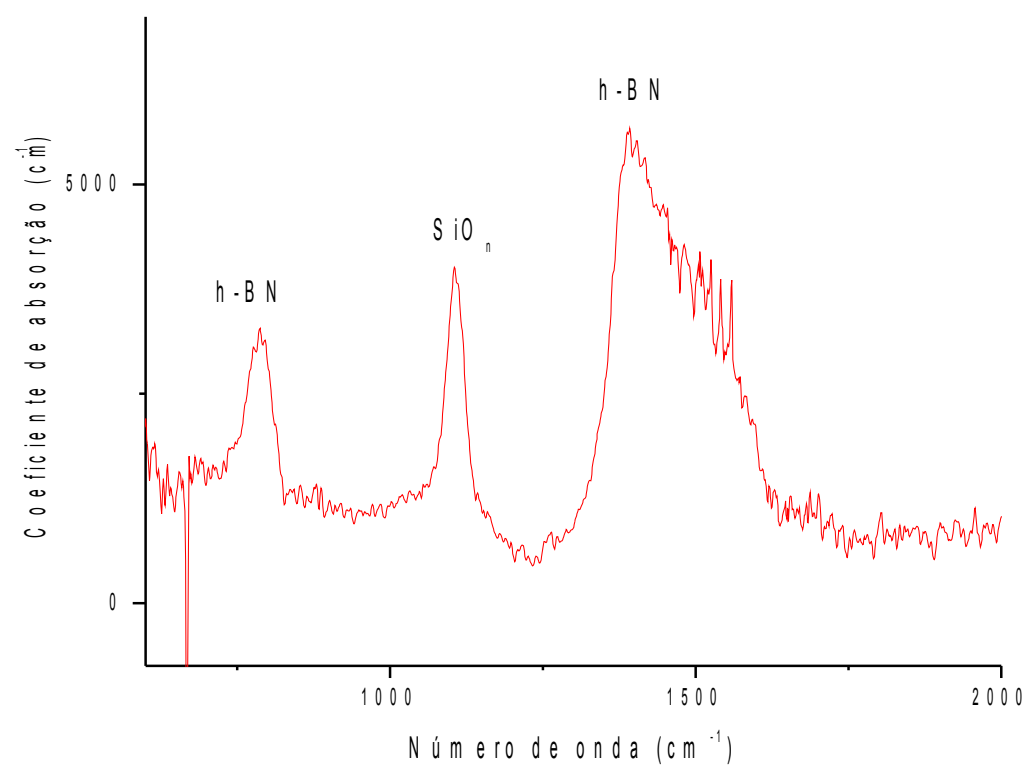

Figura 4.14: Espectro de FTIR da amostra 14 


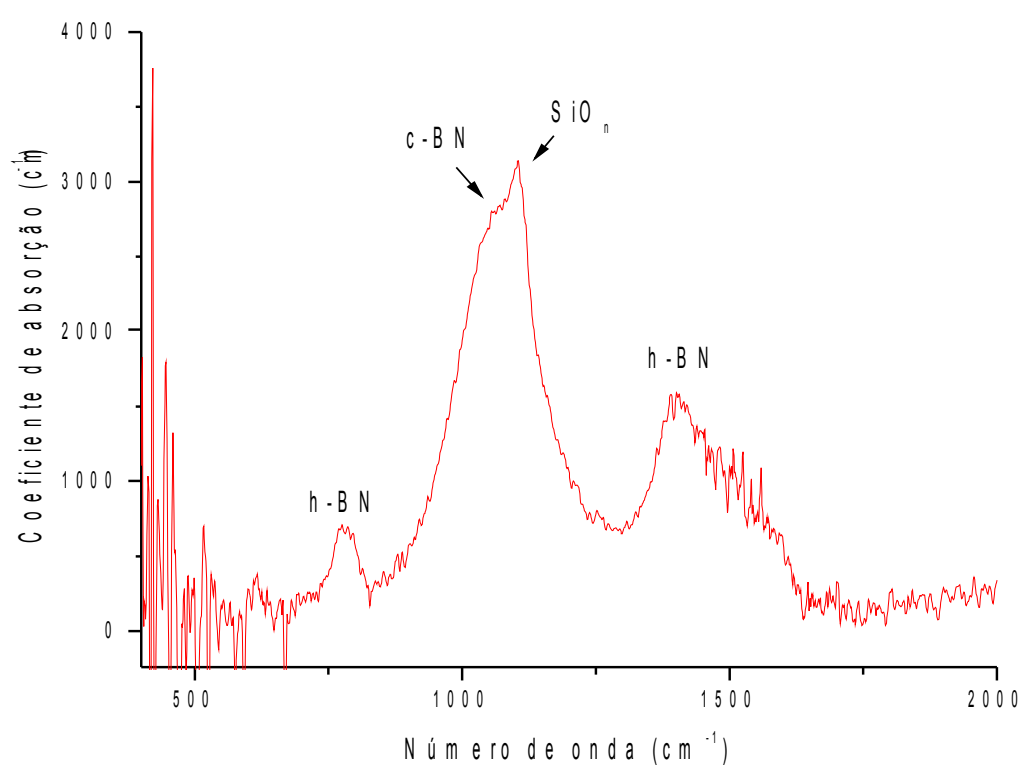

Figura 4.15: Espectro de FTIR da amostra 15

A presença dos dois picos do h-BN é observada em todas as amostras com exceção das amostras 3 e 4 . O fato de as duas amostras não apresentarem nenhum pico é devido ao descascamento acentuado dos filmes nessas amostras [ver as fotografias destas amostras, tiradas pelo microscópio óptico, apresentadas nas figura 4.16(a) e 4.16(b)]. A fotografia na figura 4.16(c) indica a existência do material de filme para a amostra 13 que deu um valor de espessura negativo

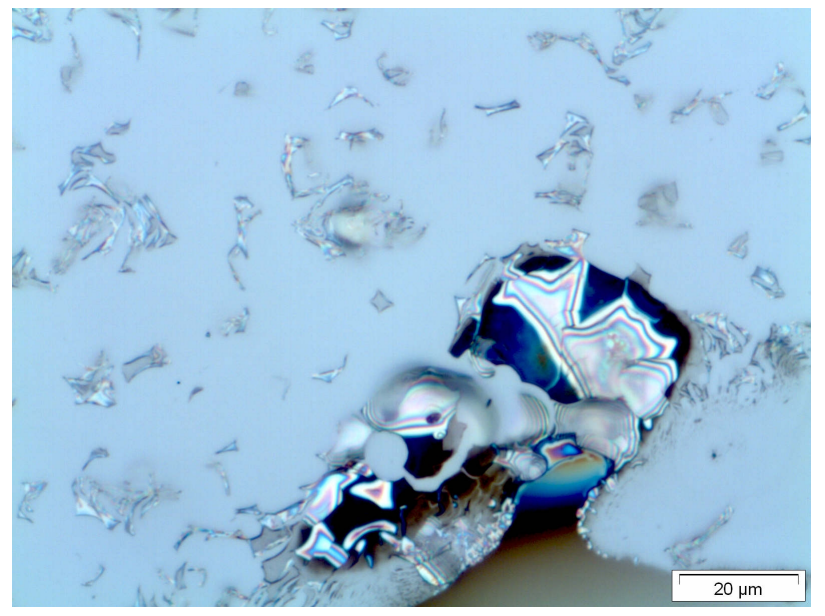

Figura 4.16 (a): Fotografia de MO da amostra 3.

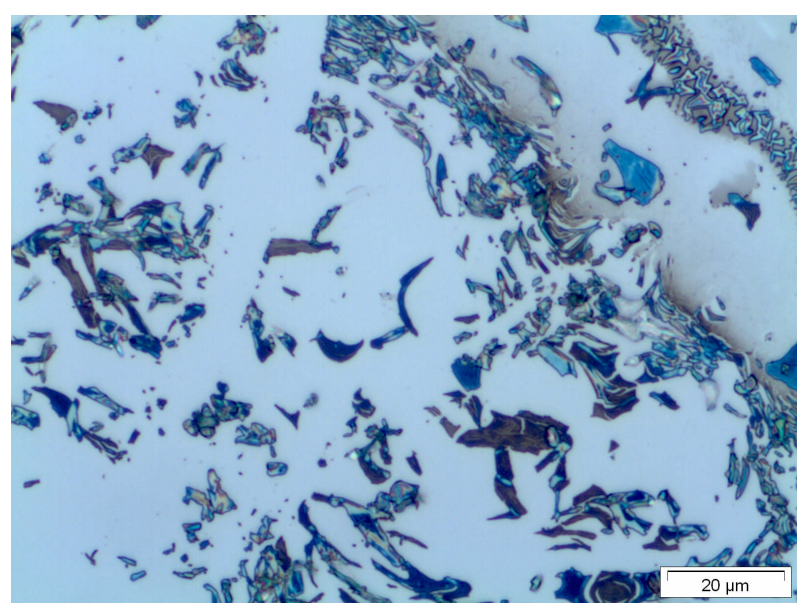

Figura 4.16 (b): Fotografia de MO da amostra 4. 


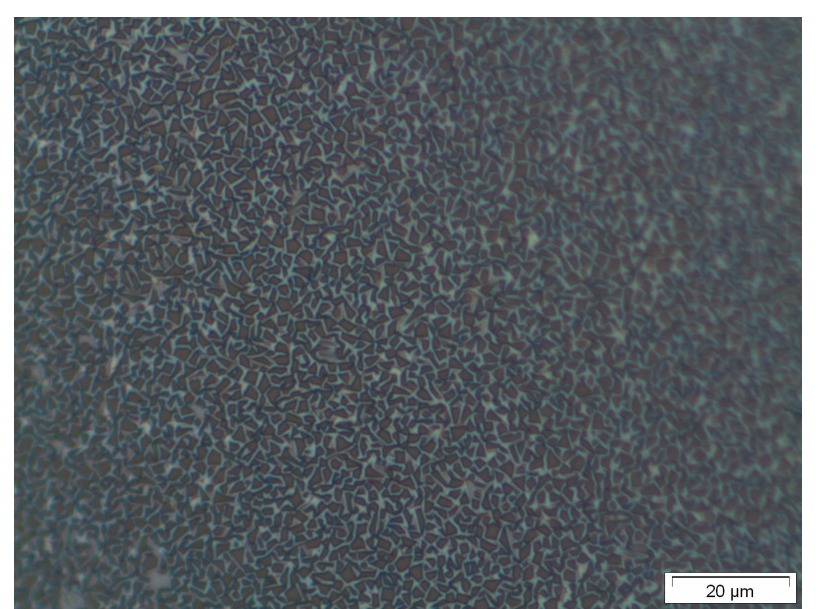

Figura 4.16 (c): Fotografia de MO da amostra 13.

O pico $1070 \mathrm{~cm}^{-1}$ de c-BN é observado nitidamente nas amostras 10-13 e 15 . A tabela 4.1 indica os principais parâmetros de deposição e as quantidades características dos picos de BN anteriormente mencionadas. 
INSERIR tabela 4.1 


\section{(a)Temperatura do substrato, TS}

A fim de estudarmos os efeitos da TS nas características dos filmes de BN, foram escolhidos os seguintes quatro pares de amostras: 1 e $5 ; 2$ e $6 ; 3$ e 7; 9 e 14, em que todas as condições de deposição, exceto a TS, são iguais dentre cada par (ver a tabela 4.1). Todas as amostras apresentam os dois picos de h-BN, com exceção da amostra 3, mas nenhuma amostra apresenta o pico de cBN. Como a amostra 3 não apresentou nenhum pico relacionado ao $\mathrm{BN}$, não é possível fazer análise comparativa para o par das amostras 3 e 7.

\section{- Posições dos picos}

A posição do pico $780 \mathrm{~cm}^{-1}$, P780, e a do pico $1370 \mathrm{~cm}^{-1}$, P1370, são mostradas em função da TS na figura 4.17. A partir da figura pode ser concluído que ambas as posições não dependem da TS em todos os pares das amostras, indicando que a freqüência média de cada modo vibracional permanece igual com a variação da TS.

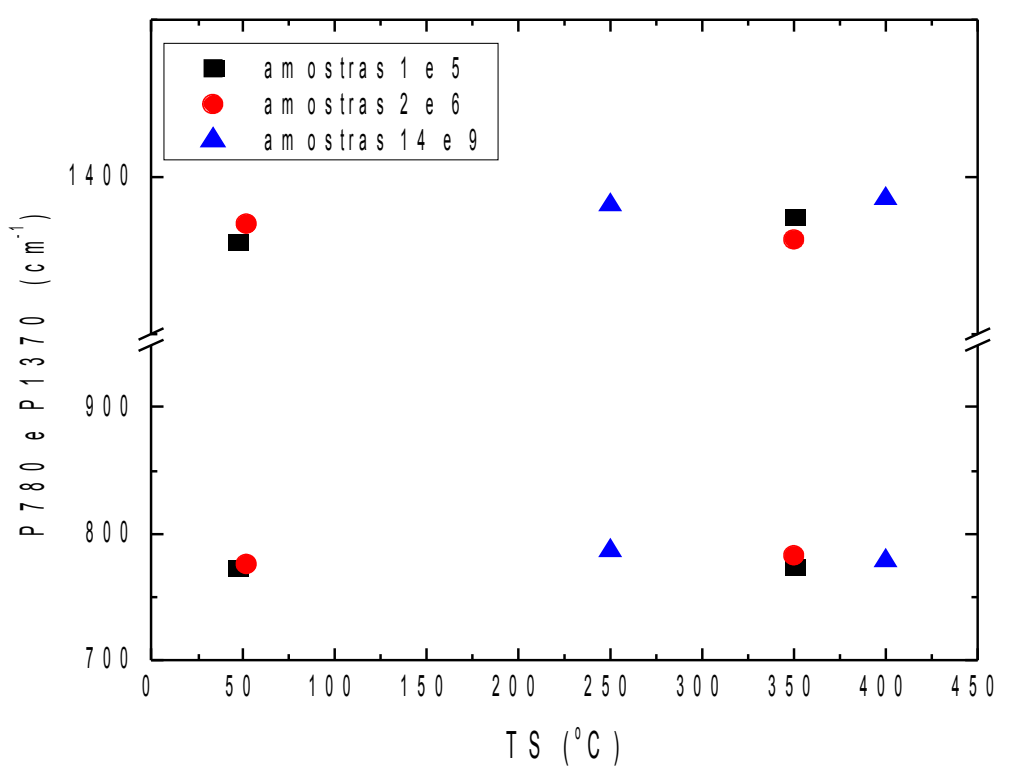

Figura 4.17: Gráfico das posições dos picos em 780 e $1370 \mathrm{~cm}^{-1}$ em função da TS. 


\section{- Largura dos picos}

A figura 4.18 mostra a dependência da TS na largura cheia à meia altura do pico de $780 \mathrm{~cm}^{-1}$, W780. Como pode se notar, é difícil observar o comportamento coerente dessa largura, enquanto que largura cheia à meia altura do pico de $1370 \mathrm{~cm}^{-1}$, W1370, diminui com o aumento da TS (figura 4.19) em todos os pares das amostras. O fato de a W1370 diminuir com o aumento da TS, da temperatura ambiente a $400^{\circ} \mathrm{C}$, significa que os planos basais paralelos ao plano de substrato estão mais ordenados e/ou o tamanho de cristalitos compostos desses planos aumentou [10]. O aumento da TS leva ao aumento da mobilidade de átomos depositados no plano basal paralelo ao plano de substrato, facilitando a formação e/ou ordenação dos planos basais.

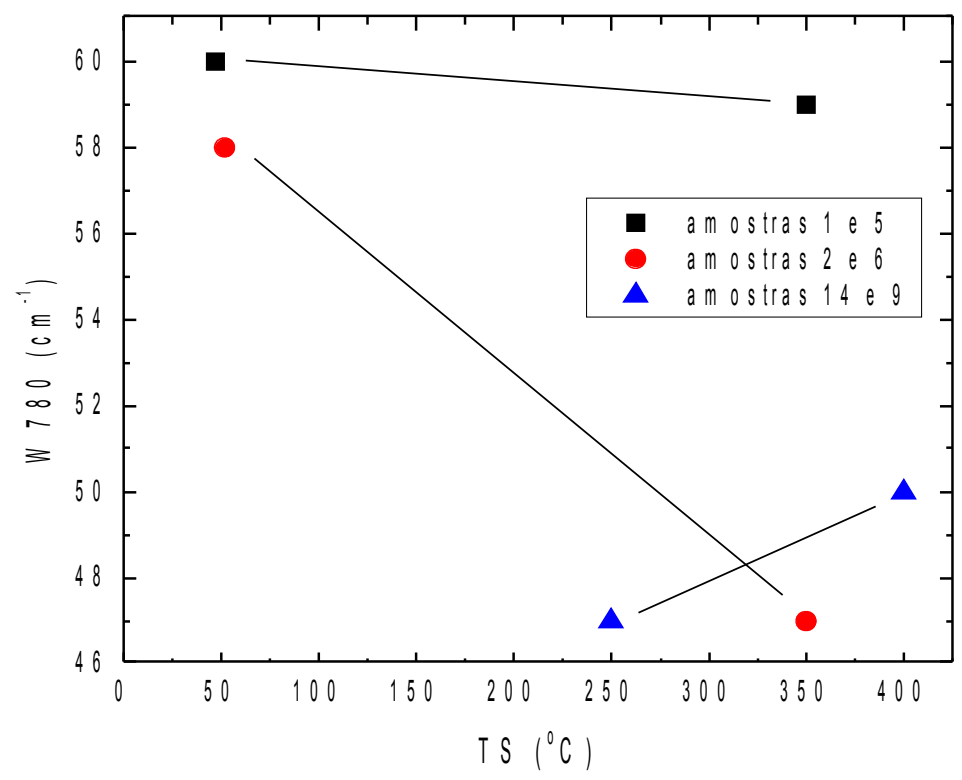

Figura 4.18: Gráfico da largura do pico em $780 \mathrm{~cm}^{-1}$ (W780) em função da TS. As retas são guias para os olhos. 


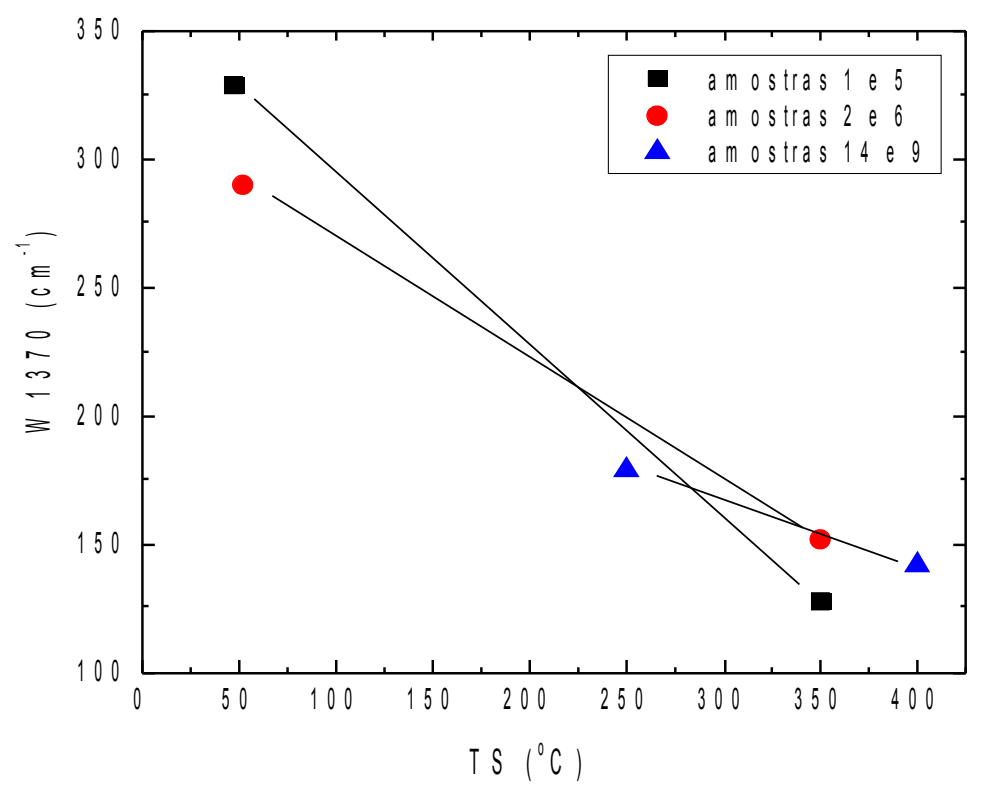

Figura 4.19: Gráfico da largura do pico em $1370 \mathrm{~cm}^{-1}$ (W1370) em função da TS. As retas são guias para os olhos.

\section{- Razão I780/I1370}

A figura 4.20 apresenta a razão I780/I1370 em função da TS. A partir da figura se pode perceber que a I780/I1370 aumenta conforme o aumento da TS em todos os pares das amostras. Este aumento significa que os planos basais estão mais perpendiculares ao plano de substrato com o incremento da TS.

Este resultado pode ser entendido da seguinte maneira: o aumento da TS leva a uma maior mobilidade dos átomos no filme, permitindo que os mesmos se arranjem de forma a minimizar a energia livre de Gibs [31]. Devido à tensão compressiva paralela ao plano de substrato, a minimização desta energia se dá quando os planos basais se tornam perpendiculares ao plano de substrato. 


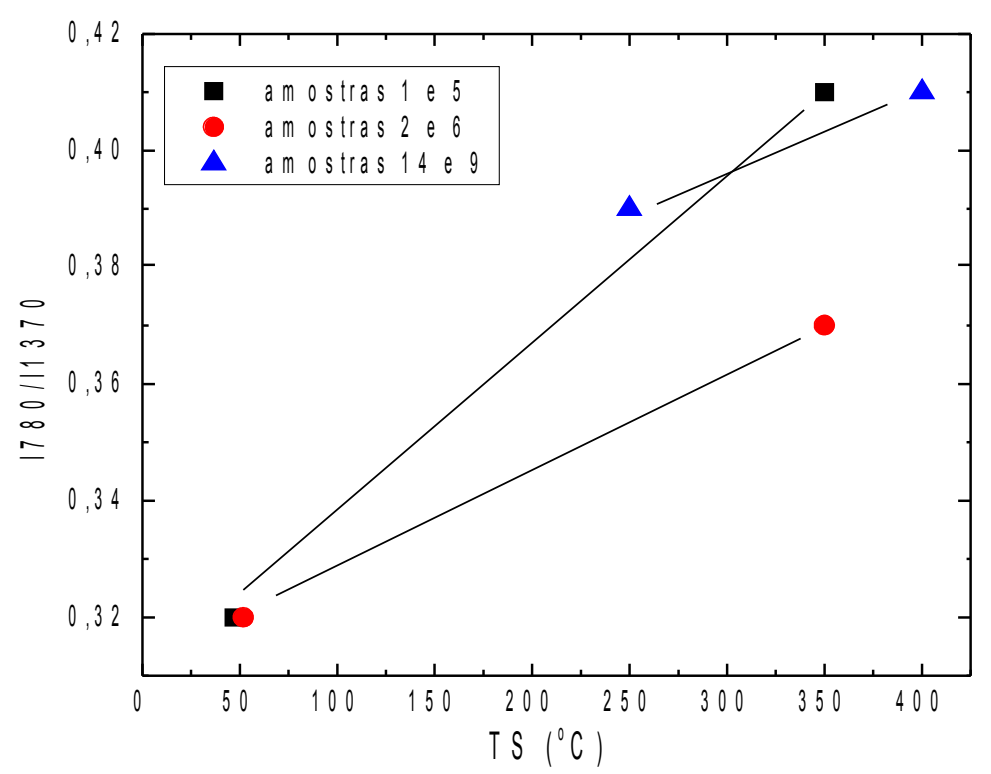

Figura 4.20: Gráfico da razão I780/I1470 em função da TS. As retas são guias para os olhos.

\section{(b) Espessura nominal En}

Nesta seção foram escolhidas quatro amostras (9-12) em que o único parâmetro de deposição distinto foi a En (ver a tabela 4.1). Todas as amostras apresentam os picos de h-BN e apenas a amostra 9 não mostra o pico de c-BN.

\section{- Posições dos picos}

As posições dos picos, P780, P1070 (posição do pico de c-BN) e P1370, são indicadas na figura 4.21 em função da En. Nesta as três posições não variam com En significando a constância da freqüência média de cada modo vibracional com a variação da En. 


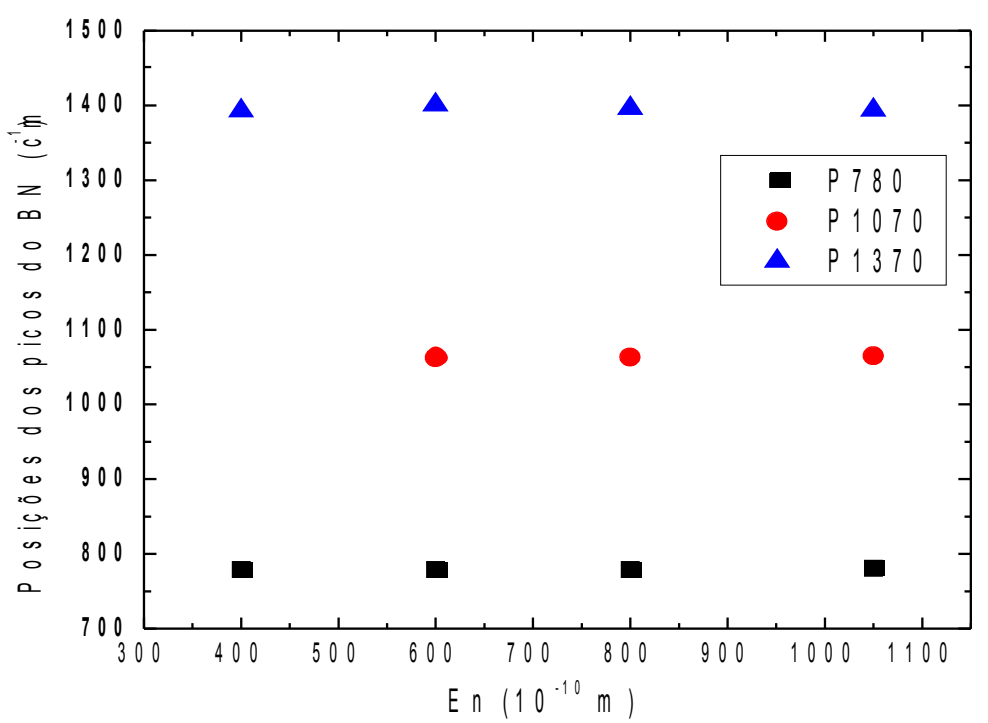

Figura 4.21: Gráfico das posições dos picos em 780, 1070 e $1370 \mathrm{~cm}^{-1}$ em função da En.

\section{- Larguras dos picos}

A figura 4.22 exibe a dependência da En nas larguras W780, W1070 (largura cheia à meia altura do pico de c-BN) e W1370. É fácil comprovar comportamentos dispersos nas W780 e W1070 com a variação da En; porém, a W1370 decresce com o aumento da En, indicando que, quanto maior a En, maior a ordenação dos planos basais paralelos ao plano de substrato e/ou o tamanho de cristalitos com esses planos [10]. 


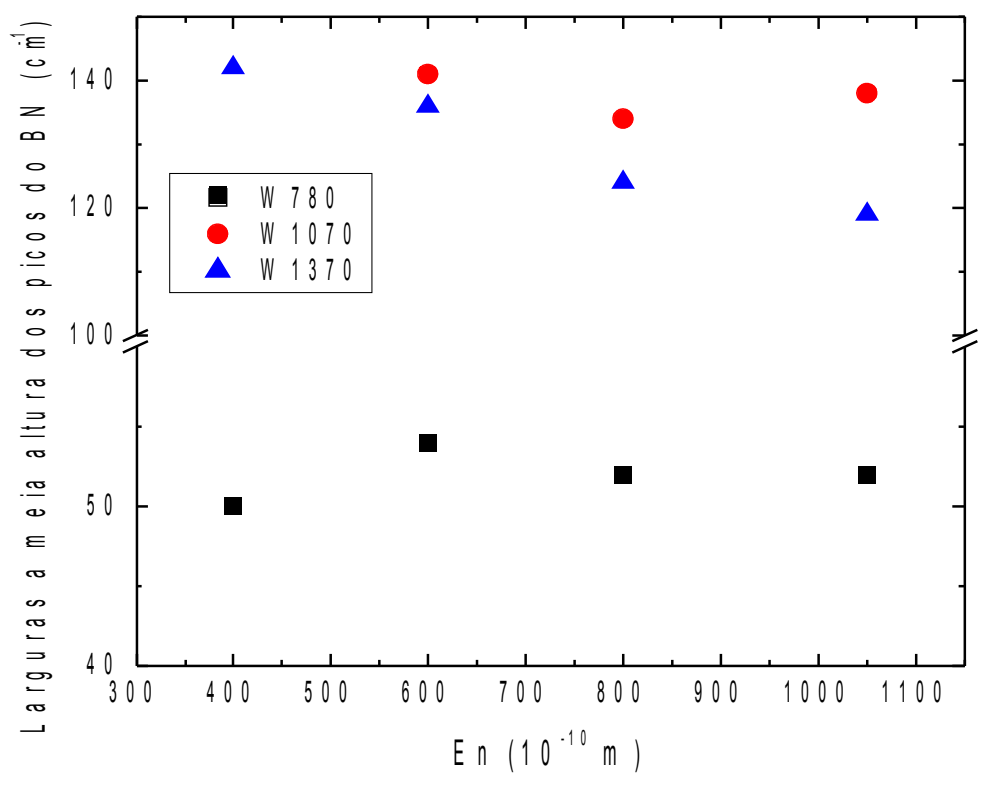

Figura 4.22: Gráfico das larguras dos picos em 780, 1070 e $1370 \mathrm{~cm}^{-1}$ em função da En.

\section{- Razões I780/I1370 e I1070/(I1070 + I1370)}

A figura 4.23 mostra a dependência da En na razão I780/I1370 e na razão I1070/(I1070 + I1370). Observa-se que a I780/I1370 praticamente não varia com a variação da En de 400 a 1050 Å. Este fato indica que a fração volumétrica dos planos basais paralelos ao plano de substrato em relação aos planos basais perpendiculares permanece constante.

Por outro lado, a I1070/(I1070 + I1370) cresce de zero até 0,8 quando a En aumenta de 400 a $800 \AA$ e, além disso, atinge um valor constante em $1050 \AA$. Este resultado concorda com a evidência experimental, obtida através da observação por microscopia eletrônica de transmissão [10], de que: na deposição inicial é formada, diretamente sobre o substrato, uma camada de BN amorfo ( $\sim 30 \AA$ de espessura) seguida por uma camada de t-BN altamente orientada e finalmente uma camada de c-BN.

Considerando que o aumento da espessura do filme é acompanhado pelo aumento da tensão 
compressiva paralela ao plano de substrato, a tensão necessária para a formação de c-BN só será atingida quando a espessura do filme superar um limiar mínimo [10, 31, 32]. A constância da razão I780/I1370 pode ser devida ao fato de todas as amostras deste conjunto terem atingido ao grau máximo de orientação dos planos basais.

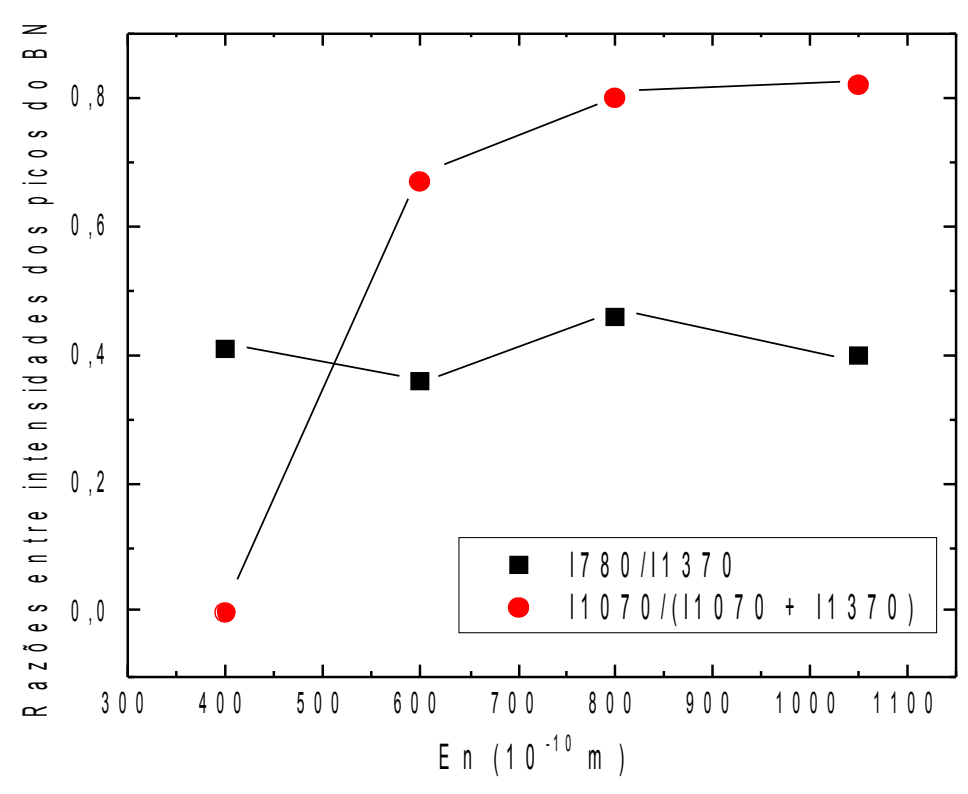

Figura 4.23: Gráfico das razões I780/I1370 e I1070/(I1070 +I1370) em função da En. As retas são guias para os olhos.

\section{(c) MTA}

Para estudar os efeitos do MTA nas características dos filmes, foram selecionados dois conjuntos de amostras: as amostras 5-7 e, amostras 12 e 15 . No primeiro conjunto são observados somente os dois picos do h-BN e o único parâmetro distinto foi a energia de íons $(600,800$ e 1000 eV). No segundo conjunto, são observados não só os dois picos de h-BN, mas também o pico de cBN, e o único parâmetro distinto foi a razão de chegada ARR(N/B) $(1,7$ e 2,2). 


\section{- Posições dos picos}

A figura 4.24 mostra as P780, P1070 e P1370 em função do MTA, indicando a constância das posições dos picos. A freqüência média de cada modo vibracional não se altera com a variação no MTA.

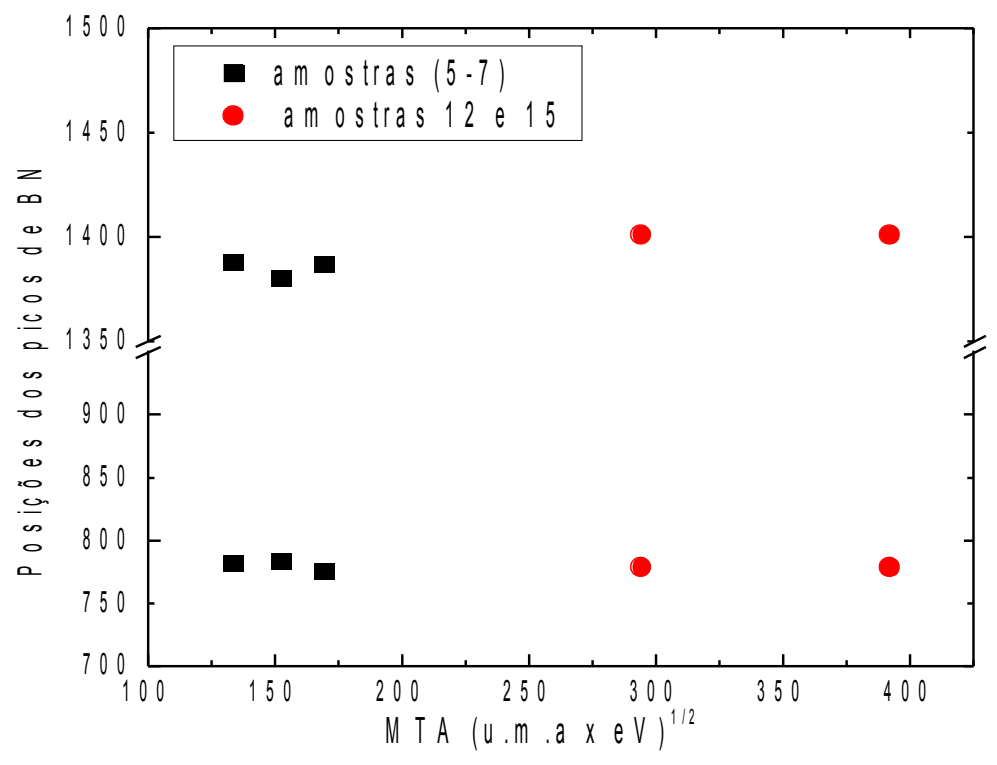

figura 4.24: Gráfico das posições doa pico BN em função do MTA.

\section{- Larguras dos picos}

As figuras 4.25 e 4.26 indicam as W780, W1070 e W1370 em função do MTA. É difícil observar comportamentos coerentes das W780 e W1370 para as amostras do primeiro conjunto, mas as W780 e W1370 para as amostras do segundo conjunto aumentam com o aumento do MTA. $\mathrm{O}$ aumento das larguras para as amostras do segundo conjunto indica que o aumento do MTA induz maior deslocamentos de átomos sob a superfície do filme, levando à formação de defeitos e resultando na diminuição da cristalinidade de h-BN. 


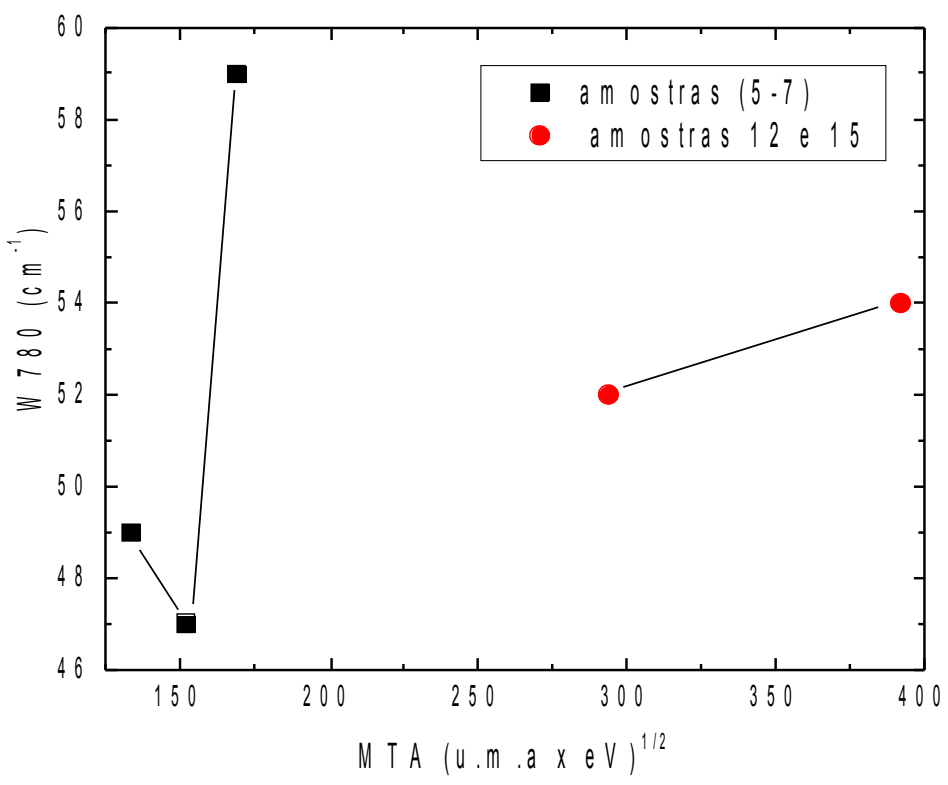

4.25: Gráfico da largura W780 em função do MTA. As retas são guias para os olhos.

Figura

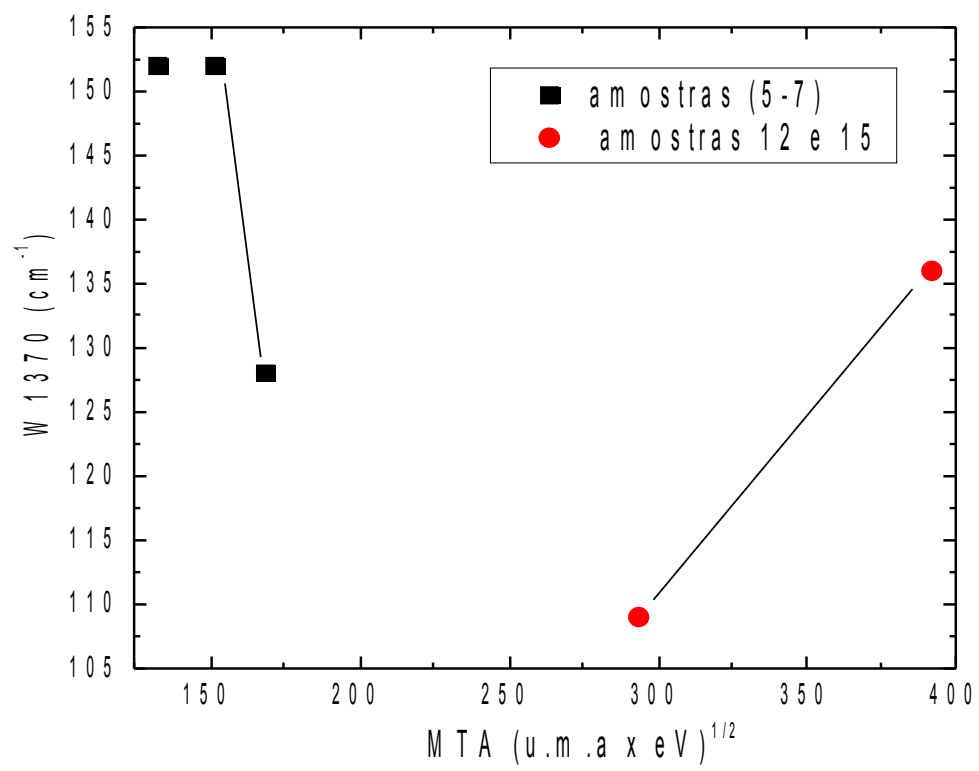

Figura 4.26: Gráfico da largura W780 em função do MTA. As retas são guias para os olhos. 


\section{- Razão I780/I1370}

A razão I780/I1370 é mostrada na figura 4.27 em função do MTA. Esta razão aumenta para as amostras do primeiro conjunto com o aumento do MTA, mas esta diminui para as amostras do segundo conjunto.

O aumento da razão para as amostras do primeiro grupo pode ser entendido como resultado de um aumento da tensão compressiva, paralela ao plano do substrato, e do deslocamento de átomos sob a superfície do filme com o aumento do MTA de 133 para 169 (eV x u.m.a. $)^{1 / 2}$,. levando às condições adequadas para a formação de h-BN com planos basais perpendiculares à superfície do substrato $[10,31,32]$.

A diminuição da razão para as amostras do segundo conjunto pode ser entendida como sendo resultado de uma diminuição da orientação dos planos basais do h-BN na direção normal ao plano do substrato, causada por incremento do sputtering do material depositado quando o MTA aumenta de 294 para 392 (eV x u.m.a.) ${ }^{1 / 2}$. A diminuição da Em de 1460 para $668 \AA$, quando o MTA sobe de 294 para 392 (eV x u.m.a. $)^{1 / 2}$, confirma esta hipótese.

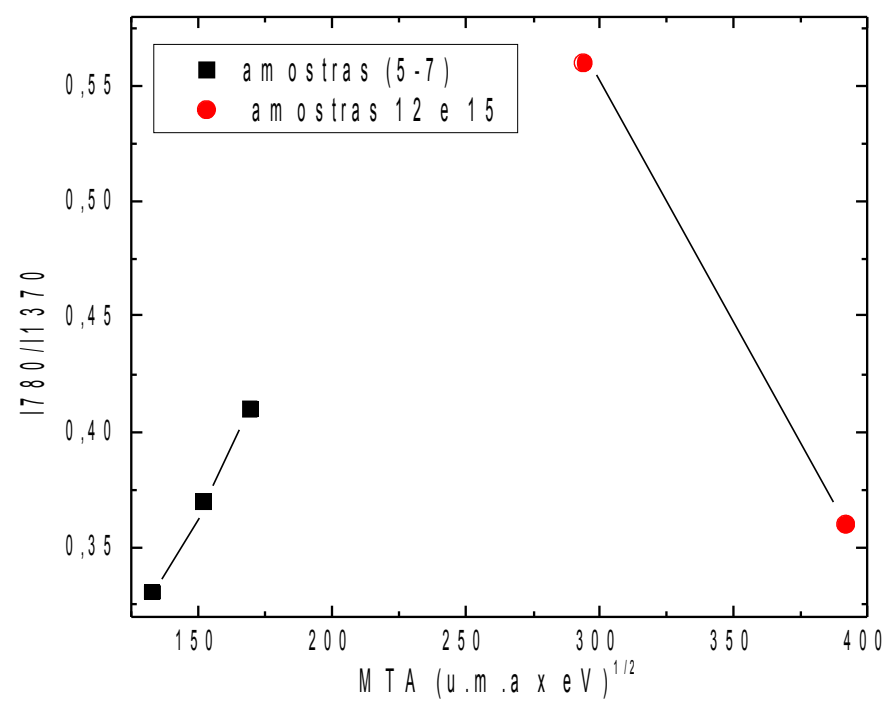

Figura 4.27: Gráfico da razão I780/I1370 em função do MTA. As retas são guias para os olhos. 
A figura 4.28 mostra a razão I1070/(I1070 + I1370) em função do MTA. Nota-se que apenas as amostras depositadas com o MTA superior a $294(\mathrm{eV} \times \text { u.m.a })^{1 / 2}$ apresentam a formação de cBN. Kester relatou um limiar máximo para a formação de c-BN igual a $\sim 250(e V \times \text { u.m.a })^{1 / 2}[29$, 30].Nosso resultado é coerente com o relatado por Kester. A diminuição da razão I1070/(I1070 + I1370) para as amostras do segundo conjunto com o aumento do MTA significa uma diminuição da fração de c-BN que pode ser causada pelo incremento do rendimento de sputtering.

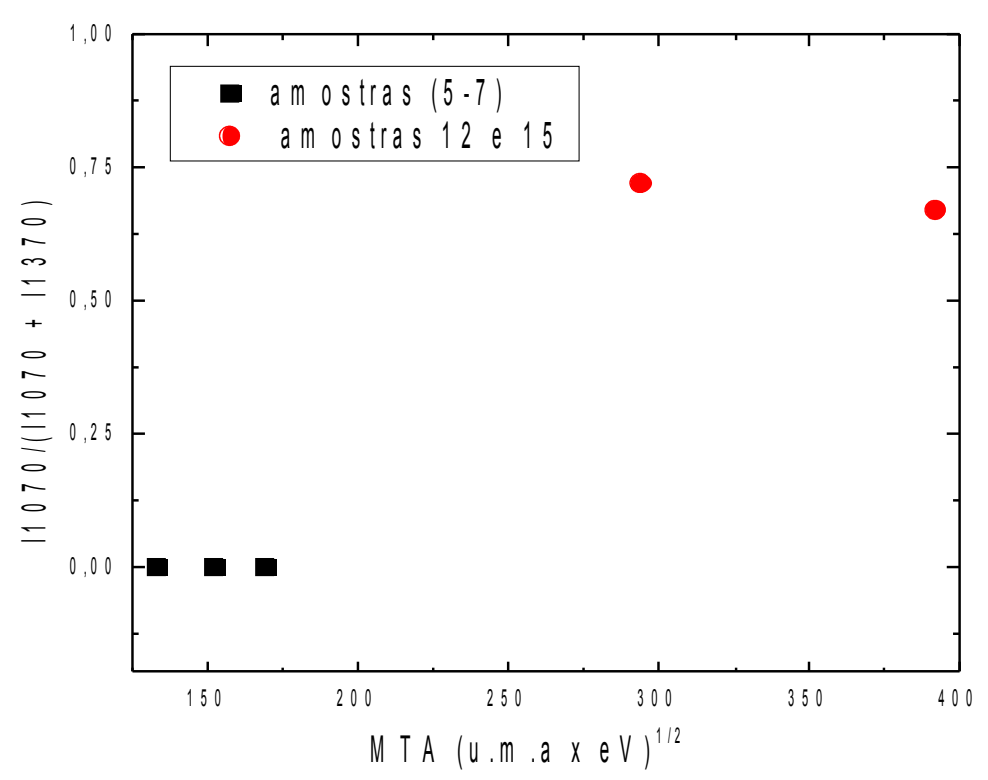

Figura 4.28: Gráfico da razão I1070/(I1070 + I1370) em função do MTA. As retas são guias para os olhos.

\section{(d) Bombardeamento prévio do substrato com íons de argônio}

Para observar o efeito do bombardeamento prévio do substrato com íons de argônio, foram comparadas duas amostras, as amostras 9 e 13. A única diferença nas condições de deposição, entre as duas amostras, é de que, precedendo à preparação do filme nesse substrato, uma irradiação 
por íons de argônio $\left(\mathrm{E}=1000 \mathrm{eV}\right.$, densidade de corrente de íons igual a $\left.0,02 \mathrm{~mA} / \mathrm{cm}^{2}\right)$ foi feita durante 20 mim no substrato da amostra 13 .

A amostra 13 apresenta o pico de c-BN além dos picos de h-BN, enquanto que a amostra 9 não apresenta o pico de c-BN. O surgimento do pico de c-BN na amostra 13 depende claramente de algumas condições da superfície do substrato.

O bombardeamento prévio do substrato provoca maior rugosidade da superfície deste, possibilitando maior aderência devida a um ancoramento do filme ao substrato. Este ancoramento permite que: o filme sofra menos fluxo plástico, suportando maior tensão que conduz a formação de c-BN.

\subsubsection{Amostras preparadas em duas camadas}

No intuito de obter um filme mais aderente ao substrato, sete amostras (amostras 16 a 22) foram preparadas em duas camadas; a primeira camada junta ao substrato é rica em h-BN e a segunda camada sobre a primeira, rica em c-BN [18].

As figuras 4.29-4.35 apresentam os espectros de FTIR para as amostras 16-22; o espectro para a amostra 22 é indicado em termos da absorbância por cauda do valor negativo da espessura medida e os outros são mostrados como o coeficiente de absorção em função do número de onda para comparação entre eles. 


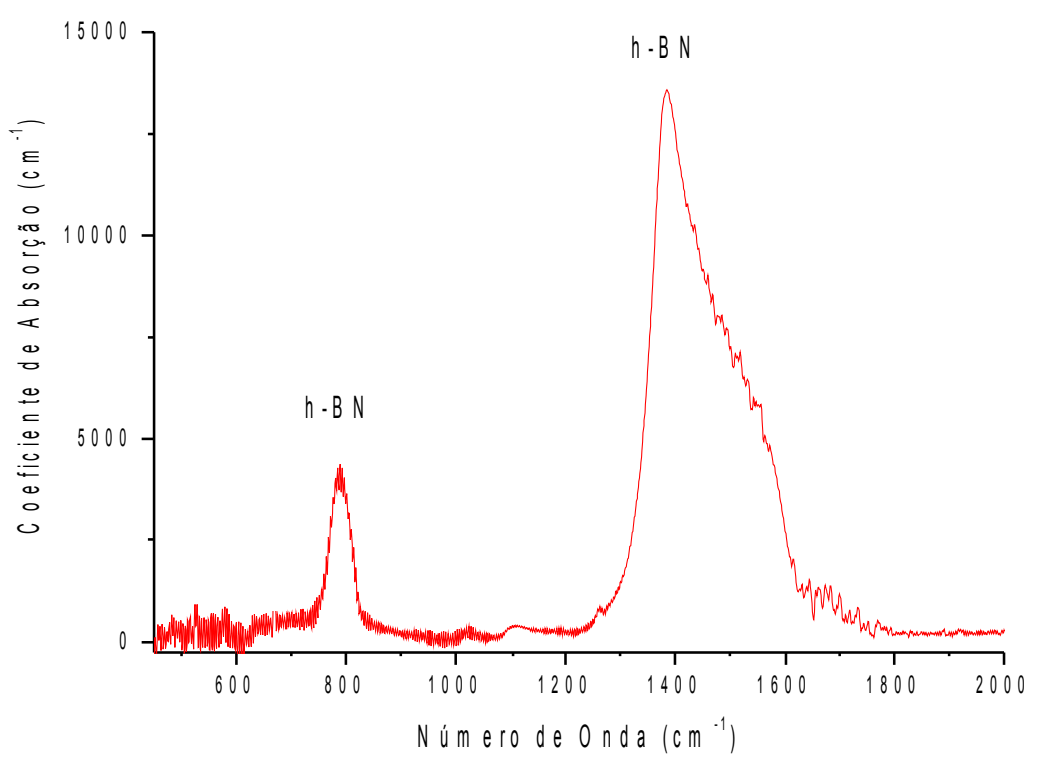

Figura 4.29: Espectro de FTIR da amostra 16

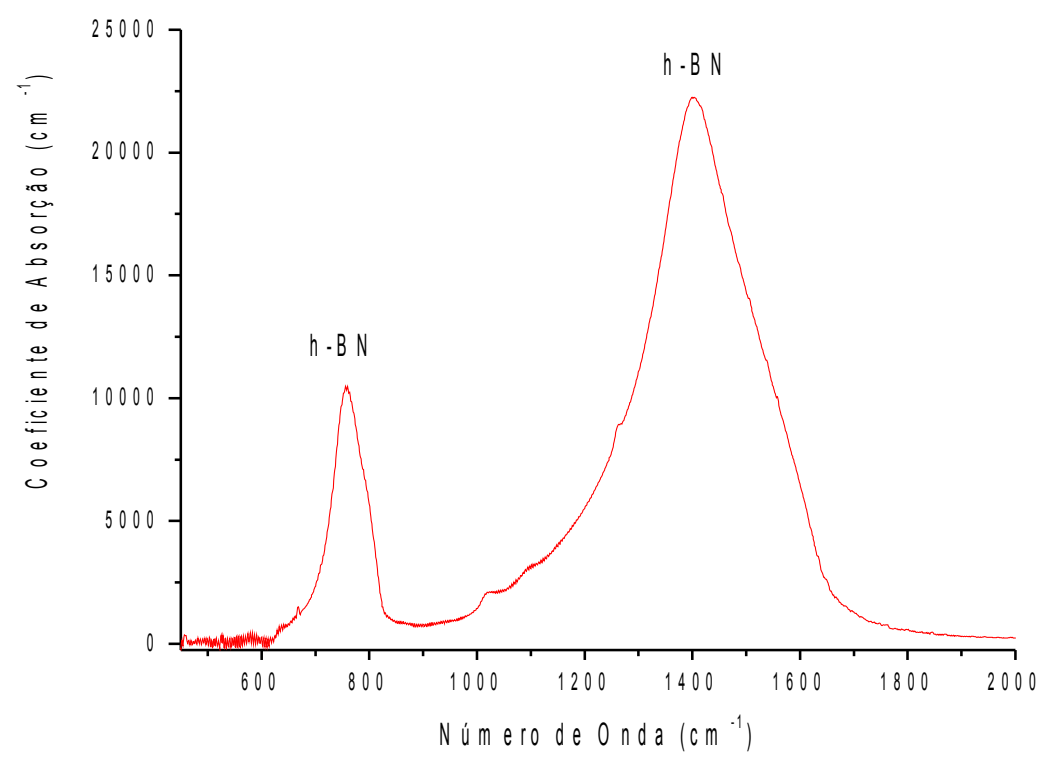

figura 4.30: Espectro de FTIR da amostra 17 


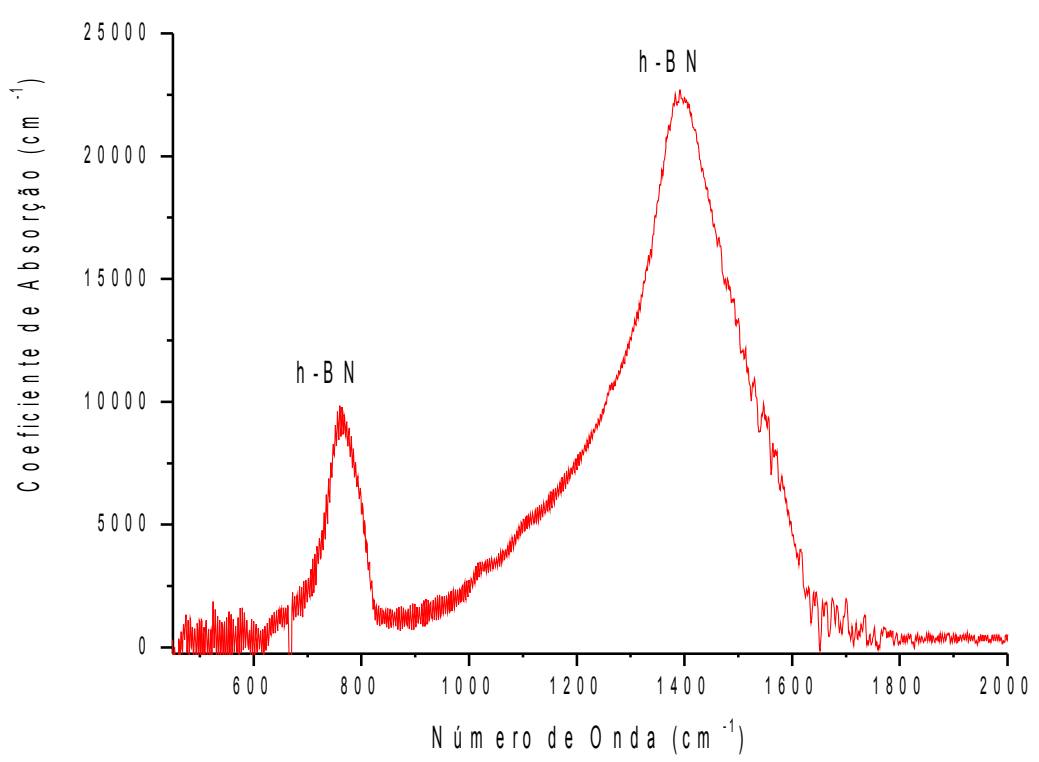

Figura 4.31: Espectro de FTIR da amostra 18

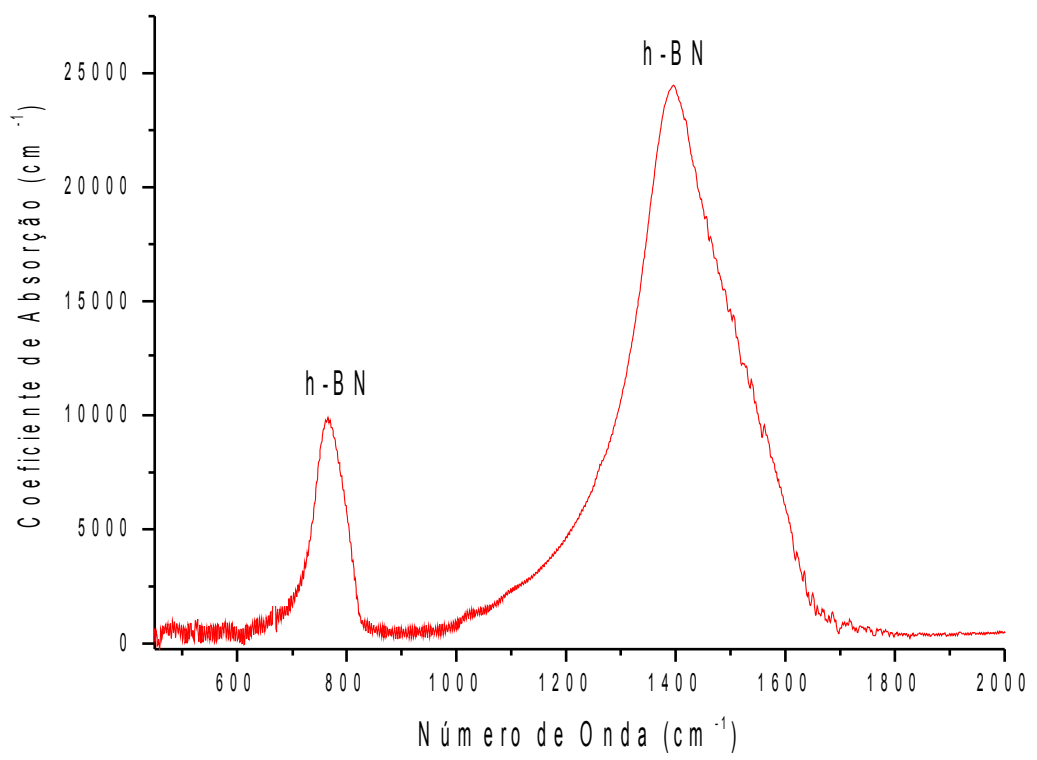

Figura 4.32: Espectro de FTIR da amostra 19 


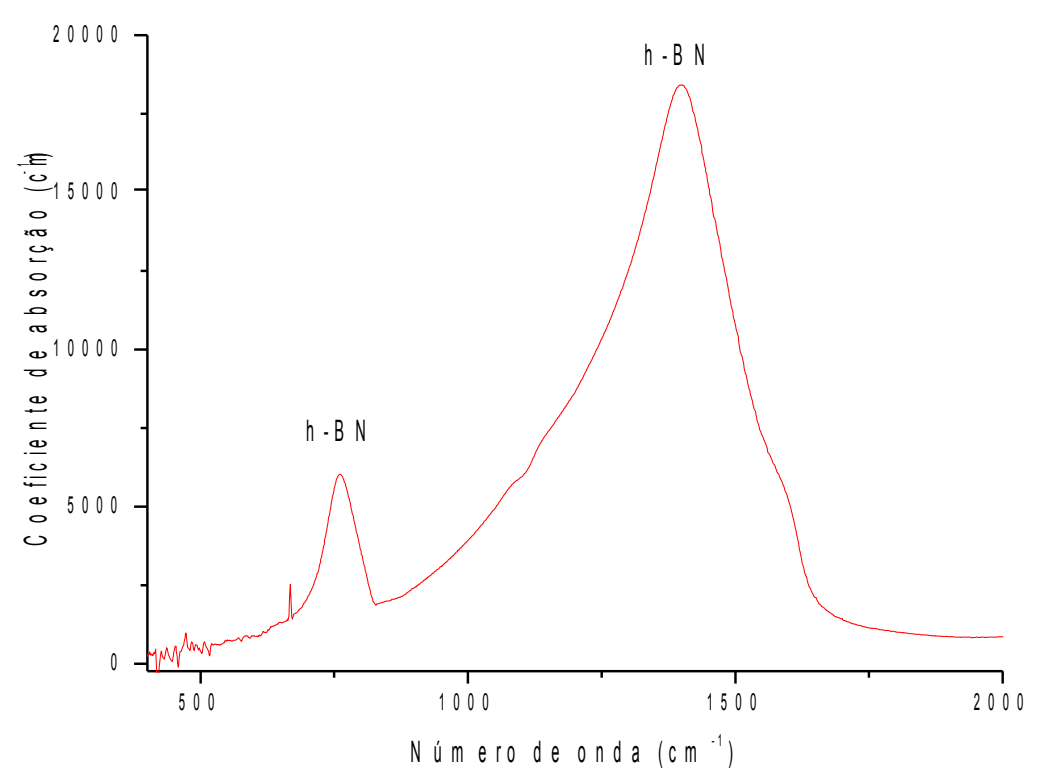

Figura 4.33: Espectro de FTIR da amostra 20

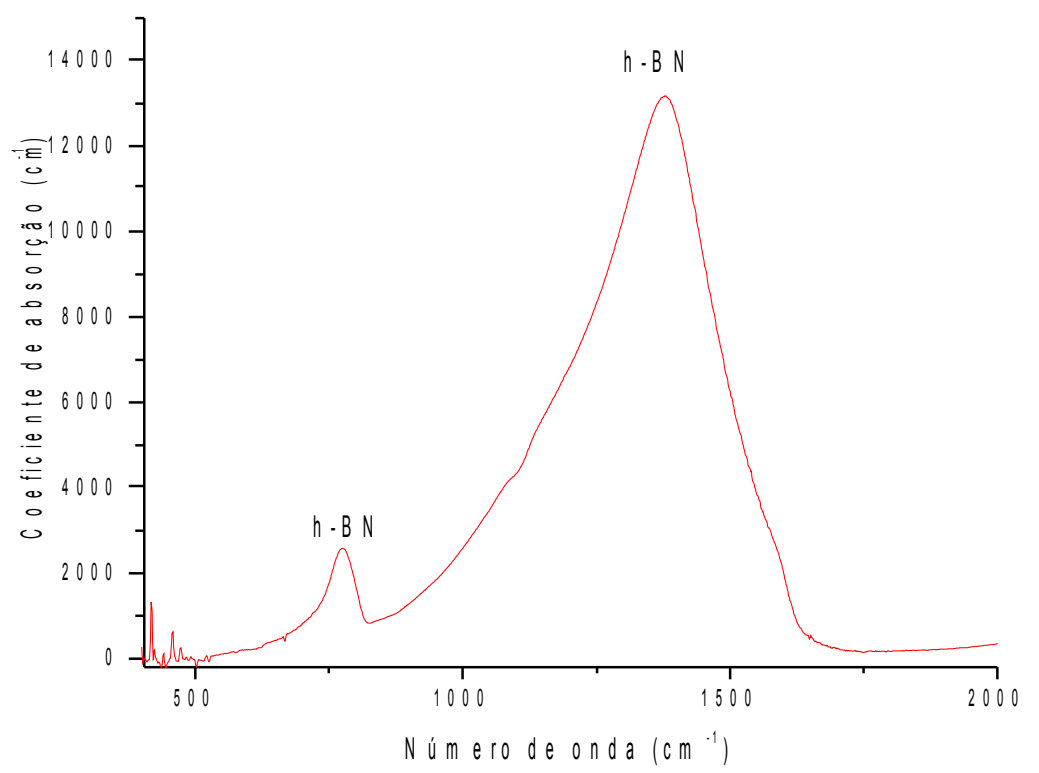

Figura 4.34: Espectro de FTIR da amostra 21 


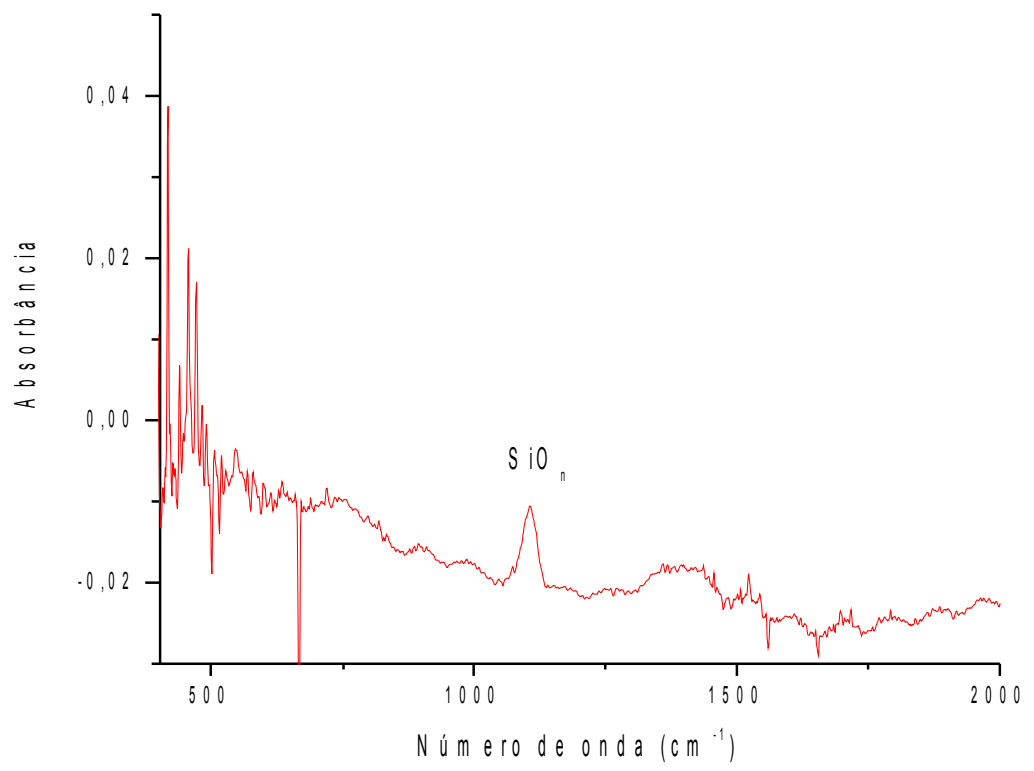

Figura 4.35: Espectro de FTIR da amostra 22

A presença dos dois picos de h-BN é observada em todas as mostras exceto a amostra 22, mas o pico de c-BN não está observado em nenhuma amostra. A tabela 4.2 indica os principais parâmetros de deposição e as quantidades características dos dois picos de h-BN. Na tabela $\mathrm{C} 1$ e C2 referem-se, respectivamente, às primeira e segunda camadas. 
INSERIR tabela 4.2 
A seguir, serão apresentados os resultados de análise para as amostras 16-21 em função de:

(a) Espessura nominal En;

(b) MTA.

\section{(a) Espessura nominal En}

A fim de estudar os efeitos das espessura nominais sobre as características dos filmes de BN, foram selecionadas as amostras $18-20$ (ver tabela 4.2).

Podemos observar somente os picos característicos do h-BN.

\section{- Posições dos picos}

As posições dos picos, P780 e P1370, são indicadas na figura 4.36 em função da En total (C1 + C2). Nesta, as duas posições não variam com em, significando que a freqüência média de cada modo vibracional naõ varia com a En.

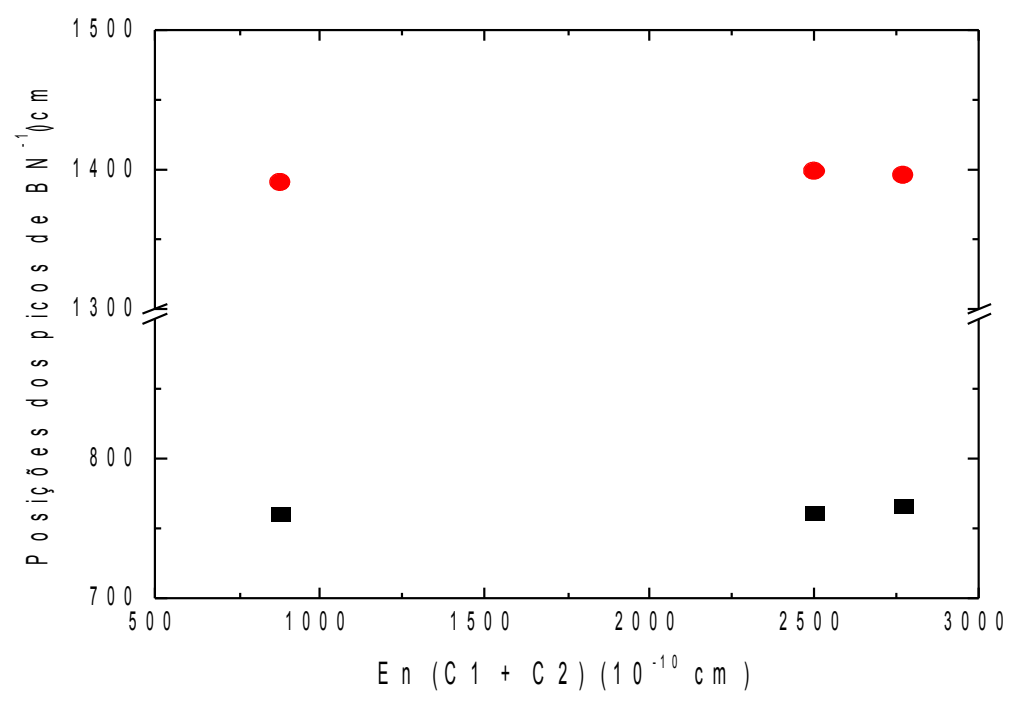

Figura 4.36: Gráfico das posições dos picos P780 e P1370 em função da En total. 


\section{- Larguras dos picos}

A figura 4.37 exibe a dependência da En nas larguras W780 e W1370. É difícil observar no gráfico comportamentos coerentes das W780 e W1370.

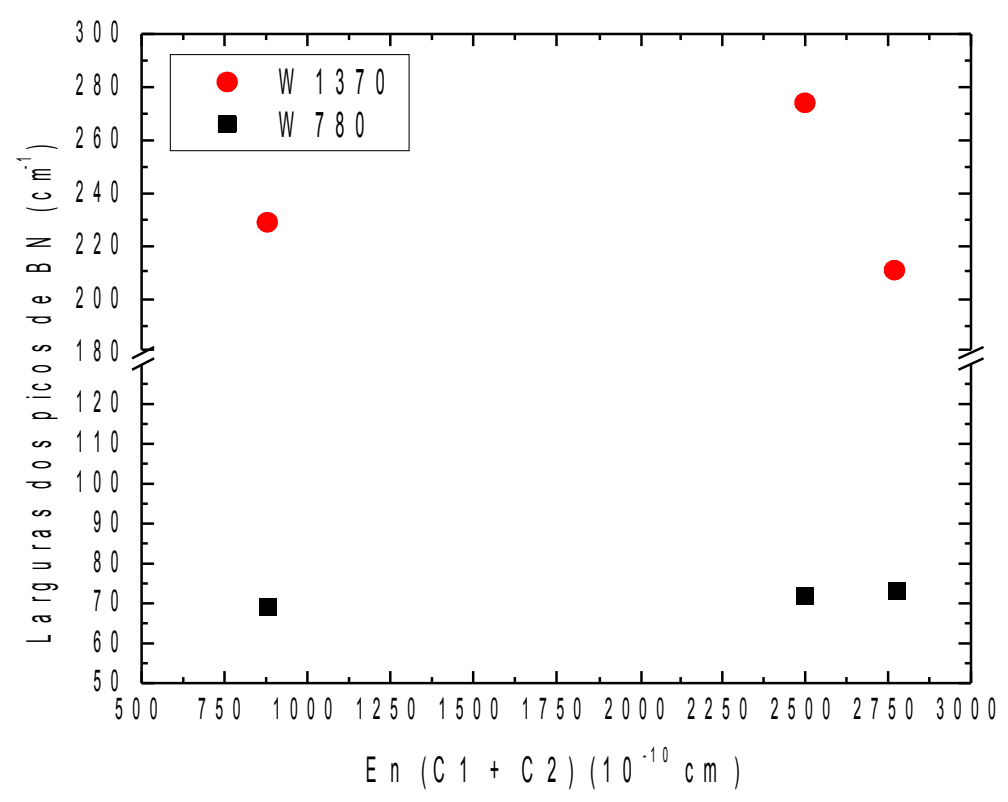

Figura 4.37: Gráfico das larguras W780 e W1370 em função da En total.

\section{- Razão I780/I1370}

A figura 4.38 mostra a dependência da En na razão I780/I1370. É difícil observar comportamentos coerentes da razão em função da En. O valor mais baixo da razão $(0,26)$ pode ser devido a um aumento do rendimento de sputtering, gerado pelo aumento da razão k entre os fluxos de gás argônio e gás nitrogênio, isto é, a amostra com I780/I1370 = 0,26 tem $\mathrm{k}=0,5$ e as outras, $\mathrm{k}=0,2$. 


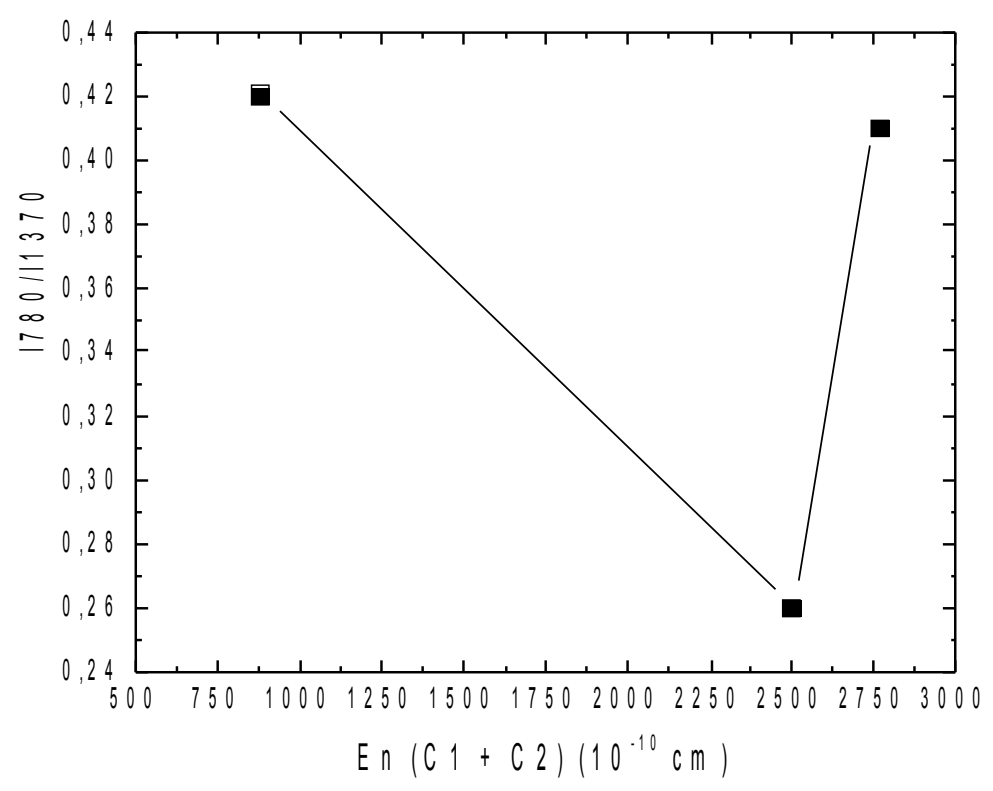

4.38: Gráfico da razão I780/I1370 em função da En total. As linhas são guias para os olhos.

Figura

\section{(c) MTA}

Para estudar os efeitos do MTA nas características dos filmes, foram selecionadas as amostras 20 e 21, que apresentam somente os dois picos do h-BN.

\section{- Posições dos picos}

A figura 4.39 mostra as P780 e P1370 em função do MTA, indicando a constância das posições dos picos. 


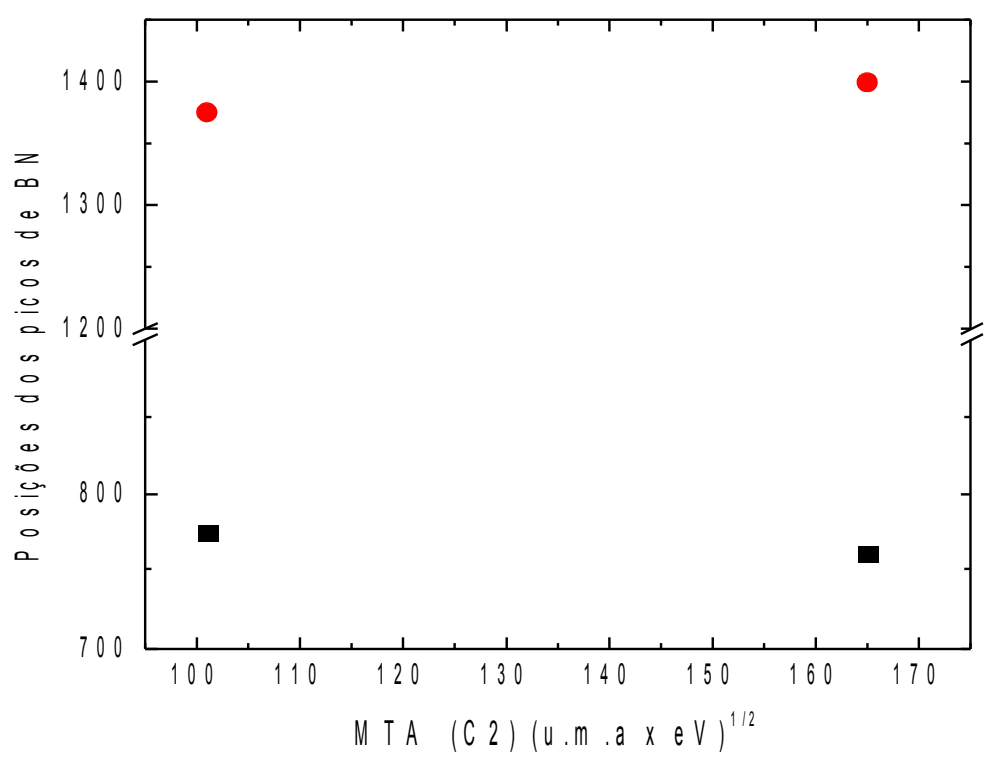

Figura 4.39: Gráfico das posições dos picos P780 e P1370 em função do MTA durante a deposição da camada C2.

\section{- Larguras dos picos}

A figura 4.40 apresenta as W780 e W1370 em função do MTA.. Não há variação de W780 no gráfico, porém. a diminuição da largura W1370, com o aumento do MTA, significa que os planos basais paralelos ao plano de substrato estão mais ordenados e/ou o tamanho de cristalitos compostos desses planos aumentou [10]. 


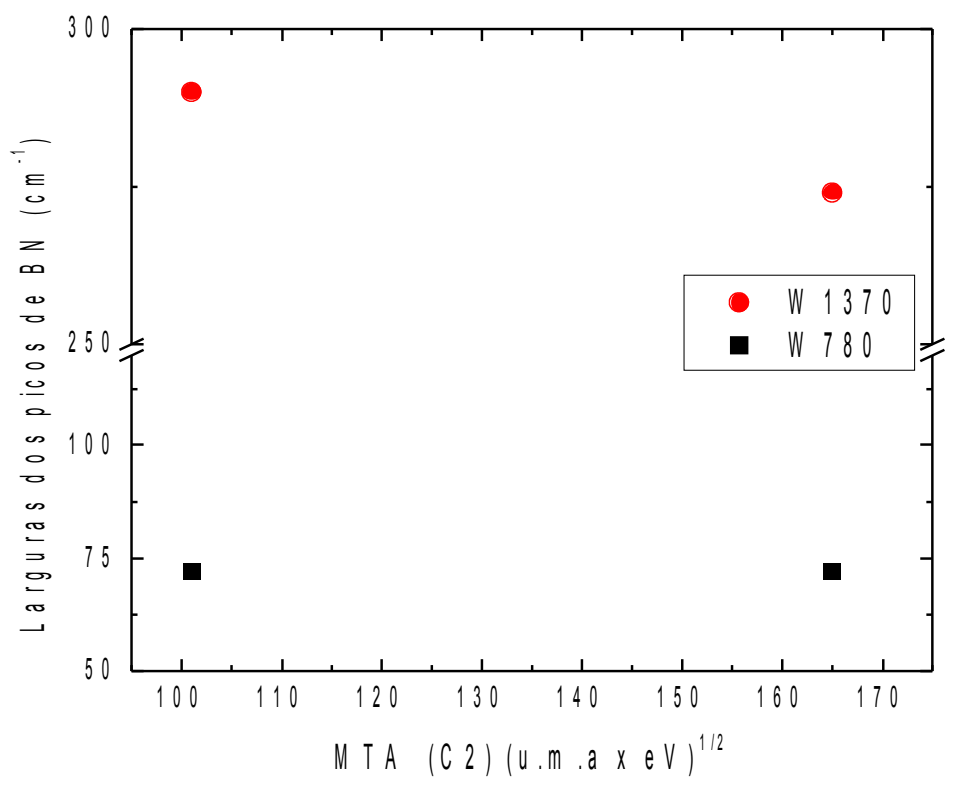

Figura 4.40: Gráfico das plrgurasW780 e W1370 em função do MTA durante a deposição da camada $\mathrm{C} 2$.

\section{- Razão I780/I1370}

A razão I780/I1370 é mostrada na figura 4.41 em função do MTA. Esta razão aumenta com o aumento do MTA. O aumento da razão pode ser entendido como resultado de um aumento da tensão compressiva, paralela ao plano do substrato, e do deslocamento de átomos sob a superfície do substrato com o aumento do MTA, levando às condições adequadas para a formação de h-BN com planos basais perpendiculares à superfície do substrato [10, 31, 32].

A diminuição da En de 3819 para 3262 A (ver tabela 4.2), com o aumento do MTA, indica um aumento do rendimento de sputtering. 


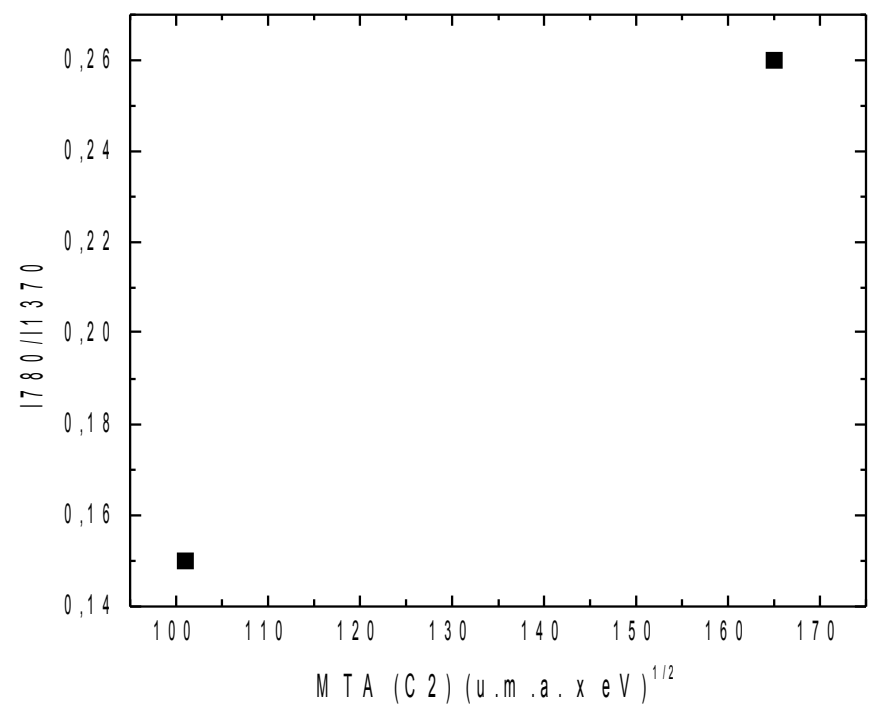

Figura 4.41: Gráfico da razão I780/I1370 em função do MTA durante a deposição da camada C2.

\subsection{Difratogramas de raios-X}

Foram feitas as medidas de difratograma de raios-X para algumas amostras caracterizadas anteriormente com a técnica de FTIR, para correlações com os resultados obtidos nas análises dos espectros de FTIR. Cada pico observado no difratograma foi identificado através de comparações com os cartões JCPDS(BN 26 - 7731, BN 34 - 421, BN 25 - 1033, B 31 - 206, $\mathrm{SiO}_{2} 32$ - 993, Si 27 - 1402, 17 - 901, 35 - 1158, 40 - 932, e 39 - 973) e com valores relatados na literatura [3, 10, $11]$.

As figuras 4.42 a 4.46 apresentam os difratogramas de raios-X para as amostras 1,11 e $16-18$, respectivamente. 


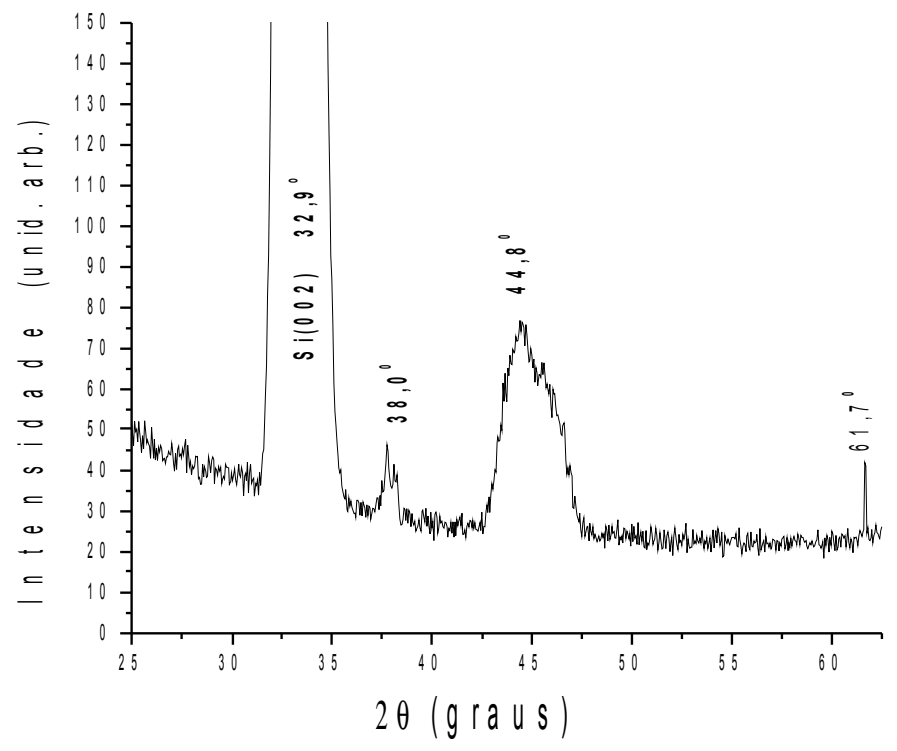

Figura 4.42: Difratograma de raios- $X$ da amostra 1.

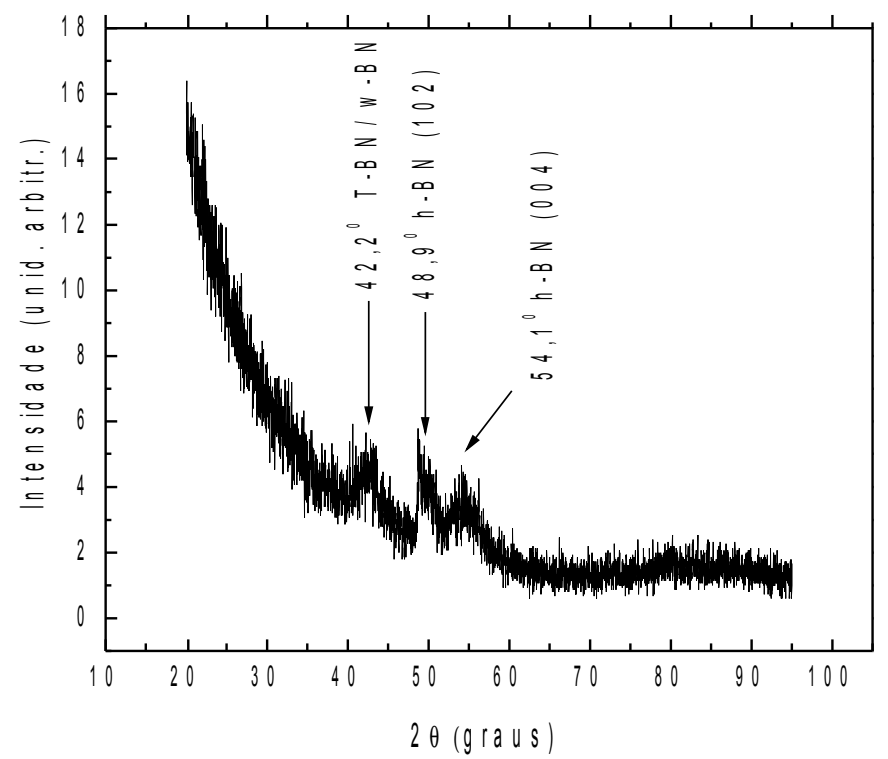

Difratograma de raios-X da amostra 11.

Figura 4.43: 


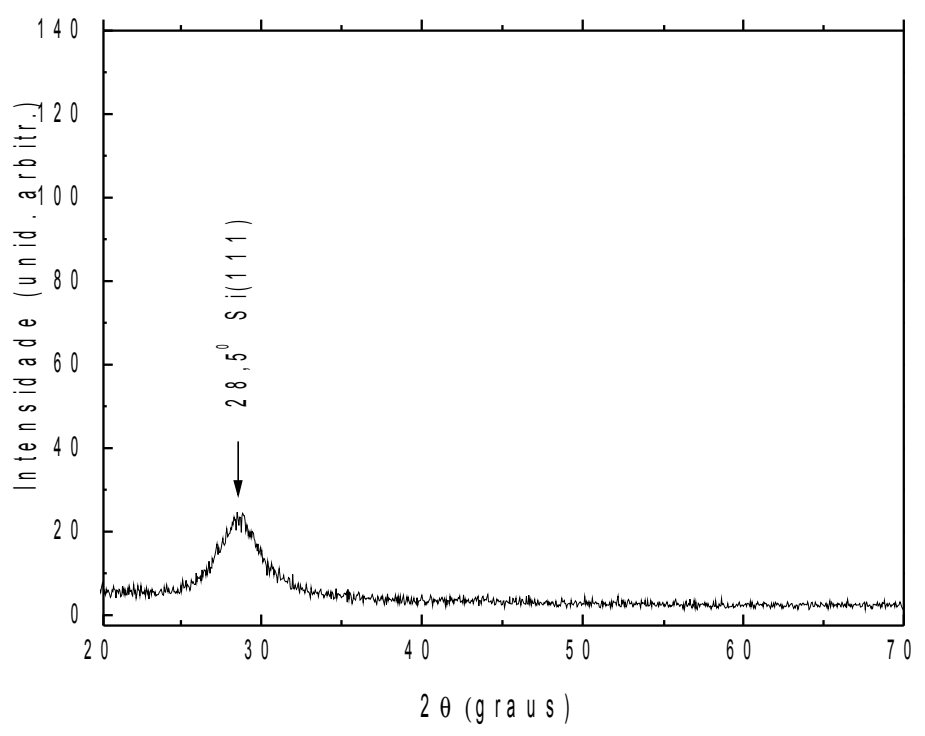

Figura 4.44: Difratograma de raios- $X$ da amostra 16

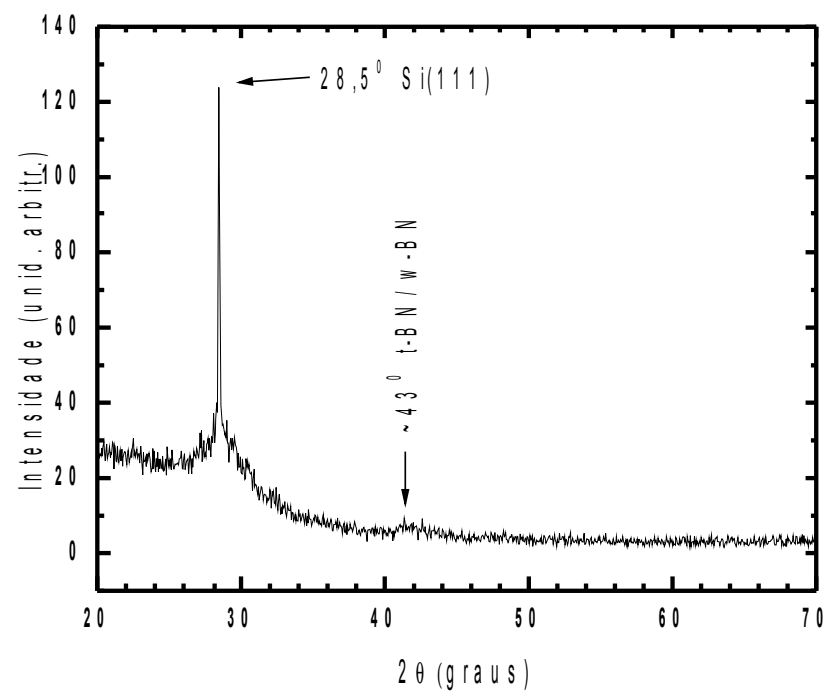

Figura 4.45: Difratograma de raios- $X$ da amostra 17. 


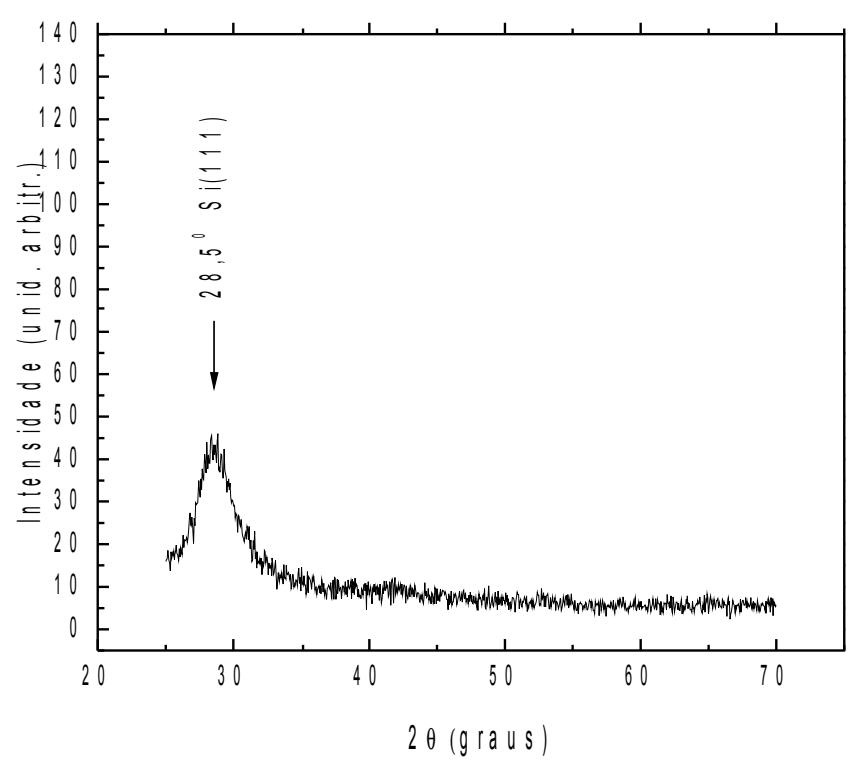

Figura 4.46: Difratograma de raios- $X$ da amostra 18.

A figura 4.42 mostra o difratograma obtido com o método $\theta-2 \theta$ para a amostra 1 . Nele são observados quatro picos de difração em: $32,9^{\circ}$ pelo plano (002) de Si de substrato; $38,0^{\circ}$, que não foi identificado; $44,8^{\circ}$ pelo plano (101) de h-BN; $61,7^{\circ}$ pelo plano (103) de h-BN e/ou pelo plano (102) de w-BN. Como não foi observado o pico de c-BN no espectro de FTIR desta amostra, o último pico pode ser de h-BN.

A figura 4.43 apresenta o difratograma para a amostra 11 que apresenta o pico de c-BN. Há três picos distintos em $42,2^{\circ}, 48,9$ e $54,1^{\circ}$. O primeiro pico é devido à reflexão pelo plano $(010)$ de t-BN e/ou pelo plano (002) de w-BN; o segundo, pelo plano (102) de h-BN e o último, pelo plano (004) do h-BN.

As amostras 16-18, que mostram somente os picos de h-BN nos espectros de FTIR, apresentam somente um pico em $28,5^{\circ}$, devido ao plano (111) de $\mathrm{Si}$, nos difratogramas correspondentes (figuras 4.44-4.46). Portanto, os picos h-BN podem se originar de cristalitos menores de h-BN que não seriam observados no difratograma, e/ou de t-BN. 


\section{Capítulo 5}

\section{Conclusões}

Esta dissertação teve como objetivo principal depositar filmes de BN pelo método IBAD e caracterizá-los através das técnicas de FTIR, MO e XRD. Visava-se relacionar os parâmetros de deposição com os resultados das medidas de caracterização para encontrar os parâmetros adequados de deposição de filmes de $\mathrm{BN}$ ricos em c-BN e aderentes ao substrato.

Os resultados obtidos em termos dos parâmetros de deposição: TS, En, MTA e bombardeamento prévio do substrato com íons de argônio, são descritos nas sessões 5.1 a 5.4 .

\subsection{Dependência da TS}

Todas as amostras $(1,2,5,6,9$ e 14), depositadas em uma camada e analisadas neste estudo, apresentam somente os dois picos de h-BN (figuras 4.1, 4.2, 4.5, 4.6, 4.9 e 4.14). O resultado do difratograma de raios-X para a amostra 1 (figura 4.42) confirma a presença desta fase cristalina. Com o aumento de TS que leva a uma maior mobilidade dos átomos no filme, nota-se que: (1) a cristalinidade nos planos basais paralelos ao plano do substrato aumenta (figuras 4.18 e 4.19); (2) os planos basais se tornam mais perpendiculares ao plano do substrato (figura 4.20). 


\subsection{Dependência da En}

\section{- Amostras depositadas em uma camada}

Neste estudo, todas as amostras (9-12) apresentam os picos de h-BN e c-BN, com exceção da amostra 9, cujo espectro de FTIR apresenta apenas os dois picos de h-BN (figuras 4.9-4.12).

A diminuição da W1370, observada com o aumento da En, significa a maior ordenação dos planos basais paralelos ao plano de substrato e/ou aumento do tamanho de cristalitos nestes planos (figura 4.22). Por outro lado, a I1070/(I1070 + I1370) cresce de zero até 0,8 quando a En aumenta de 400 a $800 \AA$ (figura 4.23) e, além disso, atinge um valor constante em 1050 A. Considerando que o aumento da En acompanha o aumento da tensão compressiva paralela ao plano de substrato, a tensão necessária para a formação de c-BN só será atingida quando a En superar um limiar mínimo ( $600 \AA$ Å). A constância da razão I780/I1370 pode ser devida ao fato de todas as amostras deste conjunto terem atingido ao grau máximo de orientação dos planos basais.

O difratograma para a amostra 11 (figura 4.43) indica a presença de h-BN e w-BN (no espectro de FTIR, o pico de w-BN não difere do de c-BN).

\section{- Amostras depositadas em duas camadas}

Todas as amostras depositadas em duas camadas (amostras 16-22) mostram somente os dois picos de h-BN (figuras 4.29-4.35). Nota-se que a W1370 decresce com o aumento da En para as amostras 19 e 20, indicando que os planos basais paralelos ao plano de substrato se tornam mais ordenados e/ou o tamanho de cristalitos compostos desses planos aumenta (figura 4.37). Uma diminuição da razão I780/I1370 para as amostras 19 e 20 indica o aumento do rendimento de 
sputtering, gerado pelo aumento da razão k entre os fluxos de gás argônio e gás nitrogênio $(0,2$ par as amostras 18 e 19 e 0,5 para a amostra 20$)$.

\subsection{Dependência do MTA}

\section{- Amostras depositadas em uma camada}

As amostras selecionadas em dois conjuntos: 5-7; 12 e 15, apresentam os dois picos de h-BN nos seus espectros de FTIR (figuras 4.5-4.7, 4.12 e 4.15). Apenas o segundo conjunto de amostras mostra, além destes picos, o pico de c-BN.

Observa-se que: a largura W1370 diminui, com o aumento do MTA, para o primeiro conjunto de amostras e aumenta para o segundo conjunto de amostras (figura 4.27). As amostras do primeiro conjunto foram depositadas sem a presença de íons de argônio e com menor ARR(N/B), enquanto que as amostras do segundo conjunto, com a presença de íons de argônio e maior ARR(N/B). Portanto, o MTA para amostras do primeiro conjunto é menor do que o para o segundo. O aumento do MTA de 133 a 169 (u.m.a. x eV) ) $^{1 / 2}$ pode levar a um aumento da ordenação dos planos basais paralelos ao plano de substrato e/ou aumento do tamanho de cristalitos nestes planos. Enquanto que, para as amostras do segundo conjunto, o aumento do MTA de 294 a 392 (u.m.a. $\mathrm{x} \mathrm{eV})^{1 / 2}$ deve ter o efeito oposto.

As razões I780/I1370 e I1070/(I1070 + I1370) aumentam, com o aumento do MTA, para o primeiro conjunto de amostras, e diminuem para o segundo conjunto. $\mathrm{O}$ aumento da razão para as amostras do primeiro conjunto pode ser entendido como resultado de um aumento da tensão compressiva, paralela ao plano do substrato, e do deslocamento de átomos sob a superfície do substrato com o aumento do MTA de 133 para 169 (eV x u.m.a. $)^{1 / 2}$, levando às condições adequadas para a formação de h-BN com planos basais perpendiculares à superfície do substrato 
$[10,31,32]$.

A diminuição das razões para as amostras do segundo conjunto, pode ser entendida como sendo resultado de uma diminuição da orientação dos planos basais do h-BN na direção normal ao plano do substrato e diminuição da fração de c-BN, causadas por incremento do sputtering quando o MTA aumenta de 294 para 392 (eV x u.m.a. $)^{1 / 2}$. A diminuição da Em de 1460 para $668 \AA$, quando o MTA sobe de 294 para 392 (eV x u.m.a. $)^{1 / 2}$, confirma esta hipótese.

O valor mínimo do MTA para a formação de c-BN encontrado neste estudo, entre 169 e 294 (eV x u.m.a. $)^{1 / 2}$, é compatível com o valor de $\sim 250$ (eV x u.m.a. $)^{1 / 2}$ obtido por Kester e Messier [29, 30]. O aumento de rendimento de sputtering para MTA acima de 294 (eV x u.m.a.) $)^{1 / 2}$ é compatível com o obtido por Kester [29, 30].

Verificamos que para os três grupos de amostras analisadas (5 -7; 12 e 15; 20 e 21) o aumento do MTA foi acompanhado de uma diminuição da Em. Este resultado pode ser explicado por um aumento do sputtering devido ao aumento do MTA.

\section{- Amostras depositadas em duas camadas}

$\mathrm{Na}$ figura 4.40 notamos a diminuição da largura W1370, com o aumento do MTA, significando que os planos basais paralelos ao plano de substrato estão mais ordenados e/ou o tamanho de cristalitos compostos desses planos aumentou [10].

Na figura 4.41 notamos um aumento da razão I780/I1370 com o aumento do MTA. O aumento da razão pode ser entendido como resultado de um aumento da tensão compressiva, paralela ao plano do substrato, e do deslocamento de átomos sob a superfície do filme com o aumento do MTA, levando às condições adequadas para a formação de h-BN com planos basais perpendiculares à superfície do substrato [10, 31, 32].

A diminuição da Em de 3819 para 3262 A (ver tabela 4.2), com o aumento do MTA, indica um aumento do rendimento de sputtering. 


\subsection{Dependência do bombardeamento prévio do substrato com íons de}

argônio

O bombardeamento prévio do substrato, com íons de argônio, induz a formação de c-BN (figuras 4.9 e 4.13). Este bombardeamento provoca maior rugosidade da superfície do substrato, possibilitando maior aderência devida a um ancoramento do filme ao substrato, permitindo que o filme sofra menos fluxo plástico e suportando maior tensão que conduz a formação de c-BN. 


\section{Apêndice A}

\section{Determinação da razão de chegada ARR(N/B)}

\section{A.1 Cálculo do fluxo de átomos de boro}

O fluxo de átomo de boro transportados ao substrato é calculado pela seguinte equação:

$$
T_{B}=\frac{E_{B} \times 10^{-8} \rho_{B} N_{A}}{M_{B}}
$$

onde $T_{B}$ é o fluxo em questão dado em $1 /\left(\mathrm{cm}^{2} \mathrm{~s}\right) ; E_{B}$ é a taxa de deposição em $\AA / \mathrm{s} ; \rho_{\mathrm{B}}$ é a densidade do boro igual a $2,35 \mathrm{~g} / \mathrm{cm}^{3} ; N_{\mathrm{A}}$ é número de Avogadro igual a $6,022 \times 10^{23}$ e $M_{\mathrm{B}}$ é a massa molar do boro igual a $10,95 \mathrm{~g}$.

\section{A.2 Cálculo do fluxo de partículas atômicas de nitrogênio}

Para relacionar o fluxo de cada espécie de íon com a corrente total medida no copo de Faraday $\left(\mathrm{I}_{\mathrm{T}}\right)$, é preciso levar em conta que uma parte dos íons sofrerá transferência de carga com átomos e moléculas de gás ao longo da trajetória de $41 \mathrm{~cm}$ entre a saída da fonte de íons e o substrato, tornando-se partículas neutras e mantendo sua energia inicial. Por esse motivo é necessário correlacionar as correntes final e inicial $i_{0}$ através da seguinte equação [40]: 


$$
i=i_{0} e^{-p_{0} P_{c}(v) x}
$$

onde $\mathrm{p}_{0}$ é a pressão reduzida definida em termos da pressão $\mathrm{p}$ por $\mathrm{p}_{0}=273 \mathrm{p} / \mathrm{T}, x$ é a distância percorrida e $P_{c}(v)$ é a a seção de choque por unidade de volume e unidade de pressão.

A concentração de átomos e moléculas de um gás por $\mathrm{cm}^{3}$ é dada por $\frac{N}{V}=3,53 \times 10^{16} p_{0}$. A seção de choque efetiva para um íon (q) é obtida através da seguinte equação:

$$
q=\frac{P_{c}(v)}{(N / V)}
$$

Combinando as equações A.3 e A.4, obtemos:

$$
i=i_{0} e^{-3,53 \times 10^{16} p q x}
$$

A corrente medida no copo de Faraday (It) é dada por:

$$
I_{T}=i\left[N^{+}\right]+i\left[N_{2}^{+}\right]+i\left[A r^{+}\right]
$$

onde i $\left[\mathrm{N}^{+}\right], \mathrm{i}\left[\mathrm{N}_{2}^{+}\right]$e i $\left[\mathrm{Ar}^{+}\right]$são as correntes finais de íons $\mathrm{N}^{+}, \mathrm{N}_{2}^{+}$, e $\mathrm{Ar}^{+}$, respectivamente.

Combinando as equações A.5 e A.6, obtemos:

$I_{T}=i_{0}\left[N^{+}\right] e^{-3,53 \times 10^{16} p q_{1} x}+i_{0}\left[N_{2}^{+}\right] e^{-3,53 \times 10^{16} p q_{2} x}+i_{0}\left[A r^{+}\right] e^{-3,53 \times 10^{16} p q_{3 \times}}$

onde p é a pressão na câmara de deposição; $\mathrm{q}_{1}, \mathrm{q}_{2}$ e $\mathrm{q}_{3}$ são as seções de choque efetivas para os íons $\mathrm{N}^{+}, \mathrm{N}_{2}^{+}$e Ar$r^{+}$, respectivamente; $\mathrm{i}_{0}\left[\mathrm{~N}_{2}^{+}\right], \mathrm{i}_{0}\left[\mathrm{~N}^{+}\right]$e $\mathrm{i}_{0}\left[\mathrm{Ar}^{+}\right]$são as correntes iniciais para os íons $\mathrm{N}^{+}, \mathrm{N}_{2}^{+}$e $\mathrm{Ar}^{+}$, respectivamente.

O fluxo de partículas atômicas de nitrogênio e argônio ( $T_{\mathrm{N}}$ e $T_{\mathrm{Ar}}$, respectivamente) podem ser 
calculados, se forem conhecidas as correntes devidas a íons de nitrogênio $\mathrm{i}_{0}\left[\mathrm{~N}_{2}{ }^{+}\right]$e $\mathrm{i}_{0}\left[\mathrm{~N}^{+}\right]$e íons de argônio $i_{0}\left[\mathrm{Ar}^{+}\right]$na posição do substrato, a partir das equações:

$$
\begin{gathered}
T_{N}=\frac{1}{\pi r^{2} e_{0}}\left\{i_{0}\left[N^{+}\right]+2 i_{0}\left[N_{2}^{+}\right]\right\} \\
T_{A r}=\frac{1}{\pi r^{2} e_{0}} i_{0}\left[A r^{+}\right]
\end{gathered}
$$

onde $r$ é o raio do copo de Faraday igual a $2,5 \mathrm{~cm}$ e $e_{0}$ é carga do elétron igual a 1,6 x $10^{-19}$

O fluxo de um gás de uma espécie $\mathrm{X}(\mathrm{F}[\mathrm{X}])$ que atravessa o controlador de fluxo de massa pode ser relacionada com a corrente total devida a íons $\mathrm{X}^{+}, \mathrm{i}_{0}\left[\mathrm{X}^{+}\right]$, como se segue:

$$
F[X]=\frac{1}{\sigma_{X}} \frac{i_{0}\left[X^{+}\right]}{e_{0}}
$$

onde $\sigma_{X}$ é a taxa de ionização dos átomos da espécie X.

A relação entre as correntes iniciais $\mathrm{i}_{0}\left[\mathrm{~N}_{2}^{+}\right]$e $\mathrm{i}_{0}\left[\mathrm{~N}^{+}\right]$é dada pela expressão [41]:

$$
i_{0}\left[N_{2}^{+}\right]=8 i_{0}\left[N^{+}\right]
$$

Combinando as equações A.8 a A.10, obtemos as relações:

$$
F\left[N_{2}\right]=\frac{2 i_{0}\left[N^{+}\right]+16 i_{0}\left[N_{2}^{+}\right]}{17 e_{0} \sigma_{N_{2}}} \quad \mathrm{e} \quad F[A r]=\frac{i_{0}\left[A r^{+}\right]}{e_{0} \sigma_{A r}}
$$

Como pudemos controlar $\mathrm{F}[\mathrm{Ar}]$ e $\mathrm{F}\left[\mathrm{N}_{2}\right]$ separadamente, pudemos definir uma razão $\mathrm{k}$ entre os fluxos de gás expressa por: 


$$
F[A r]=k F\left[N_{2}\right]
$$

Combinando as equações A.7, A.11 e A.12 e considerando $\sigma_{N_{2}}=\sigma_{A r}$, obtemos a seguinte relação:

$$
i_{0}\left[\mathrm{Ar}^{+}\right]=\frac{130 k}{17} i_{0}\left[N^{+}\right]
$$

Combinado as equações A.7, A.8 e A.13, chegamos à seguinte relação:

$$
i_{0}\left[N^{+}\right]=\frac{I_{T}}{e^{-3,53 \times 10^{16} p q_{1} x}+8 e^{-3,53 \times 10^{16} p q_{2} x}+\frac{130}{17} k e^{-3,53 \times 10^{16} p q_{3 \mathrm{x}}}}
$$

Substituindo $\mathrm{i}_{0}\left[\mathrm{~N}^{+}\right]$definido na equação A.14 na primeira das equações A.8 e na equação A.13, obtemos as equações para os fluxos $\mathrm{T}_{\mathrm{N}}$ e $\mathrm{T}_{\mathrm{Ar}}$ :

$$
\begin{aligned}
T_{N}= & \frac{17}{\pi r^{2} e_{0}} \frac{I_{T}}{e^{-3,53 \times 10^{16} p q_{1} x}+8 e^{-3,53 \times 10^{16} p q_{2} x}+\frac{130}{17} k e^{-3,53 \times 10^{16} p q_{3} x}} \\
T_{A r} & =\frac{130 k}{17 \pi r^{2} e_{0}} \frac{I_{T}}{e^{-3,53 \times 10^{16} p q_{1} x}+8 e^{-3,53 \times 10^{16} p q_{2} x}+\frac{170}{17} k e^{-3,53 \times 10^{16} p q_{3} x}}
\end{aligned}
$$

A referência [40] fornece gráficos de $\mathrm{q}_{1}, \mathrm{q}_{2}$ e $\mathrm{q}_{3}$ em função da energia de íons. 


\section{A.3 Cálculo da razão ARR(N/B)}

A razão $A R R(N / B)$ é definida pelo fluxo de partículas atômicas de $\mathrm{N}$ do feixe de íons incidentes no substrato (equação A.14) dividido pelo fluxo de átomos de B trasportados ao substrato (equação A.1):

$$
\operatorname{ARR}(N / B)=\frac{T_{N}}{T_{B}}
$$




\section{Apêndice B}

\section{Momentum Transferido por Átomo Evaporado}

Foi demonstrado $[29,30]$ que o momentum transferido dos íons aos átomos de boro evaporados (MTA) é um parâmetro mais útil na análise de filmes de BN depositados por IBAD do que a tradicional razão de chegada de partículas atômicas de nitrogênio por átomos de boro evaporados $(\operatorname{ARR}(\mathrm{N} / \mathrm{B}))$ e do que a energia de íons incidentes. O parâmetro se mostrou eficaz também na análise das condições de deposição de filmes de $\mathrm{BN}$ por unbalanced magnetron sputtering [18]. Em ambos os casos encontrou-se um limiar para o MTA para a formação de BN; abaixo do limiar se obtém h-BN e acima, a fase c-BN.

Esta grandeza pode ser facilmente calculada a partir da equação abaixo, supondo uma colisão elástica e frontal entre um íon e um átomo [29, 30]:

$$
\frac{p}{T_{B}}=\frac{T}{T_{B}} \sqrt{(\mathbf{2 m} \gamma E)},
$$

onde $\mathrm{p}$ é o momentum do íon, $\mathrm{T}$ é o fluxo de íons incidentes, $\mathrm{T}_{\mathrm{B}}$ é o fluxo de átomos de boro evaporados, $\mathbf{m}$ é a massa do íon, $\mathbf{E}$ é sua energia e $\boldsymbol{\gamma}$ é dado por:

$$
\gamma=\frac{4 m M}{(m+M)^{2}},
$$

onde $\mathbf{M}$ é a massa do átomo evaporado (boro). Esse fator significa a energia máxima transferida do íon ao átomo na colisão relativa à energia inicial do íon.

Como em nossos experimentos utilizamos mais de uma espécie iônica $\left(\mathrm{N}_{2}^{+}, \mathrm{N}^{+}\right.$e $\left.\mathrm{Ar}^{+}\right)$, a equação B.1 se torna: 


$$
\text { MTA }=\frac{p}{T_{B}}=\frac{1}{T_{B}} \sum_{i} T_{i} \sqrt{\left(\mathbf{2 m}_{i} \gamma_{i} E\right)}
$$

A unidade do MTA utilizada no presente trabalho foi $(\mathbf{e V} \times \mathbf{u} \text { u.m.a. })^{1 / 2}$. 


\section{Referências Bibliográficas}

[1] W J Zhang; Y M Chong; I Bello; T Lee; Nucleation, growth and characterization of cubic boron nitride (cBN) films, J. Phys. D: Appl. Phys. 40 (2007) 6159-6174.

[2] C B Samantaray; R NN Singh, Revies of synthesis and properties of cubic boron nitride (c-BN) thin films, Intern. Mater. Rev. 50 (2005) 313-344.

[3] - P. B. Mirkarimi; K. F. McCarty; D. L. Medlin; Review of advances in cubic boron nitride film synthesis; Mater. Sci. Eng. R21 (1997) 47-100.

[4] J K Hirvonen; Ion beam assited thin film deposition, Mater. Sci. Rep. 6 (1991) 215-274.

[5] M Nastasi; J Mayer; J K Hirvonen; Ion-Solid Interactions, Cambridge Univ. Press, UK, 1996.

[6] - L. Vel; G. Demazeau; J. Etourneau; Cubic boron nitride: synthesis, physiochemical properties ans applications; Mater. Sci. And Eng B 10 (1991) 149-164.

[7] - Y. Meng; H. Mao; P. J. Eng; T. P. Trainor; M. Newville; M. Y. Hu; C. Kao; J. Shu; D. Hausermann; The formation of $s p^{3}$ bonding in compressed BN; Nature Matter. 3 (2004) 111-114.

[8] - Bundy, F. P.; Wentorf, Jr, R. H. "Direct transformation of hexagonal boron nitride to denser forms", J. Chem. Phys. 38 (5), 1144-1149 (1963).

[9] - Jr, R. H Wentorf; Cubic form of boron nitride, J. Chem. Phys. 26 (1957) 956.

[10] - T.A. Friedman; P. B. Mirkarimi; D. L. Medlin; K. F. McKarty; E. J. Klaus, D. R. Boehme; H. A. Johnsen; M. J. Mills; D. K. Ottesen; J. C. Barbour; Ion-assisted pulsed laser deposition of cubic boron nitride films, J. Appl. Phys. 76 (1994) 3088-3101.

[11] - M. Latteman; K. Sell; J. Ye; P. A. O. Persson; S. Ulrich; Stress reduction in nanocomposite coatings consisting of hexagonal and cubic boron nitride; Surf. Coat. Tecchnol. 200 (2006) 6459-6464.

[12] - Y. Yamada-Takamura; O. Tsuda; H. Ichinose; T. Yoshida; Atomic-scale structure at the nucleation site of cubic boron nitride deposited from the vapor phase; Phys. Rev. B 59 (1998) 10351-10355.

[13] - S. Ulrich; H. Ehrhadt; J. Schwan; W. Donner; H. Dosch; P. Widmayer; P. Zieman; General stress reduction mechanism for the deposition of cubic boron nitride thin films; Surf. Coat. Tecchnol. 116-119 (1999) 269-273.

[14] - S. Ulrich; W. Donner; H. Dosh; H. Ehrhardt; J. Schwan; Interface investigations by infrared and X-ray reflectivity measurements of cubic boron nitride thin films; Surf. Coat. 
Tecchnol. 116-119 (1999) 274-277

[15] - Y. Panayiotatos; P. Patsalas; C. Charitidis; S. Logothetidis; Mechanical performance and growth characteristics of boron nitride films with respect to their optical, compositional properties and density, Surf. Coat. Tecchnol. 151-152 (2002) 155-159.

[16] - W. Otaño-Rivera; L. J. Pilione; J. A. Zapien; R. Messier; Cubic boron nitride thin film deposition by unbalanced magnetron sputtering and dc pulsed substrate biasing, J. Vac. Sci. Technol. A 16 (1998) 1331-1335.

[17] - DW. Donner; S. Chamera; A. Rühm; H. Dosh; S. Ulrich; E. Ehrhardt; Correlation between density and structure in boron nitride thin films by X-ray diffraction; Appl. Phys. A $\mathbf{6 5}$ (1997) $1-4$.

[18] - H. Hofsäs; H. Felderman; M. Sebastian; C. Ronning; Thresholds for the phase formation of cubic boron nitride thin films; Phys. Rev. B 55 (1997) 13230-13233.

[19] - M. Zeitler; S. Sienz; H. Neuman; M. Zeuner; J. W. Gerlach; B. Rauchenbach; In situ stress analysis of boron nitride films prepared by ion beam assisted deposition; Nucl. Instr. And Meth. B 139 (1998) 327-331.

[20] - C. Ronning; A. D. Banks; B. L. McCarson; R. Schlesser; Z. Sitar; Structural and electronic properties of boron nitride films containing silicon, J. Appl. Phys. 84 (1998) 5046-5051.

[21] - W. Fukarek; O. Kruse; A. Kolitch; W. Möller; Investigations on the structure of boron nitride films, Thin Solid Films. 38-41 (1997) 308-309.

[22] - M. A. Djouadi; D. Bouchier; A. Miotello; V. Stambouli; S. Ilias; Mechanical characterizations of nitride films deposited by ion-beam based techniques; Surf. Coat. Tecchnol. 97 (1997) 39-44.

[23] - M. F. Plass; W. Fukarek; S. Mändl; W. Möller; Phase identification of boron nitride thin films by polarised infrared spectroscopy; Appl. Phys. Lett.. 69 (1996) 46-48.

[24] - M. F. Plass; W. Fukarek; A. Kolitsh; U. Kreißig; Growth and characterisation of boron nitride thin films; Surf. Coat. Tecchnol. 84 (1996) 383-387.

[25] - M. Kumagai; S. Konuma; Y. Setsuhara; S. Miyake; K. Ogata; M. Kohata; Properties of cubic boron nitride films prepared by ion beam assisted deposition, Ion Implantation Technology Proceedings, 1998 International Conference on Volume 2, (1999) 1140 - 1143.

[26] - J. E. Döring; L. Guangnan; H.-R. Stock; The influence of ion beam assisted deposition parameters on the properties of boron nitride thin films; Diamond Relat. Mater. 8 (1998) 16971702.

[27] - S. M. Aouadi; F Namvar; E. Tobin; N. Finnegan; R. T. Haasch; R. Nilchiani; J. A. Turner; S. L. Rohde; Characterization of CrBN films deposited by ion beam assisted deposition, J. Appl. Phys. 91 (2002) 1040-1045. 
[28] - Y. Setsuhara; T. Suzuki; Y. Tanaka; S. Miyake; M. Kumagai; K. Ogata; M. Kohata; K. Higeta; T. Einishi; Y. Suzuki; Y Shimoitani; Y. Motonami; Interfacial structure control of cubic boron nitride prepared by ion-beam assisted deposition; Nucl. Instr. And Meth. B 127/128 (1997) 851-856.

[29] - D. J. Kester; R. Messier; Phase control of cubic boron nitride thin films; J. Appl. Phys. 72 (1992) 504-513.

[30] - D. J. Kester; K. S. Ailey; R. F. Davis; Phase evolution in boron nitride thin films; J. Appl. Phys. 72 (1992) 504-513.

[31] - D. R. McKenzie; W. D. McFal; W. G. Sainty; C. A. Davis; R. E. Collings; Compressive stress induced formation of cubic boron nitride, Diamond Relat. Mater 2 (1993) 970-976.

[32] - D. R. McKenzie; W. D. McFall; B.W. James; I.S. Falconer; R. W. Boswell; H. Persing; A. J. Perry; A. Duarndet; Synthesis of cubic boron nitride thin films; Surf. Coat. Tecchnol. 78 (1996) 3255-262.

[33] - F. A. Smidt; Use of ion beam assisted deposition to modify the microstructure and properties of thin films, International Materials Reviews 35 (1990) 73-128.

[34] - D. R. McKenzie; D. Muller; B. A. Pailthorpe; Compressive-stress-induced formation of thin-film tetrahedral amorphous carbon; Phys. Rev. Lett. 67 (1990) 773-776.

[35] - H. R. Kaufman; R. S. Robinson; Operation of broad-beam sources;Commonwealth Scientific Corp, Alexandria, VA (1984).

[36] - E. B. Wilson Jr.; J. C. Decius; P. C. Cross; Molecular vibrations, the theory of infrared and raman vibrational spectra; Dover Publications, Inc.: New York, (1980), pp 34.

[37] - O. Sala; Fundamentos da espectroscopia Raman e no infravermelho; Unesp, São Paulo, (1995).

[38] - B. D. Cullity; Elements of x-ray diffraction; Addison-Wesley Publishing Company Inc., Massachusets, (1967).

[39] - C. Kittel; Introdução à física do estado sólido; Ed. Guanabara Dois RJ, (1978).

[40] - S. C. Brown; Basic data of plasma physics; MIT Press, Cambridge, MA (1966) 67.

[41] - D. Van Vechten, G. K. Hubler, E. P. Donovan; Characterization of a $3 \mathrm{~cm}$ Kaufman ion source with nitrogen feed gas; Vacuum. 36 (1986) 841-845. 